\title{
Access to Galectin-3 Inhibitors from Chemoenzymatic Synthons
}

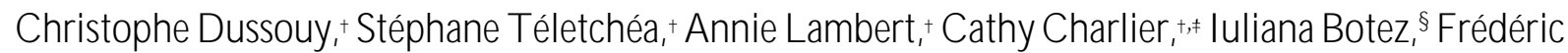
DeC euninck ${ }^{\S}$ and $C$ yrille Grandjean*,

+ U niversité de N antes, C N RS, U nité Fonctionnalité et Ingénierie des Protéines (UFIP), U M R 6286, F-44000 N antes, France

₹ U niversité de N antes, C N RS, Plateforme IM PACT , U M R 6286, F- 44000 N antes, France

$\S$ Institut de Recherches Servier, Croissy-sur-Seine, France

TABLE OF CONTENTS

$\begin{array}{ll}\text { Figure } \mathrm{S1} & \mathrm{S} 2\end{array}$

Figure S2 S2

TableS1 S3

Fluorescence anisotropy experiment S3

Figure S3 S3

${ }^{1} \mathrm{H},{ }^{13} \mathrm{C}, \mathrm{COSY}$ and H SQ C N M R Spectra of compounds 2, 4-12, 14-27 and 29-36 


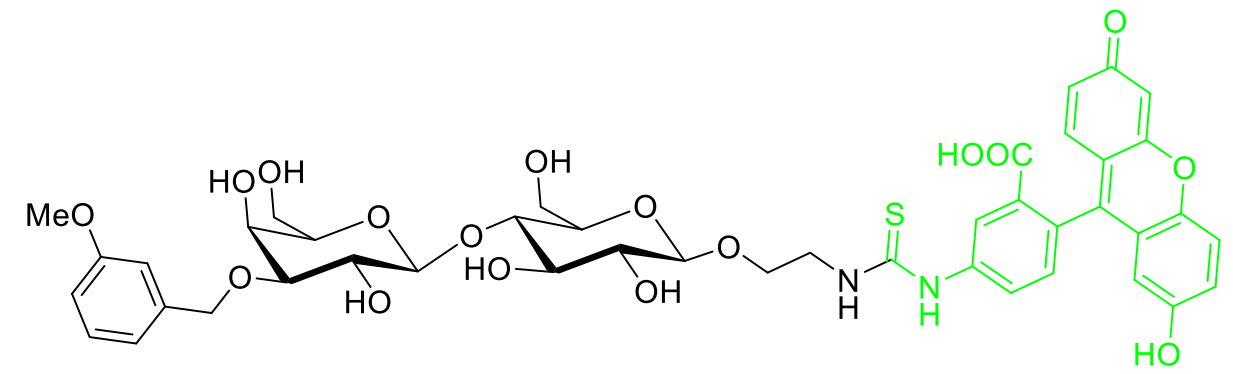

Fluorescent probe used for fluorescence anisotropy experiment

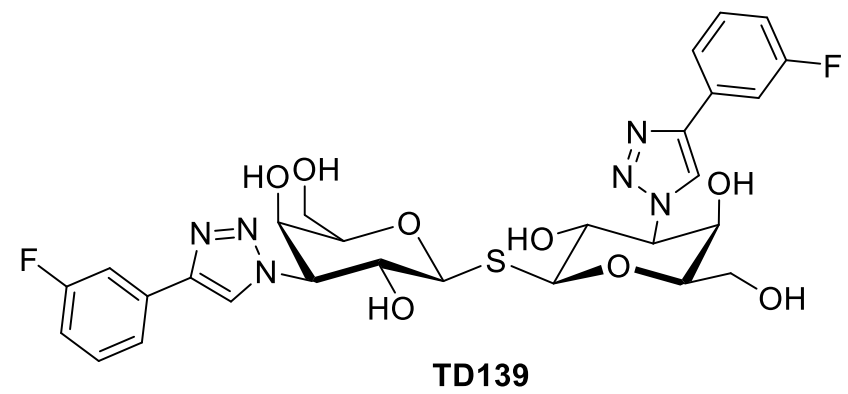

Figure S1. Structures of fluorescent probe used for fluorescence anisotropy experiment and of TD139
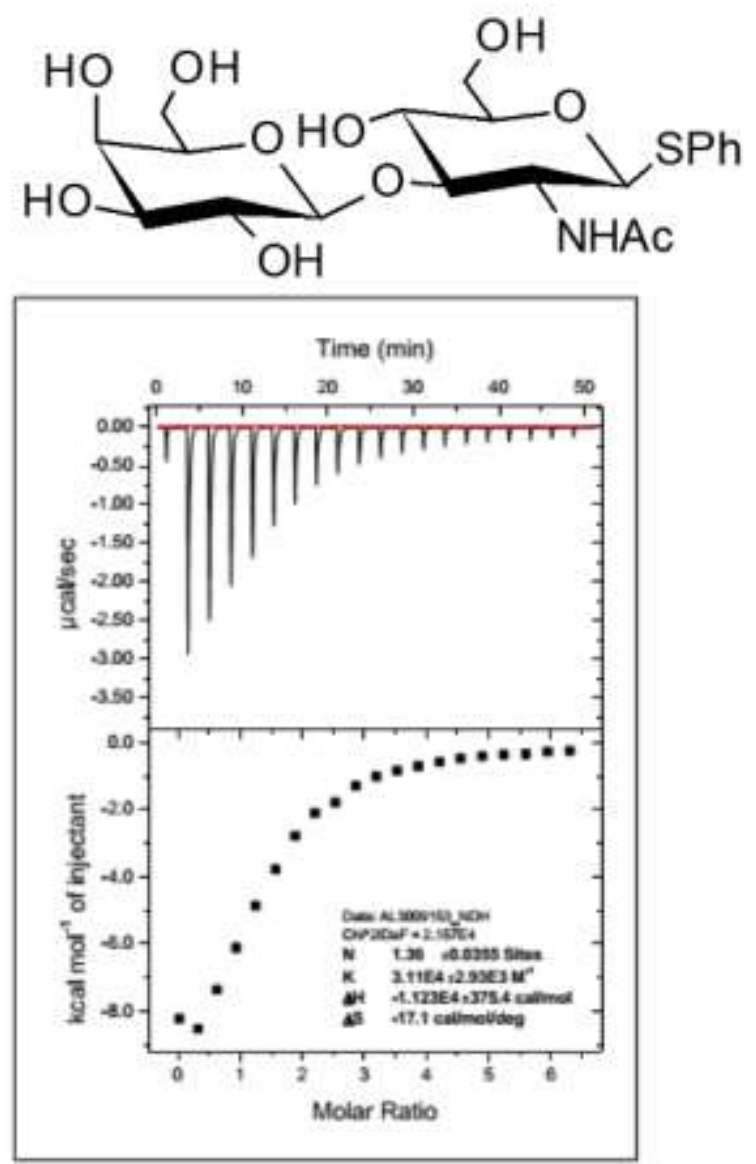

Figure S2. ITC raw data and fitting for reference compound phenyl $\beta$-D-galactopyranosyl- $(1 \rightarrow 3)$-2-acetamido-2-deoxy1-thio- $\beta$-D-glucopyranoside 27 
T able S1. ITC data for compound 27 ( at a $2.4 \mathrm{mM}$ concentration) to galectin-3 (at a $80 \mu \mathrm{M}$ concentration) by direct titration measurements.

\begin{tabular}{|c|c|c|c|c|}
\hline Compound & $\mathrm{K}_{\mathrm{d}}[\mu \mathrm{M}]$ & $\Delta \mathrm{H}^{\circ}\left[\mathrm{cal}^{\prime} \mathrm{mol}^{-1}\right]$ & $\Delta \mathrm{S}^{\circ}\left[\mathrm{call}^{\left.-\mathrm{mol}^{-1} \cdot \mathrm{K}^{-1}\right]}\right.$ & $n$ \\
\hline 27 & $32 \pm 3.41$ & -10550 & -15.4 & 1.4 \\
\hline
\end{tabular}

\section{Fluorescence anisotropy measurements}

Every inhibitor was mixed at several concentrations ( 800 to $0.01 \mu \mathrm{M}$ in the reported experiments except TD 139, $10^{-11}$ to $5.10^{-5} \mu \mathrm{M}$ ) in phosphate buffer with a mixture of galectin/ probe couple in a final volume of $200 \mu \mathrm{L}$ in phosphate buffer. Fluorescence anisotropy measurements were undertaken as described above. $K_{i}$ of each inhibitor was determined using the following equation,

$$
\log E C 50=\log \left(10^{\log K i} \times\left(1+\frac{C P}{K d}\right)\right) ; Y=\operatorname{Amax} /\left(1+10^{\wedge}(X-\log E C 50)\right)+A 0
$$

where EC50 $=\mathrm{H}$ alf maximal effective concentration $(\mu \mathrm{M}) ; \mathrm{Ki}=$ Inhibitor dissociation constant $(\mu \mathrm{M})$, $\mathrm{K}_{\mathrm{d}}=$ probe dissociation constant; $\mathrm{Amax}=$ anisotropy of the galectin-probe couple in absence of inhibitor.

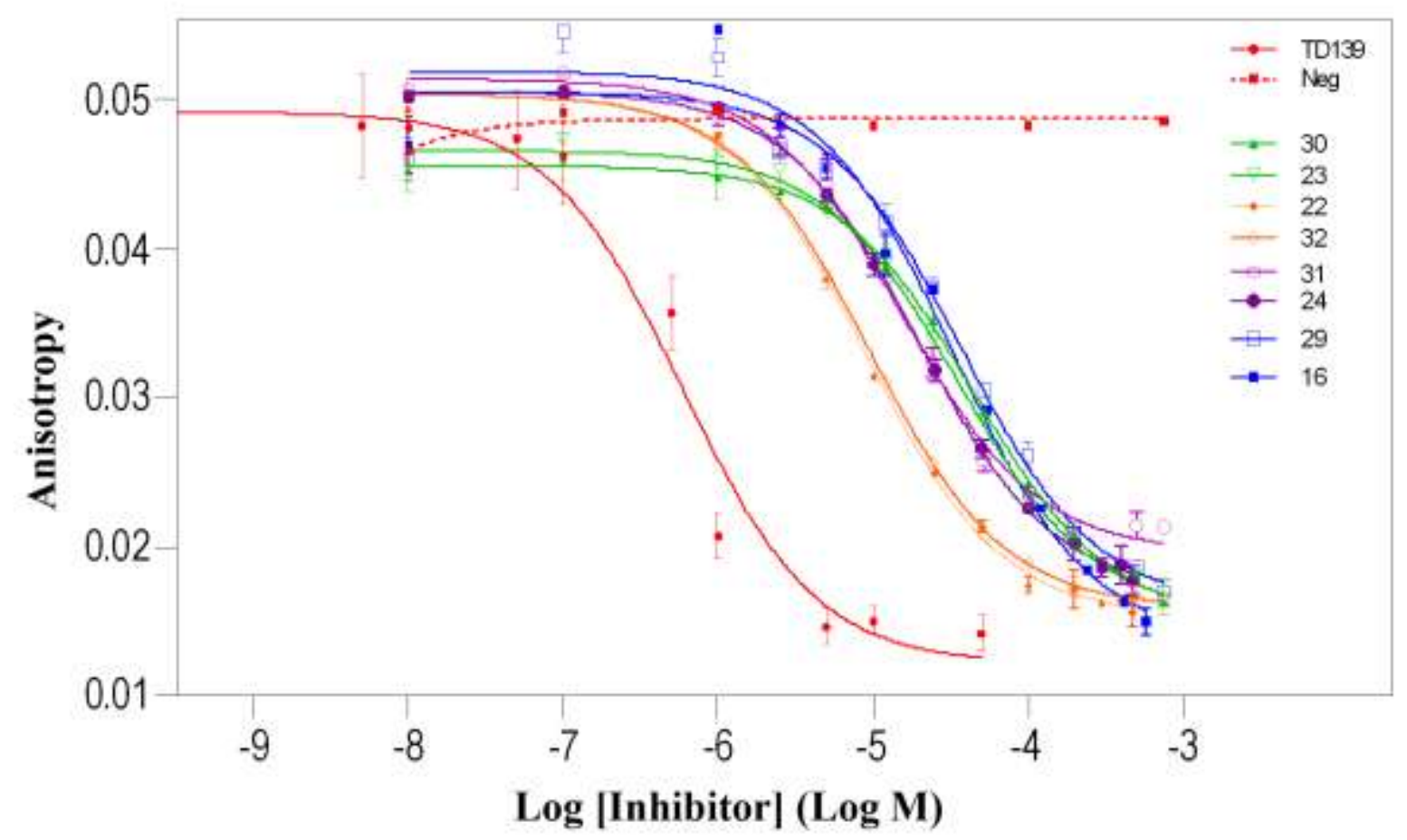

Figure S3. G raph representative of representative titration ( 0.01 to $800 \mu \mathrm{M})$ of inhibitors with galectin-3 $(1 \mu \mathrm{M})$ and probe 2-[( fluoresceinyl) thioureido] ethyl 4-O-[3-O-(3-methoxybenzyl)- $\beta$-D-galactopyranosyl]- $\beta$-D-glucopyranoside ( $100 \mathrm{nM}$ ) at RT. D uplicate measurements are shown for all data points. The curves represent fitting of the data by non-linear regression for a one to one interaction. $K_{i}$ values are extracted from the fitting. Fluorescence was measured at $\lambda=470 \mathrm{~nm}$ (excitation) , $\lambda=525 \mathrm{~nm}$ (emission). $\mathrm{NEG}=\mathrm{N}$ egative control, $\mathrm{O}-\mathrm{N}$ itrophenyl $\alpha-\mathrm{D}$-glucopyranoside 


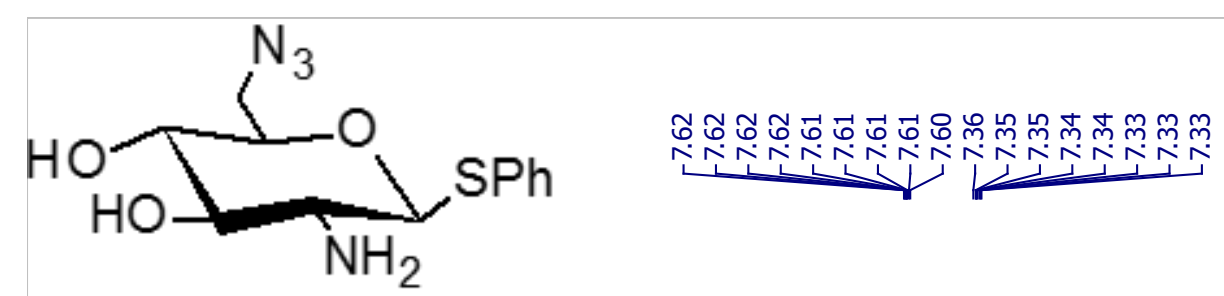

$2{ }^{1} \mathrm{H} N M R, 400 \mathrm{MHz}, \mathrm{CD}_{3} \mathrm{OD}$
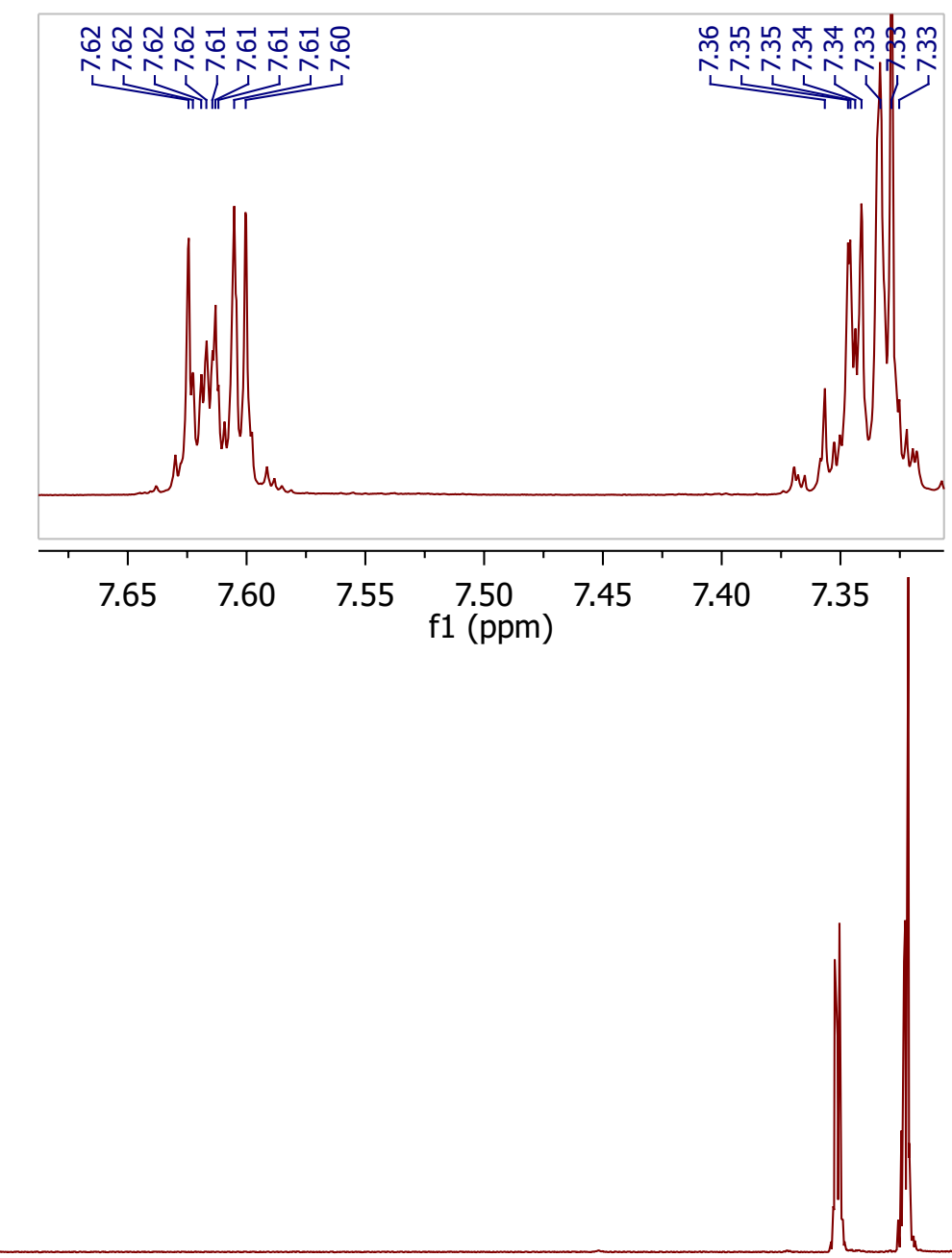
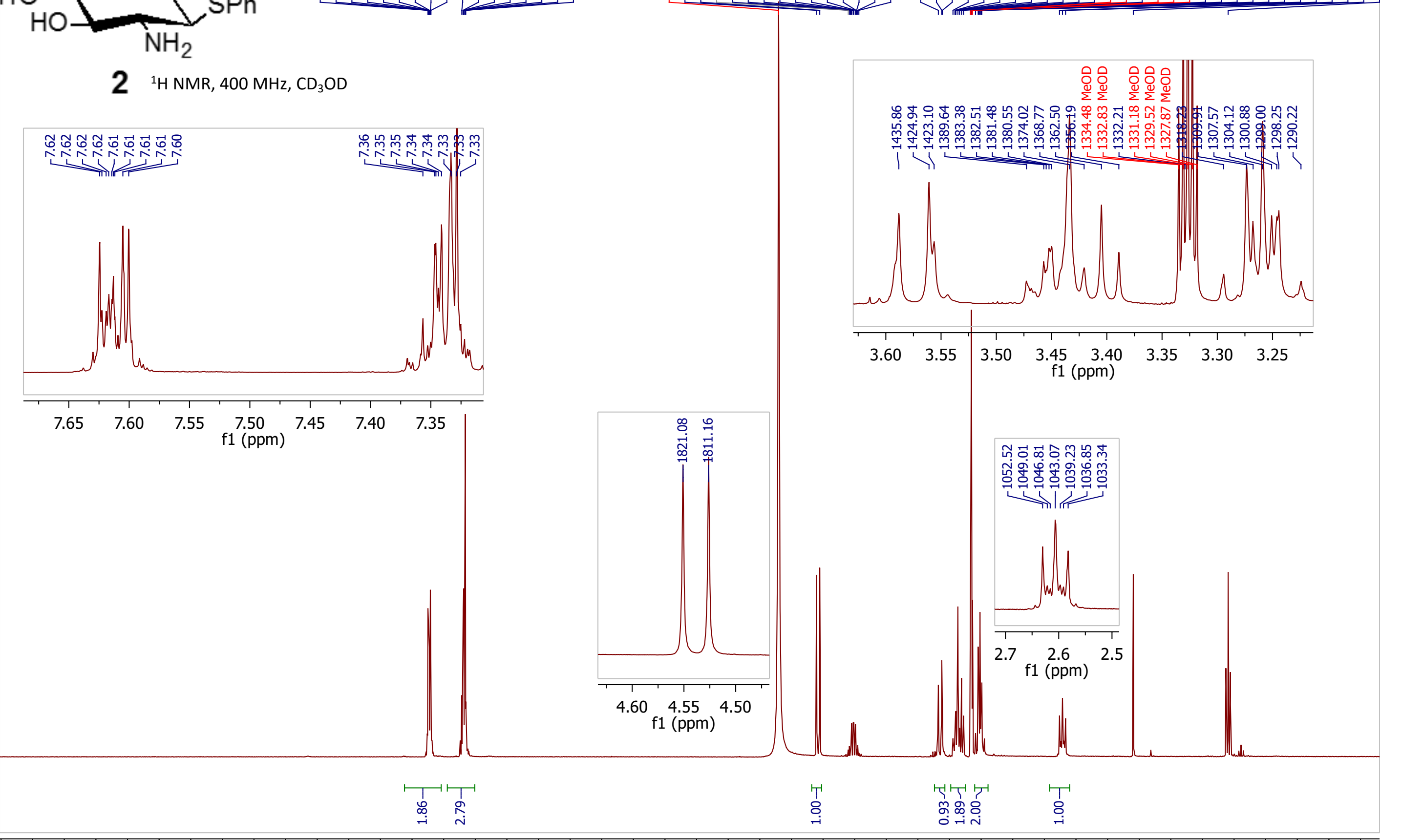$$
.
$$

10.5

10.0

$9.5 \quad 9.0$

$8.5 \quad 8.0$

1,1

6.5

$6.0 \underset{f 1(\mathrm{ppm})}{5.5} 5.0$

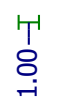

\begin{tabular}{|c|c|}
\hline 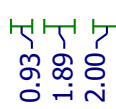 & \\
\hline 3.5 & 3.0 \\
\hline
\end{tabular}

$\begin{array}{llll}2.0 & 1.5 & 1.0 & 0.5\end{array}$


<smiles>N#CC1O[C@H](c2ccccc2)[C@H](N)C(O)[C@H](O)[C@H]1O</smiles>

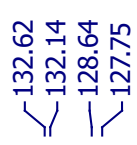

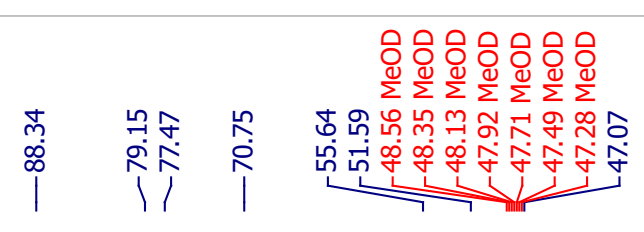

$\left.2{ }^{13} \mathrm{C}_{\{1}^{1} \mathrm{H}\right\} \mathrm{NMR}, 100 \mathrm{MHz}, \mathrm{CD}_{3} \mathrm{OD}$

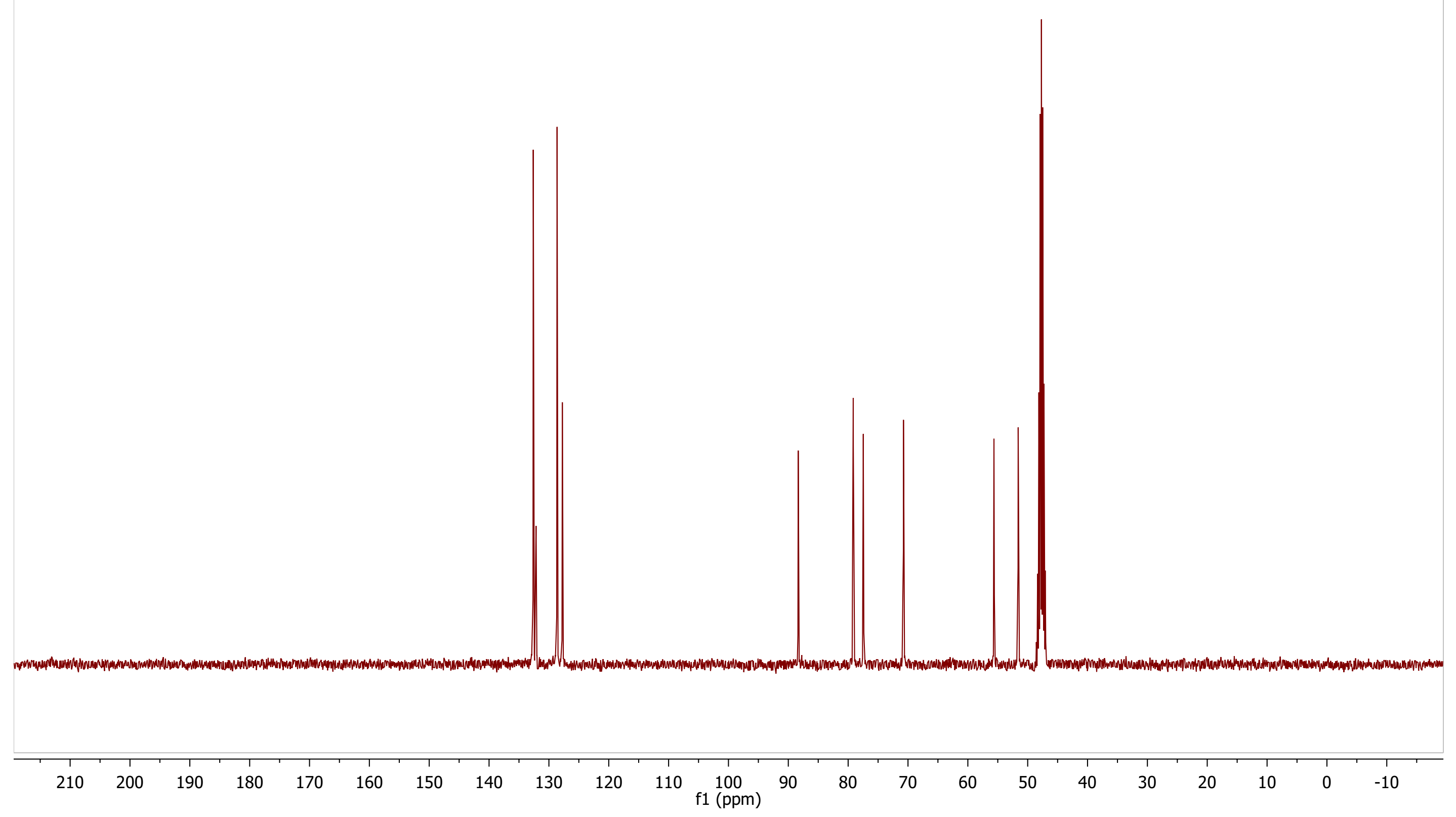




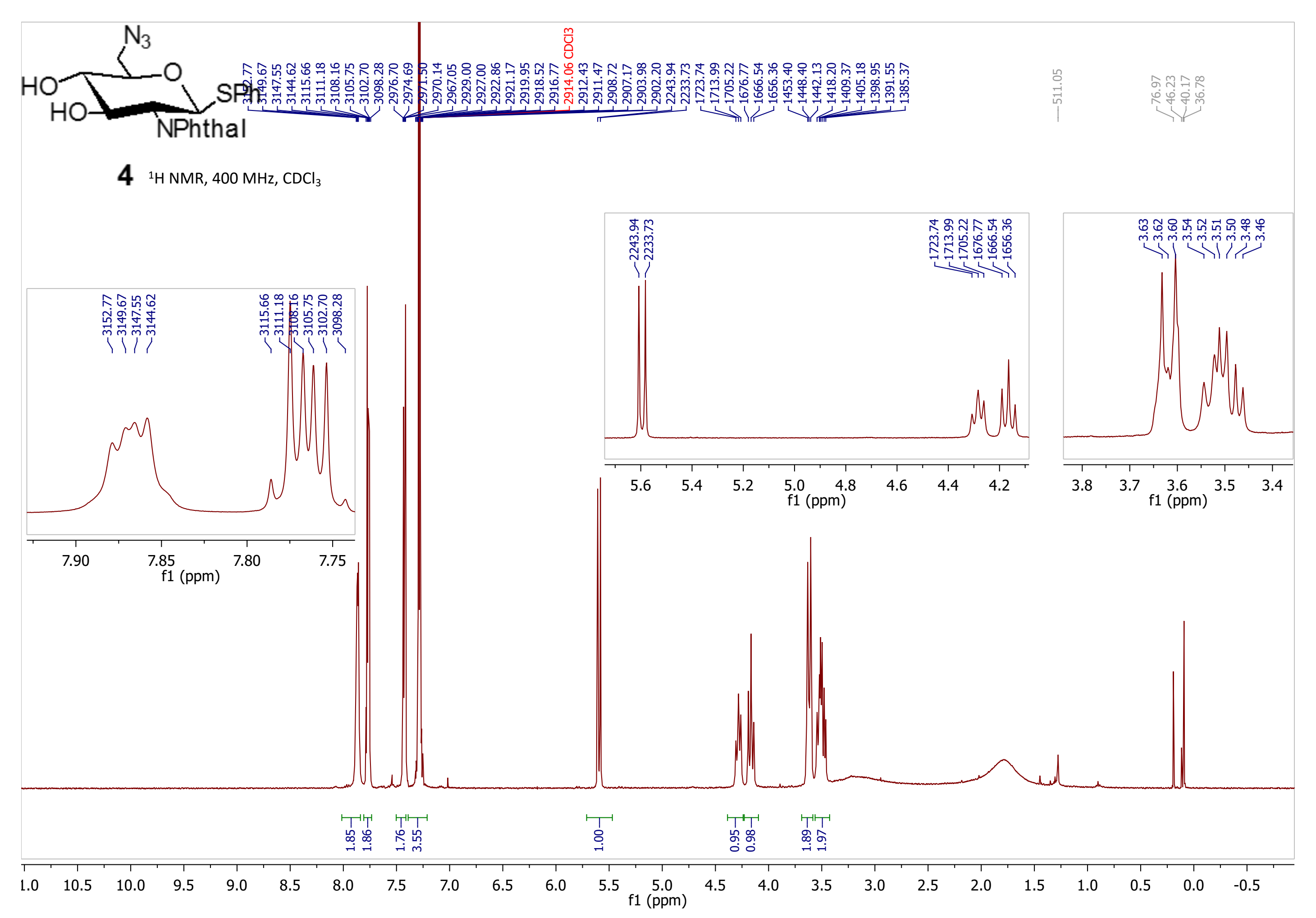




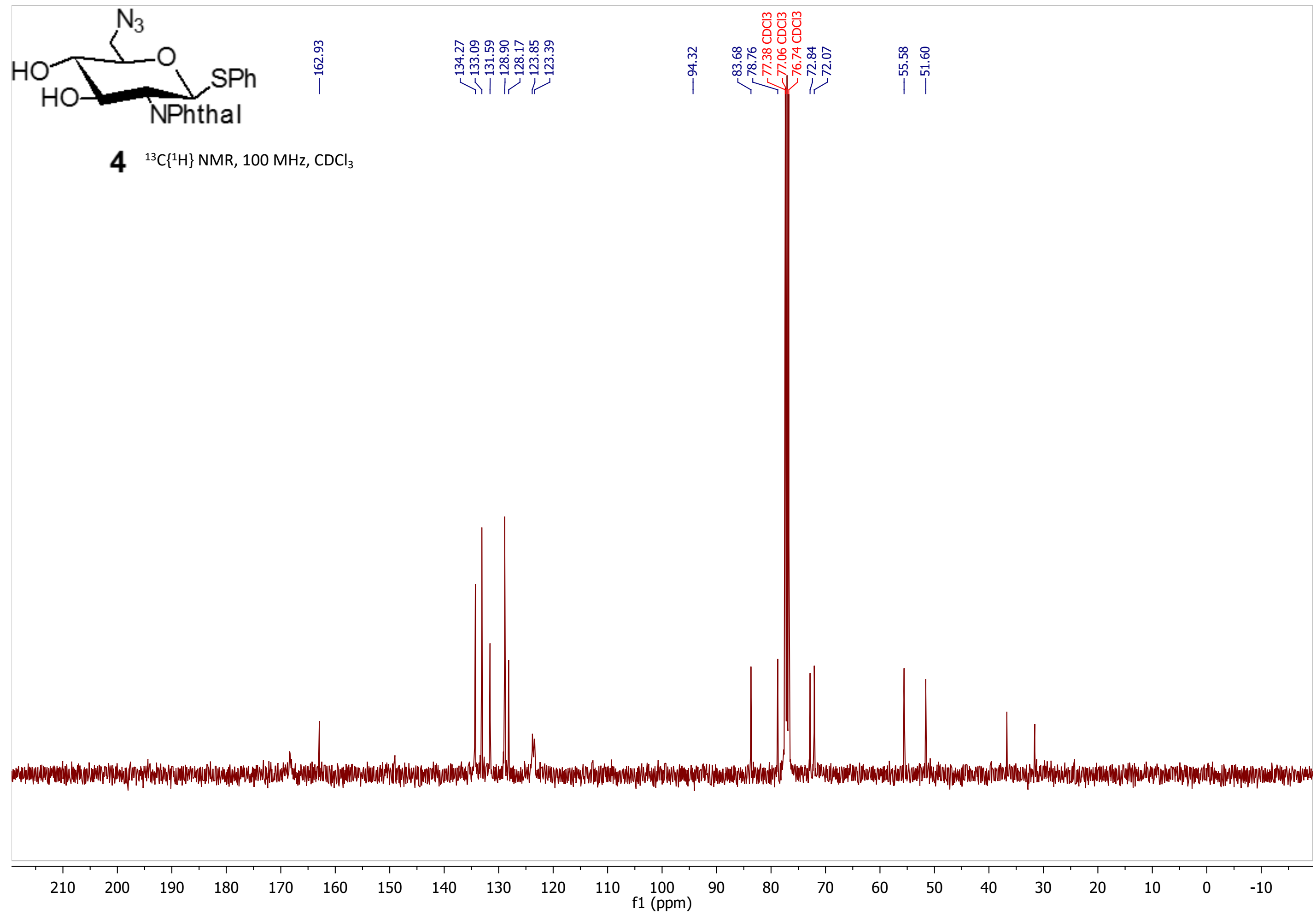




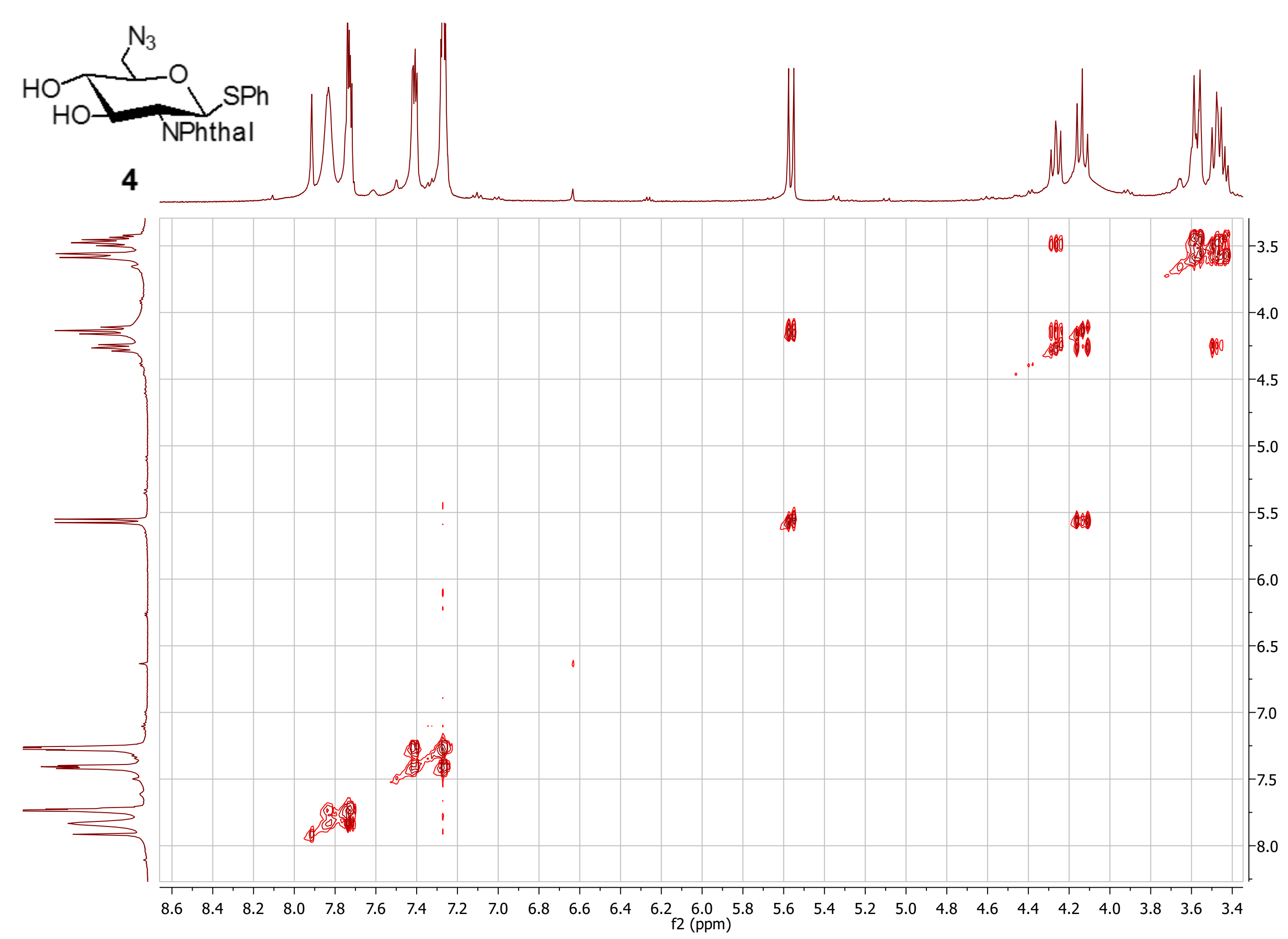




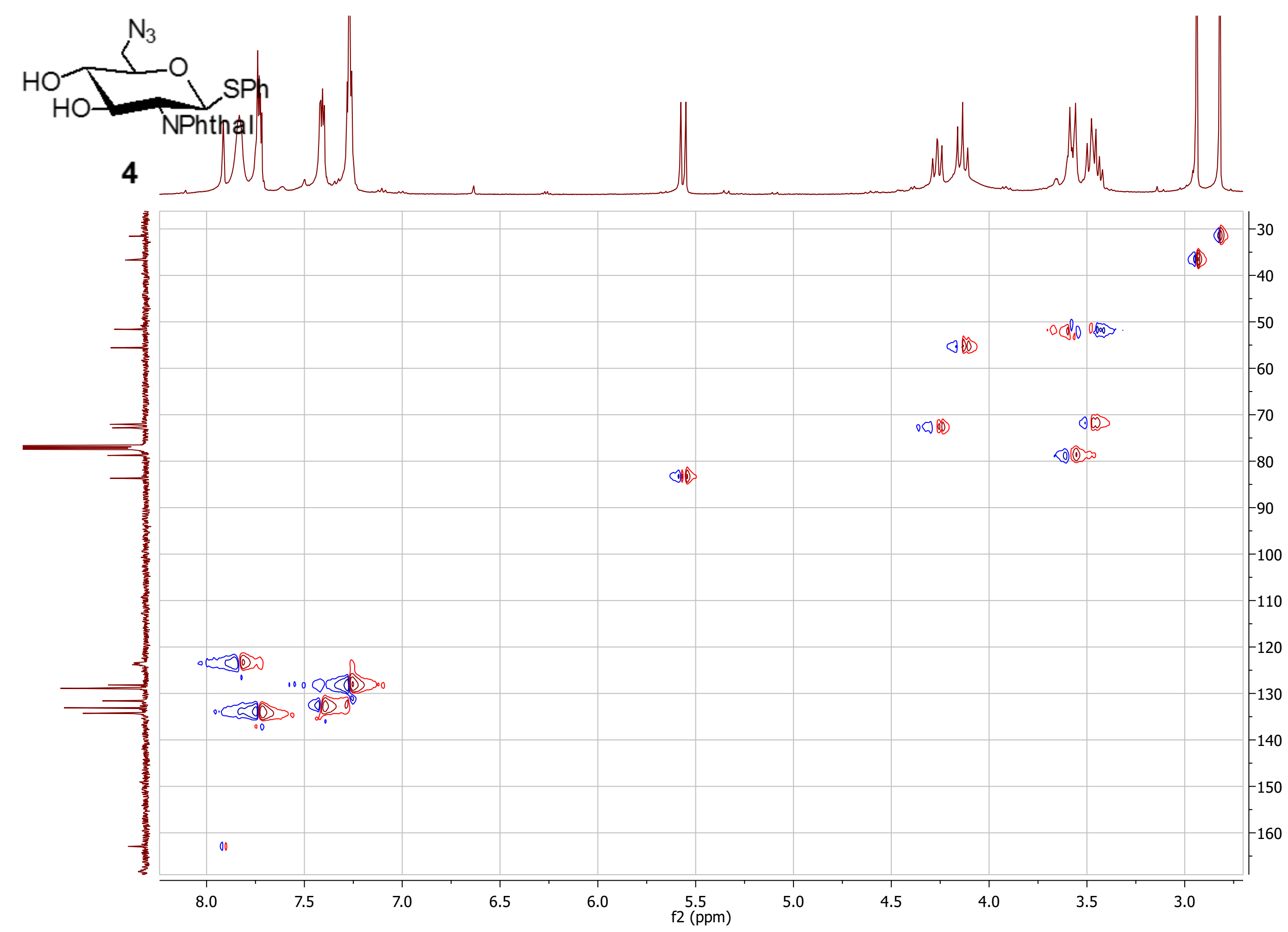




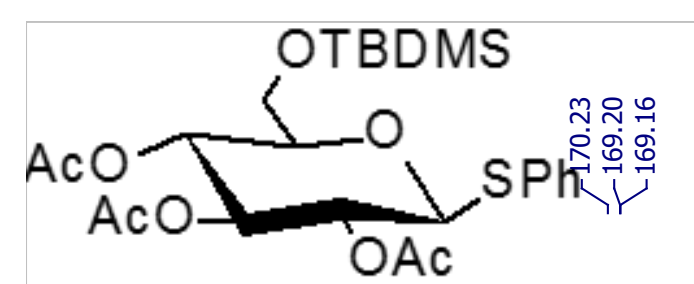

$6{ }^{13} \mathrm{C}\left\{{ }^{1} \mathrm{H}\right\} \mathrm{NMR}, 100 \mathrm{MHz}, \mathrm{CDCl}_{3}$

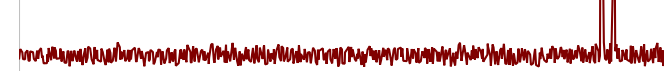
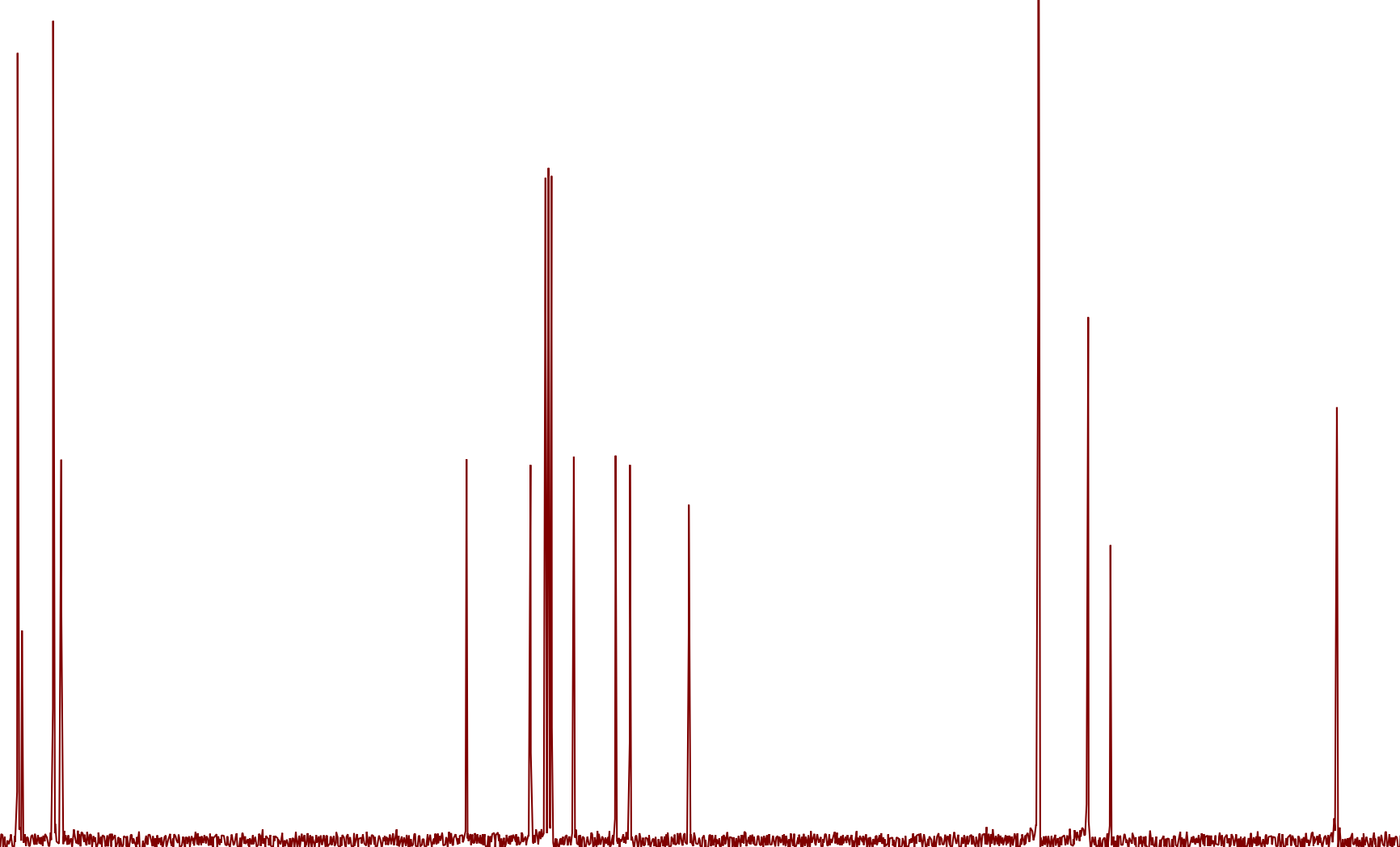


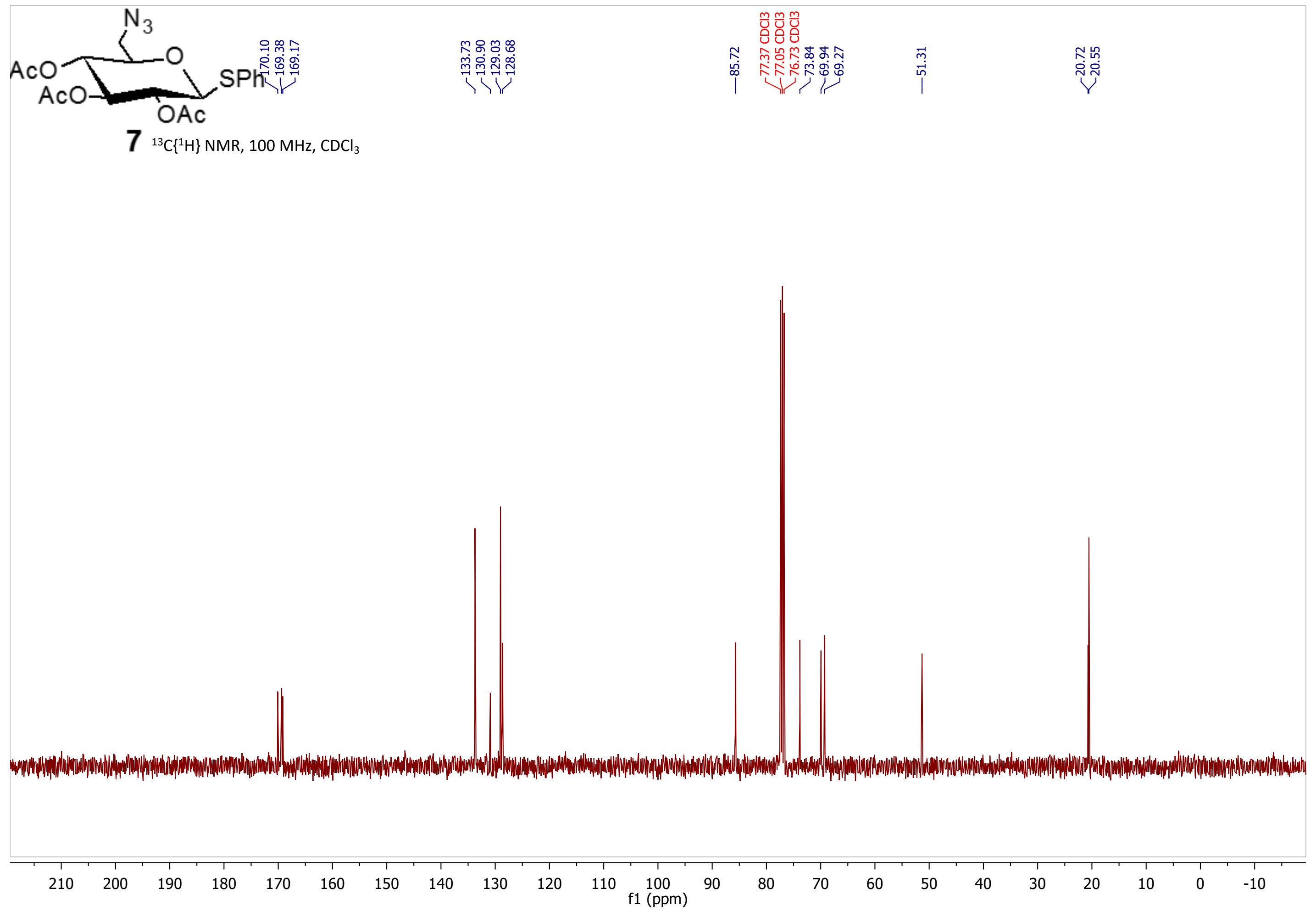




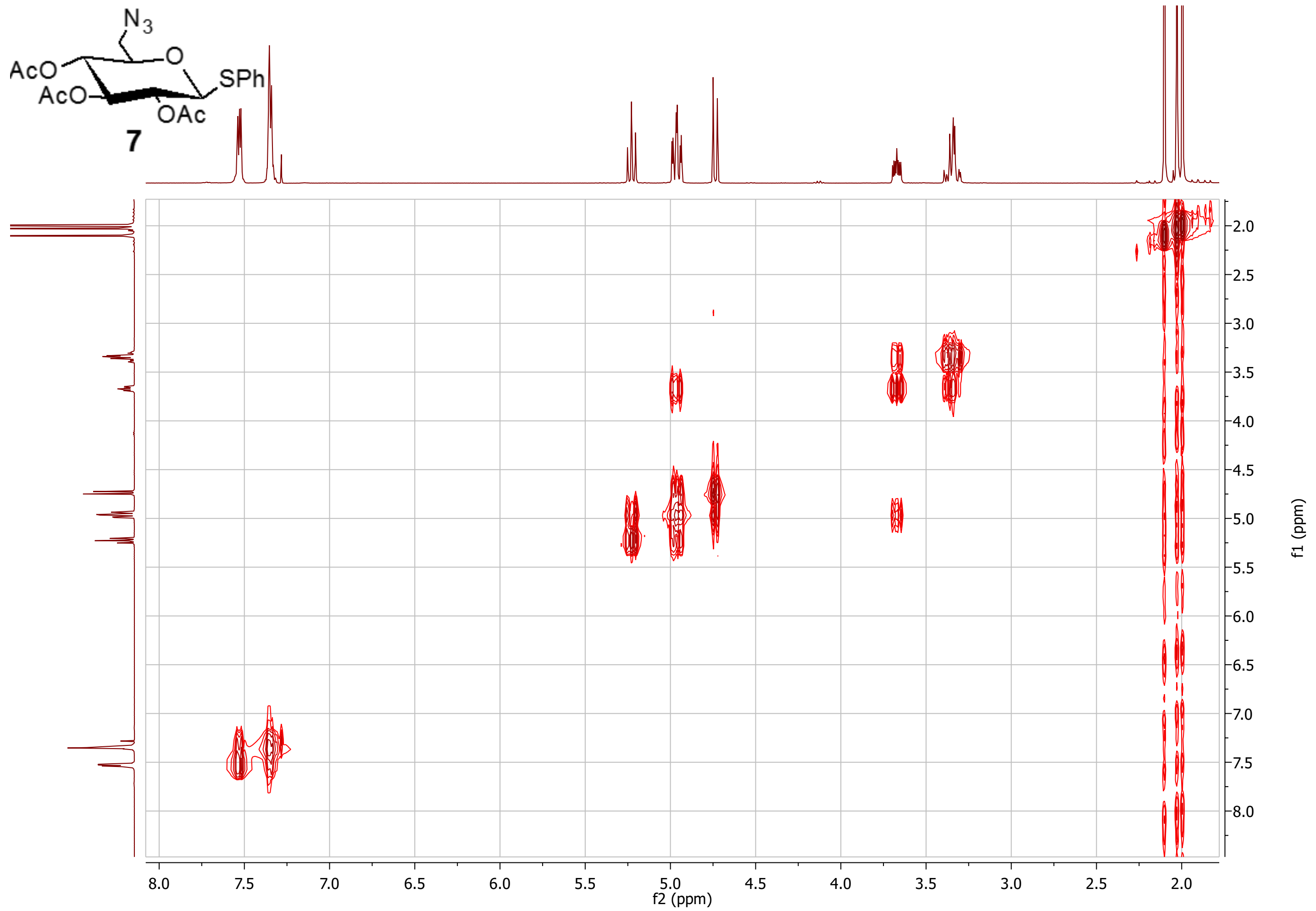




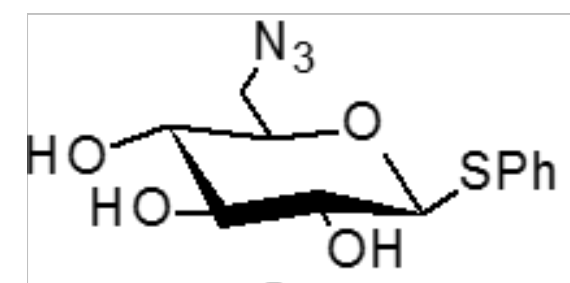

$8{ }^{1} \mathrm{H} N M R, 400 \mathrm{MHz}, \mathrm{CD}_{3} \mathrm{OD}$

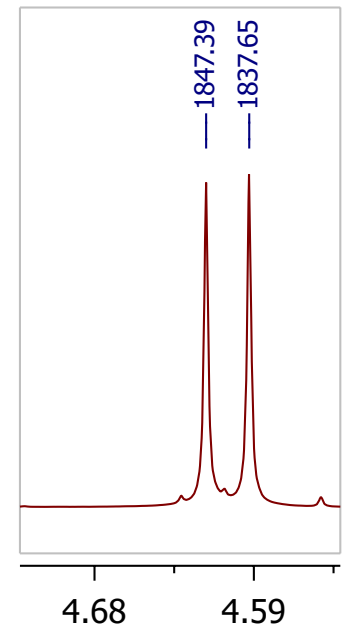

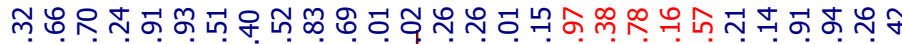

\section{응ำ 응ำ}

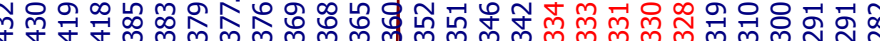

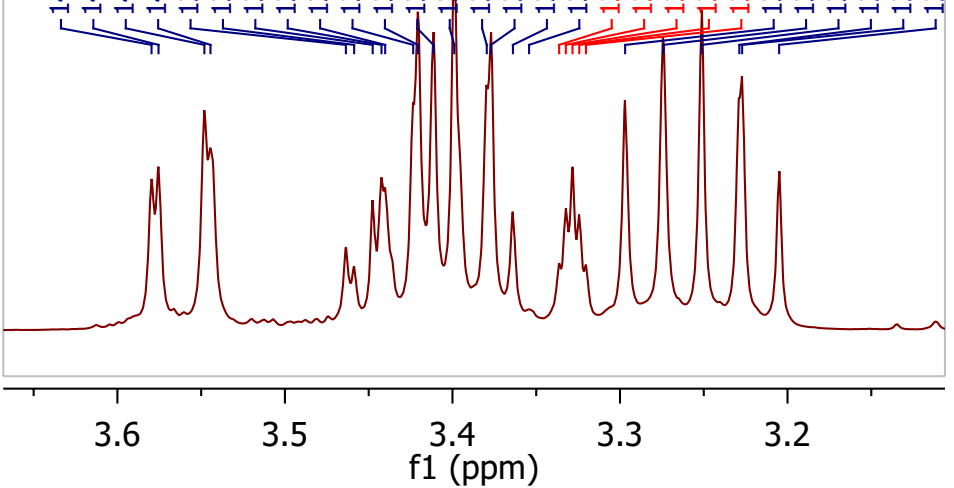

f1 (ppm)
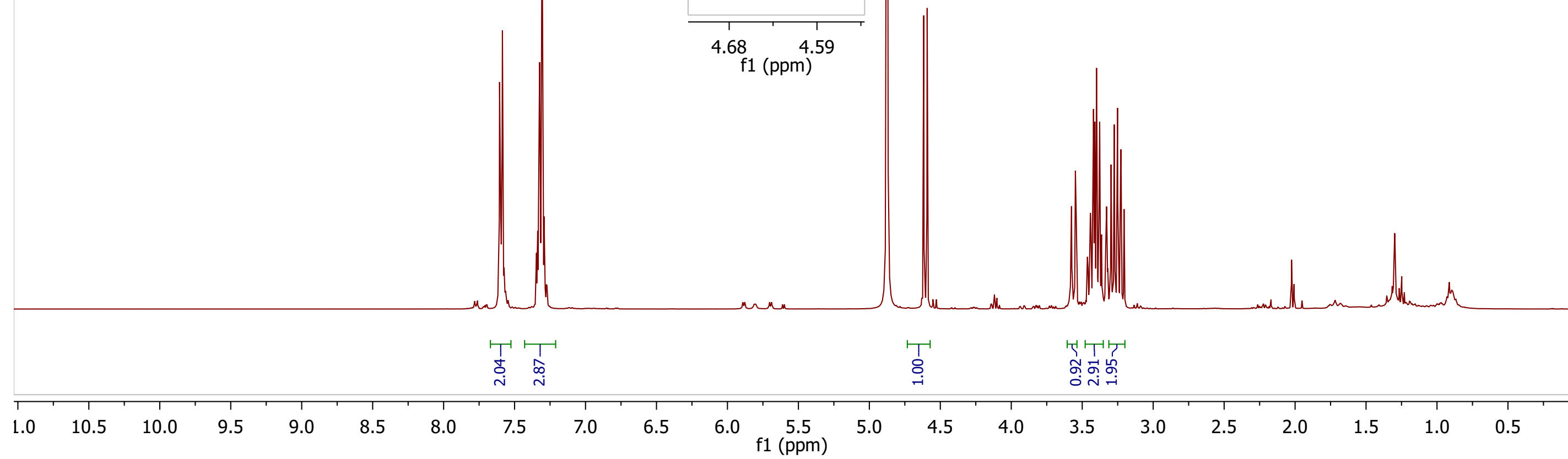


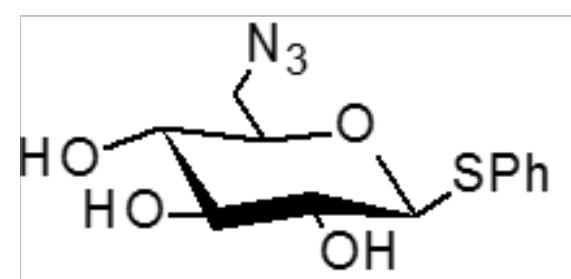

$8{ }^{13} \mathrm{C}\left\{{ }^{1} \mathrm{H}\right\} \mathrm{NMR}, 100 \mathrm{MHz}, \mathrm{CD}_{3} \mathrm{OD}$

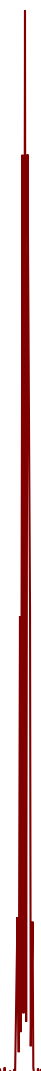

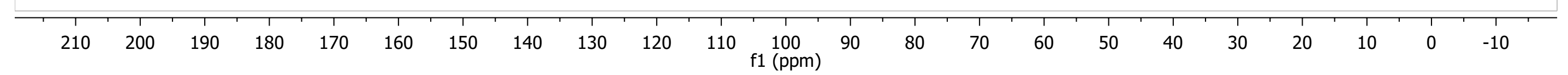




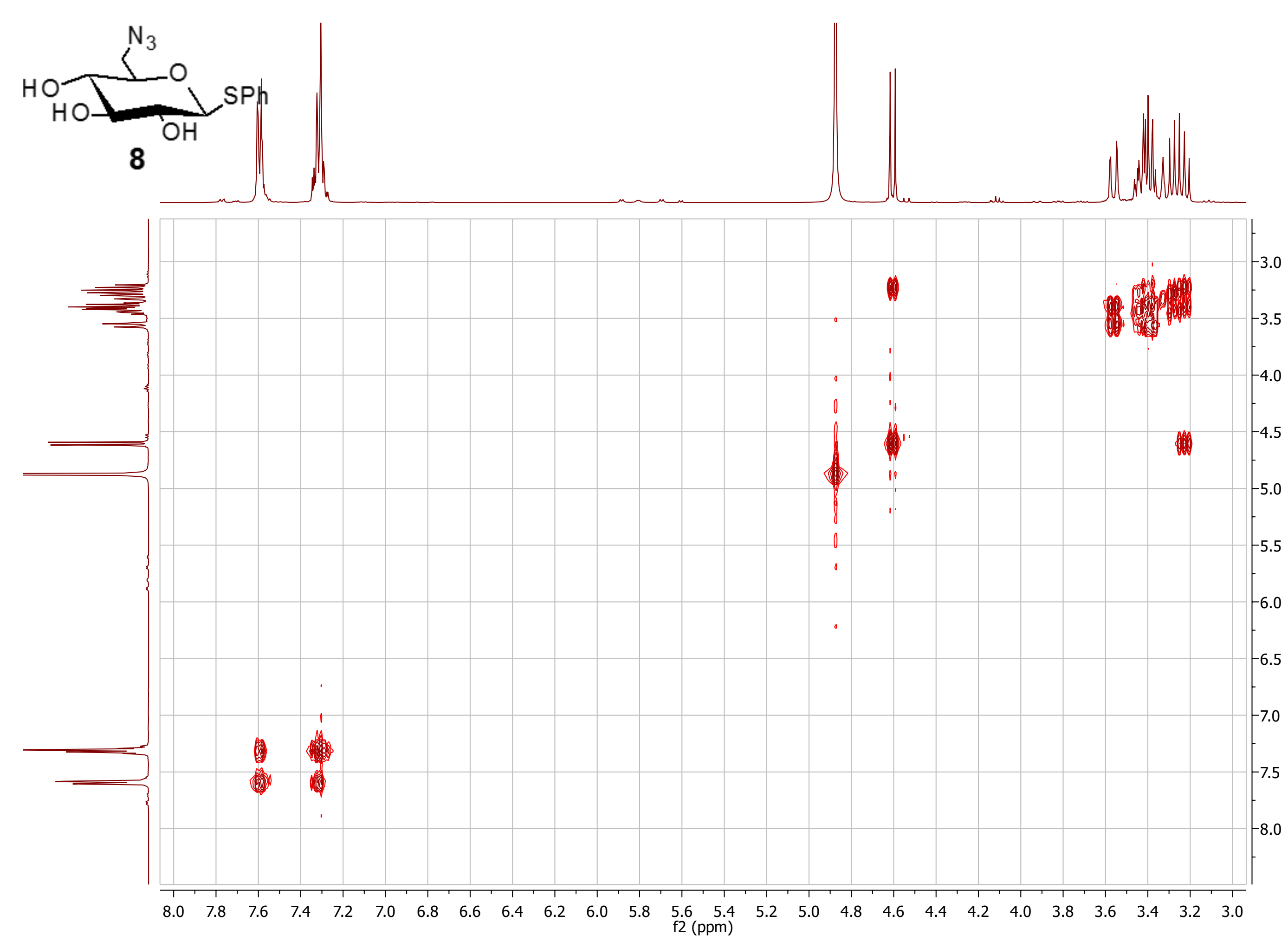




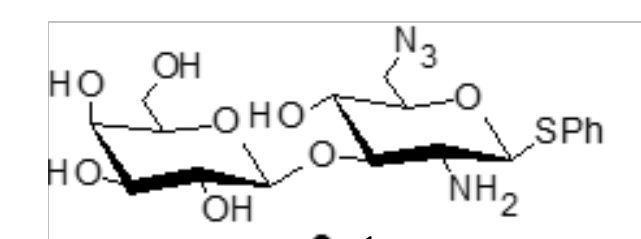

$9{ }^{1} \mathrm{H} N M R, 400 \mathrm{MHz}, \mathrm{D}_{2} \mathrm{O}$

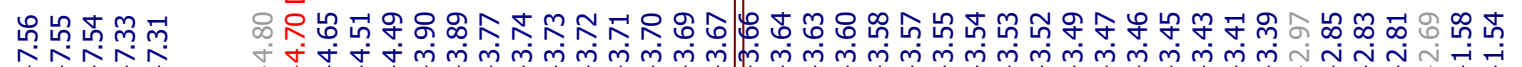

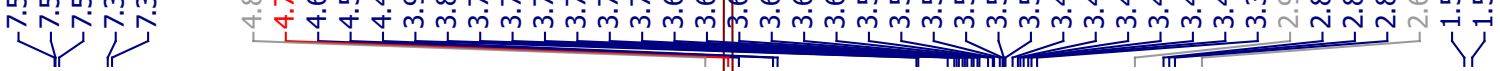

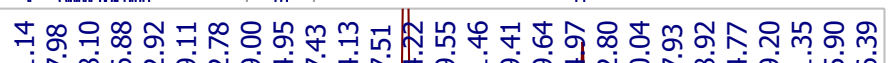

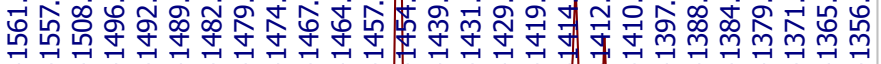
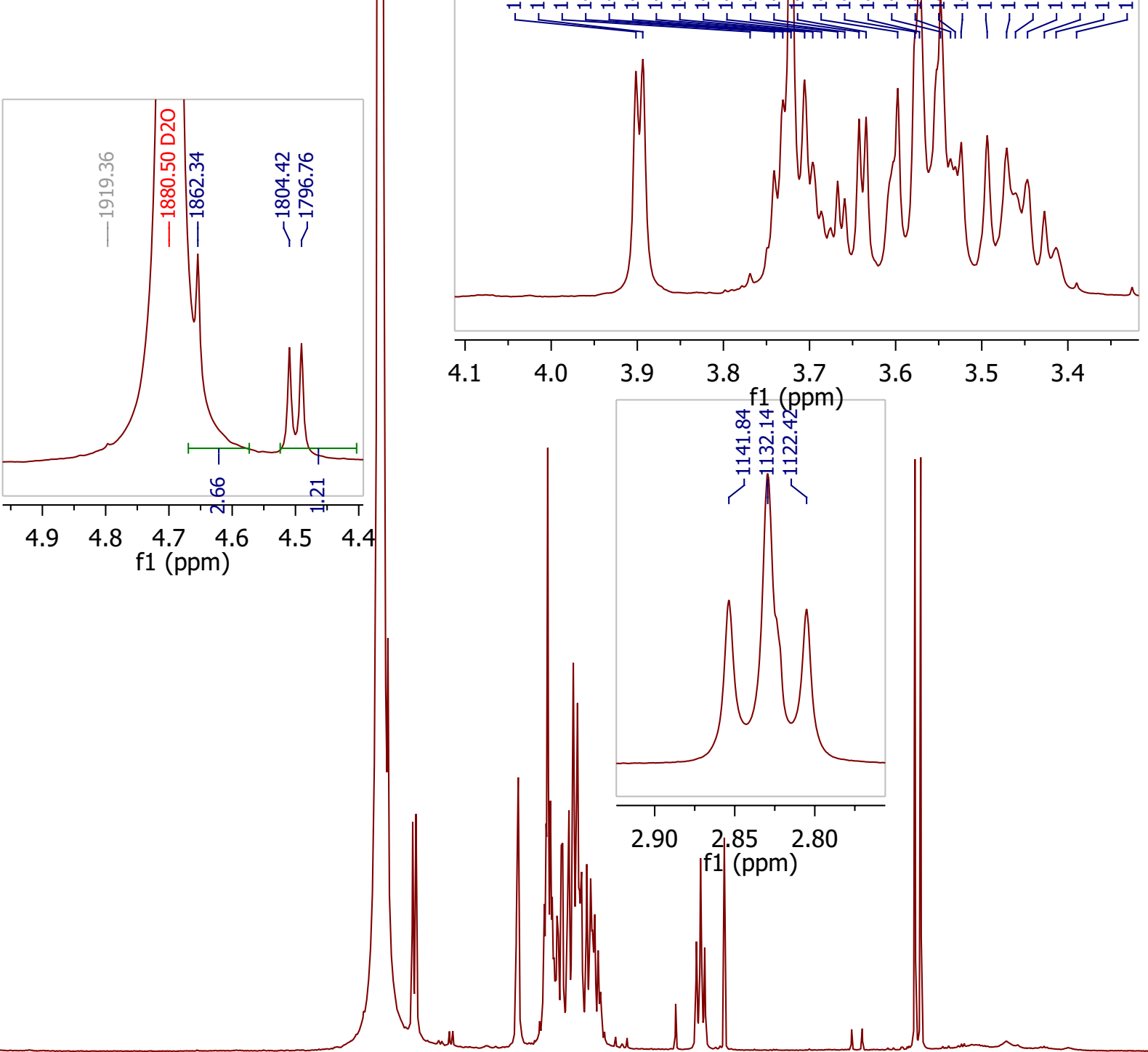

$\mu$

\begin{tabular}{|c|c|c|c|c|c|c|c|c|c|c|c|c|c|c|c|c|c|c|c|c|c|c|c|}
\hline & & & & & & & 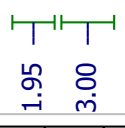 & & & & & & 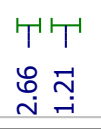 & & $\begin{array}{l}\frac{1}{\infty} \\
\infty \\
0 \\
0 \\
0\end{array}$ & $\begin{array}{l}T \\
8 \\
\stackrel{T}{+}\end{array}$ & & & & & & & \\
\hline .0 & 10.5 & 10.0 & 9.5 & 9.0 & 8.5 & 8.0 & 7.5 & 7.0 & 6.5 & 6.0 & 5.5 & $\begin{array}{c}5.0 \\
\mathrm{f} 1(\mathrm{ppm})\end{array}$ & 4.5 & 4.0 & 3.5 & 3.0 & 2.5 & 2.0 & 1.5 & 1.0 & 0.5 & 0.0 & -0.5 \\
\hline
\end{tabular}




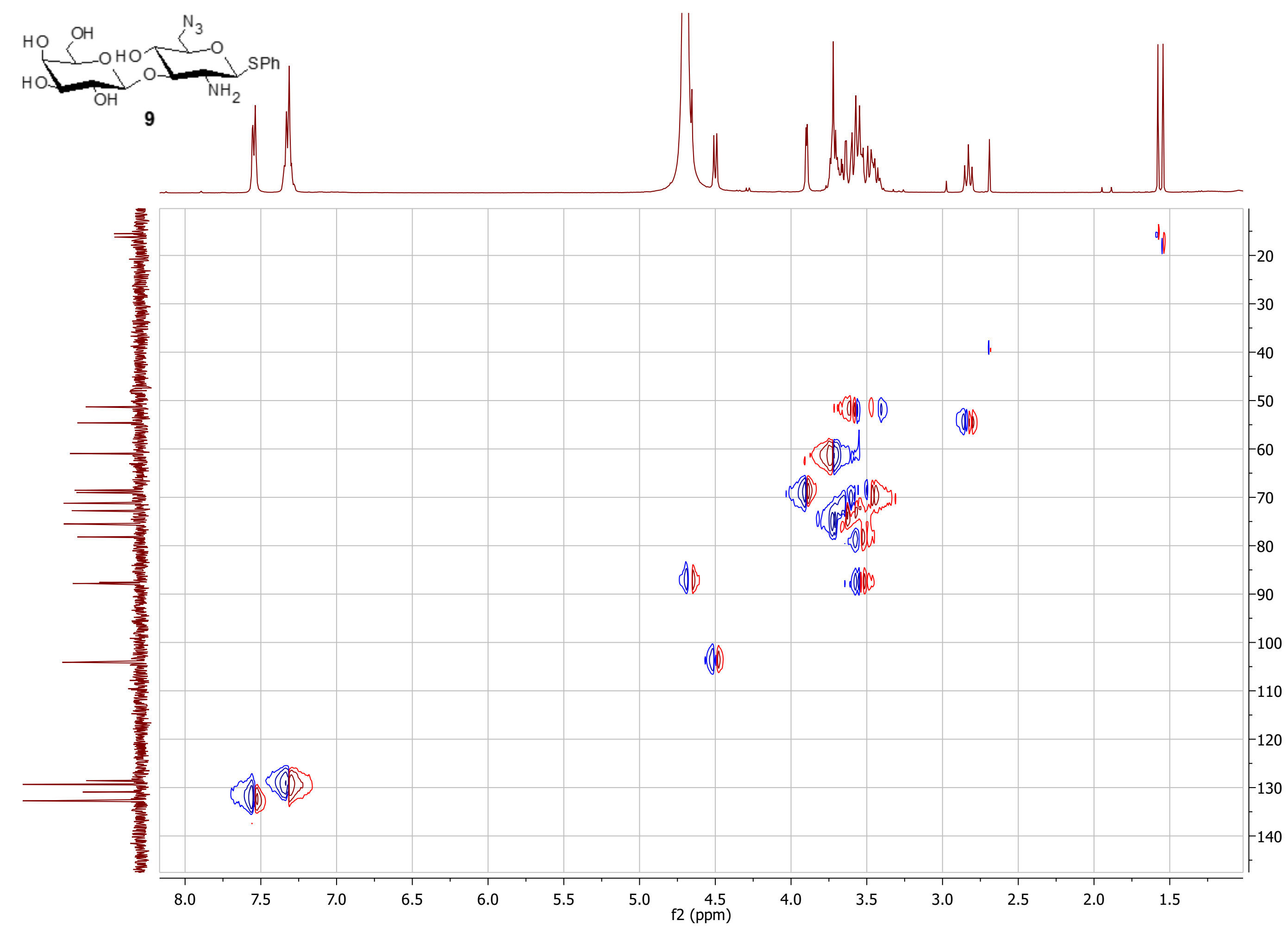

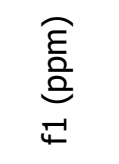




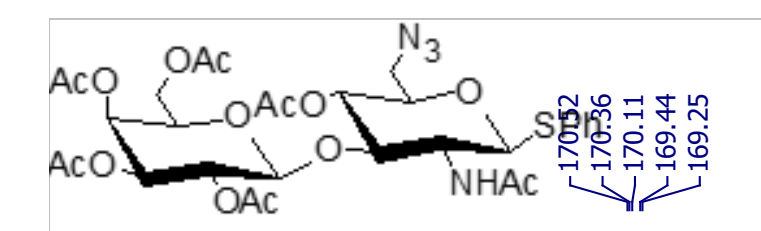

$10{ }^{13} \mathrm{C}\left\{{ }^{1} \mathrm{H}\right\} \mathrm{NMR}, 100 \mathrm{MHz}, \mathrm{CDCl}_{3}$

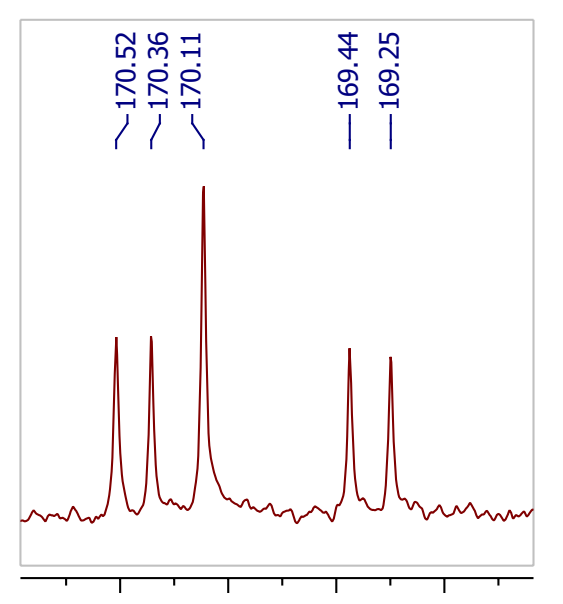

$\begin{array}{llll}170.5 & 170.0 & 169.5 & 169.0\end{array}$ f1 (ppm)
מํ.

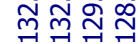

$\backslash 11$

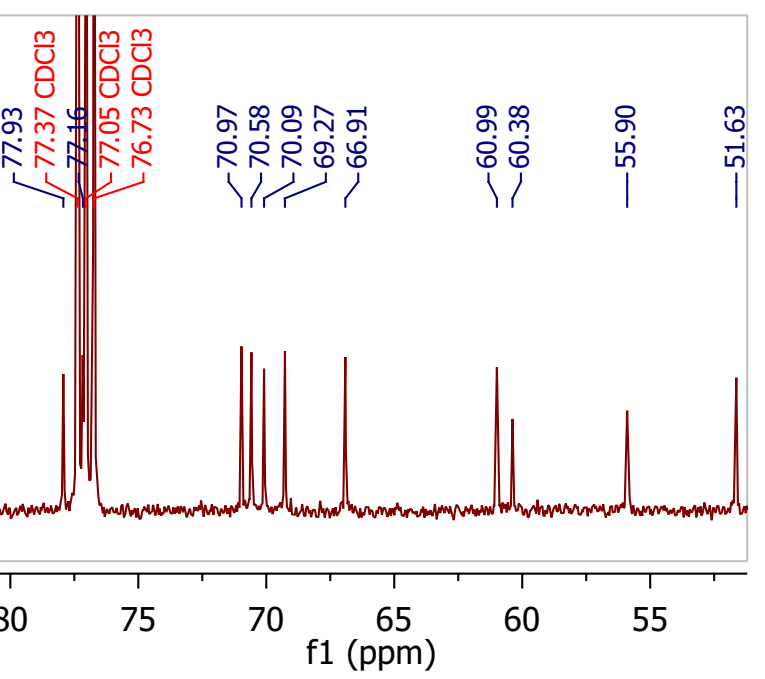

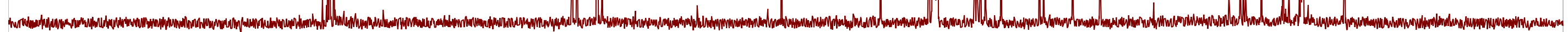




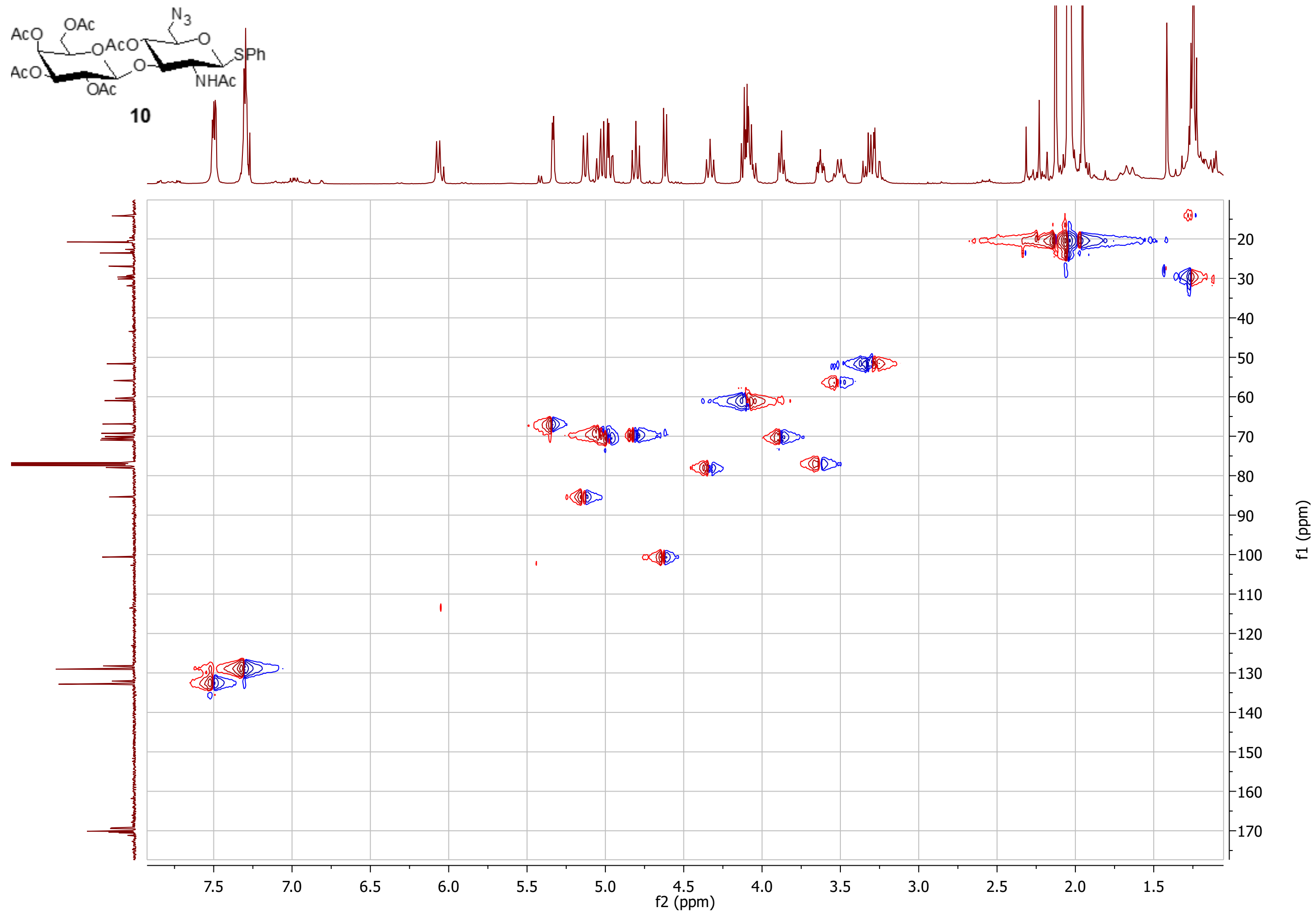




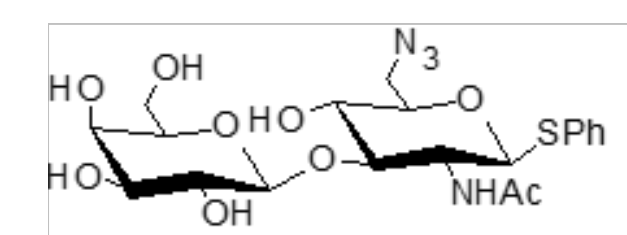

$11{ }^{1} \mathrm{H}$ NMR, $400 \mathrm{MHz}, \mathrm{DMSO}-d_{6}$
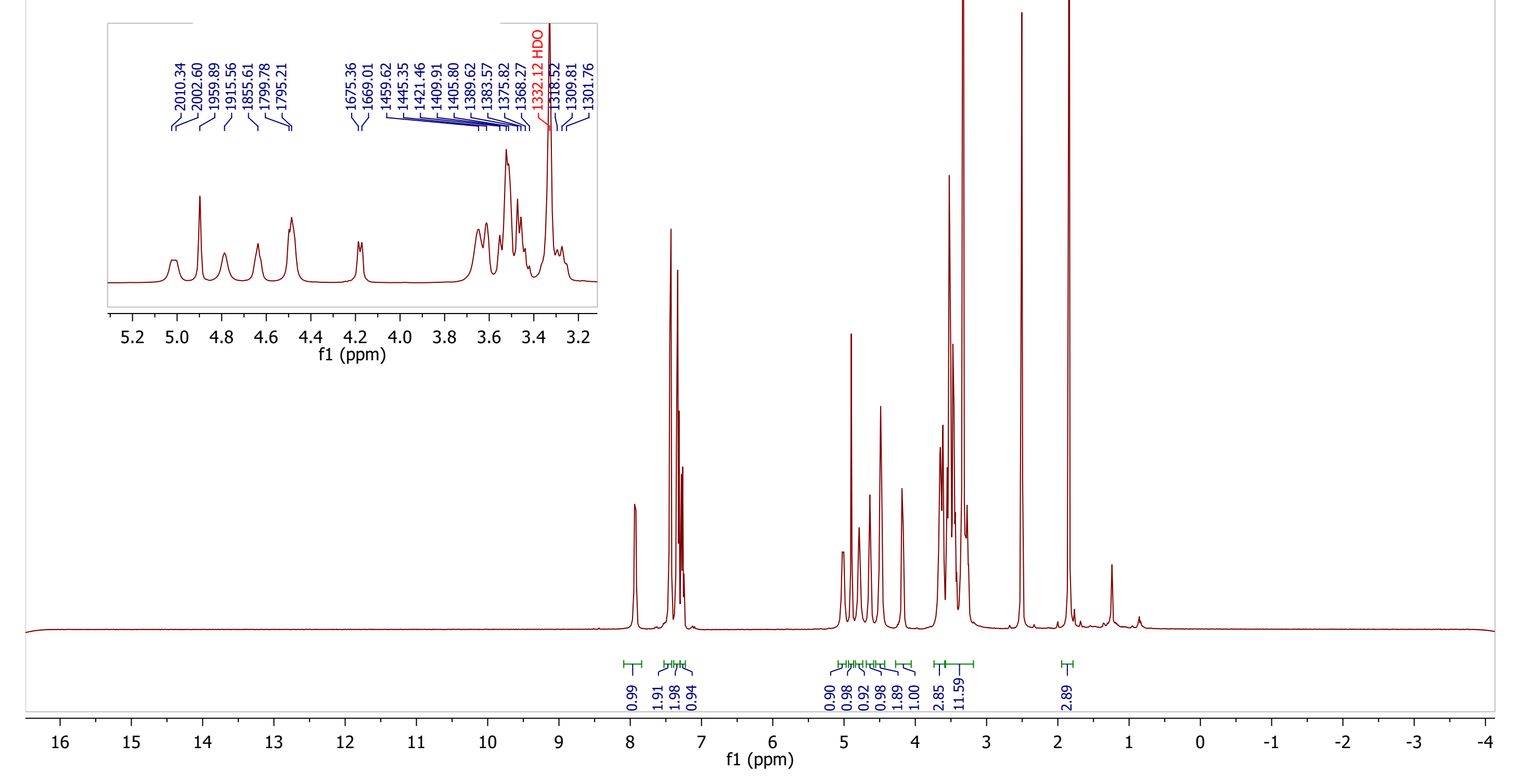

11 ${ }^{2} N M R, 400 \mathrm{MHz}$, DMSO-d 
${ }_{\mathrm{OH}}^{\mathrm{OH}}{ }_{\mathrm{OH}}^{\mathrm{OH}}$

$12{ }^{1} \mathrm{H} \mathrm{NMR}, 400 \mathrm{MHz}, \mathrm{CD}_{3} \mathrm{OD}$
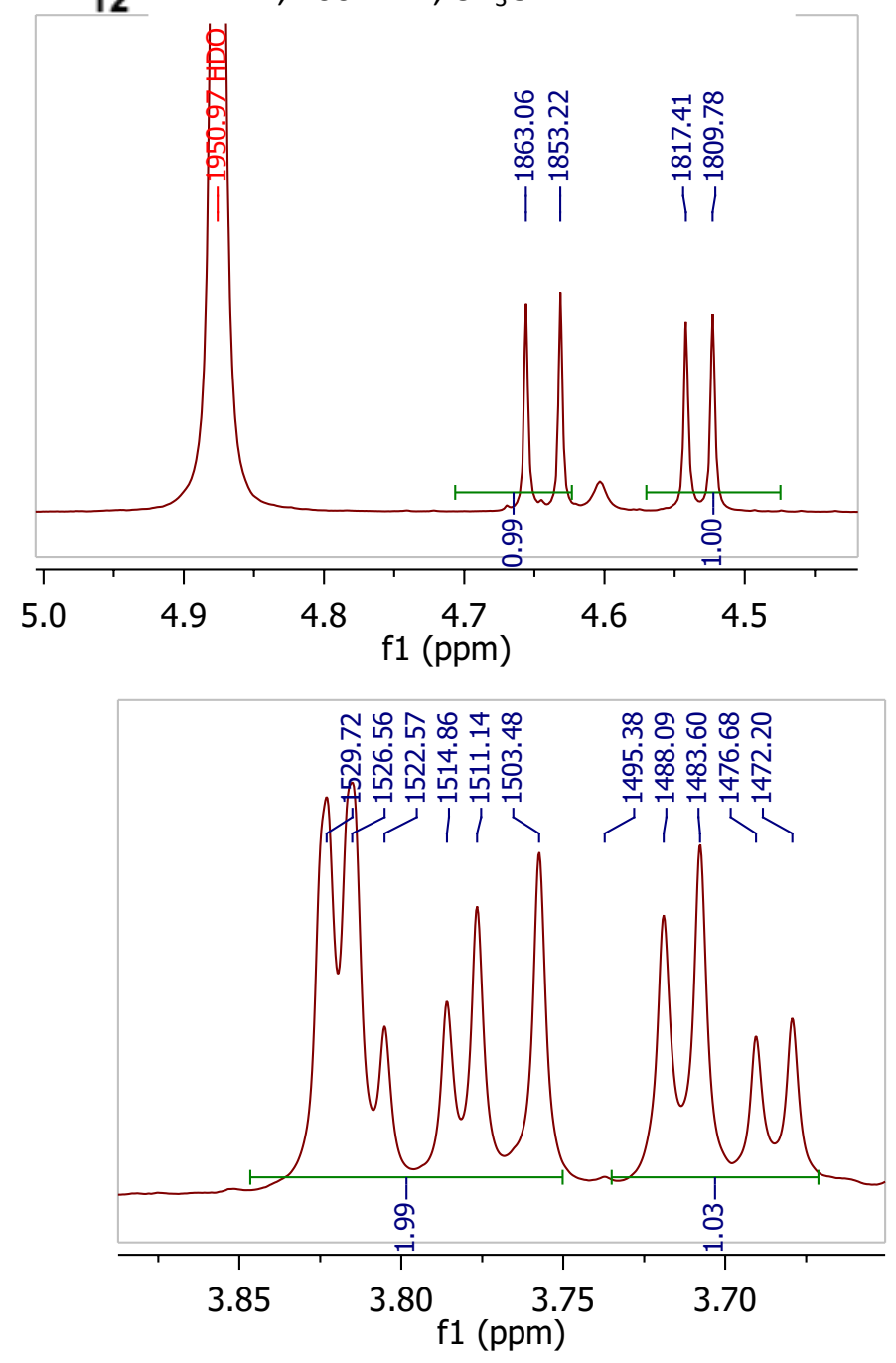

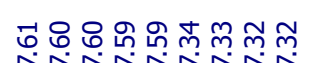

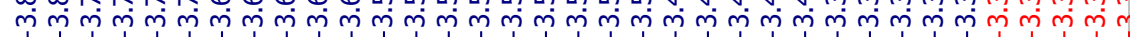
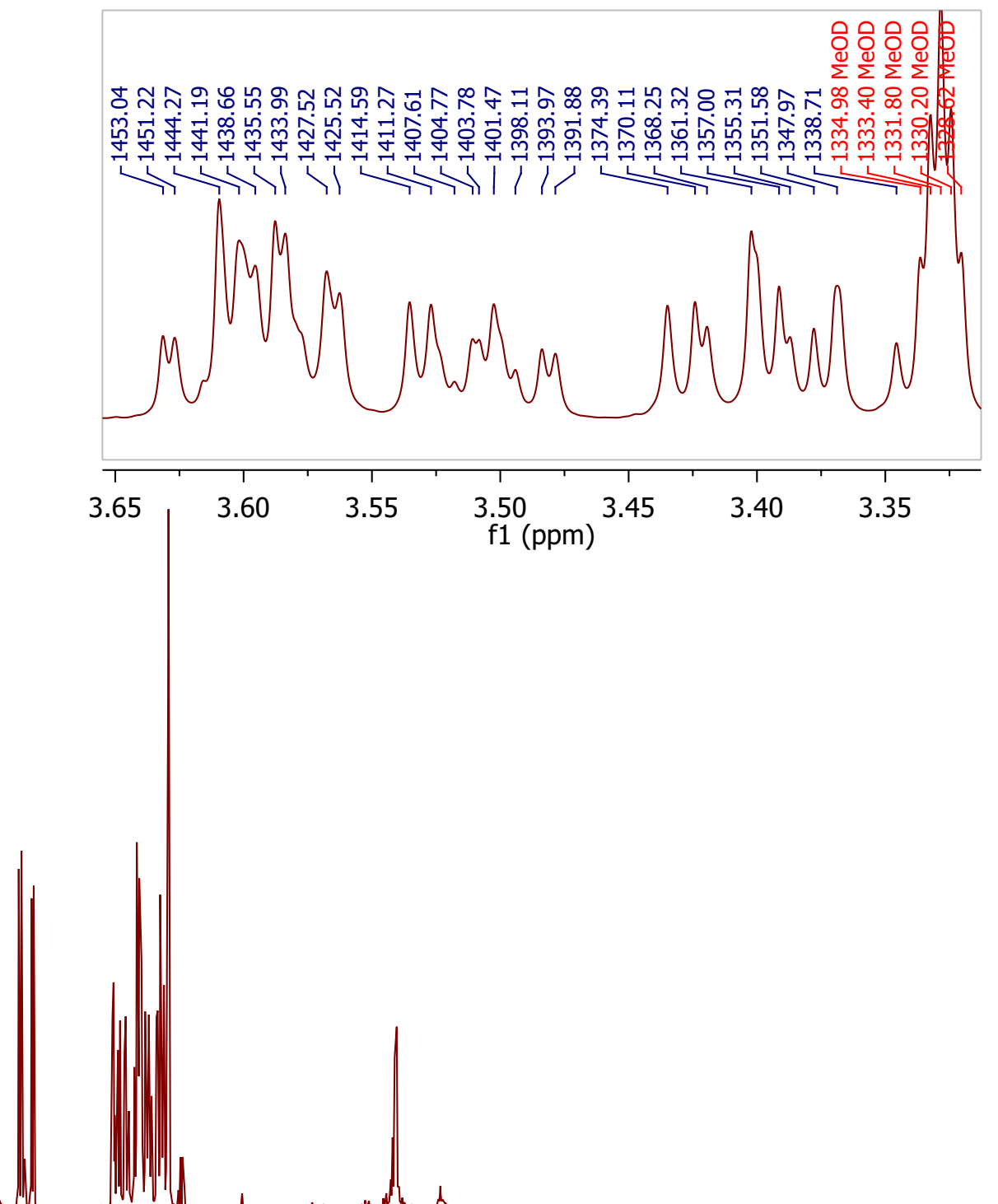

\begin{tabular}{|c|c|c|c|c|c|c|c|c|c|c|c|c|c|c|c|c|c|c|}
\hline & & & & & & & & & & & & & & & & & & \\
\hline 16 & 15 & 14 & 13 & 12 & 11 & 10 & 9 & 8 & 7 & 4 & 3 & 2 & 1 & 0 & -1 & -2 & -3 & -4 \\
\hline
\end{tabular}




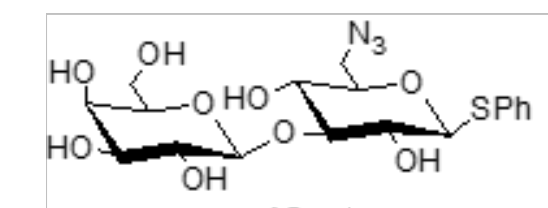

$12{ }^{13} \mathrm{C}\left\{{ }^{1} \mathrm{H}\right\} \mathrm{NMR}, 100 \mathrm{MHz}, \mathrm{CD}_{3} \mathrm{OD}$

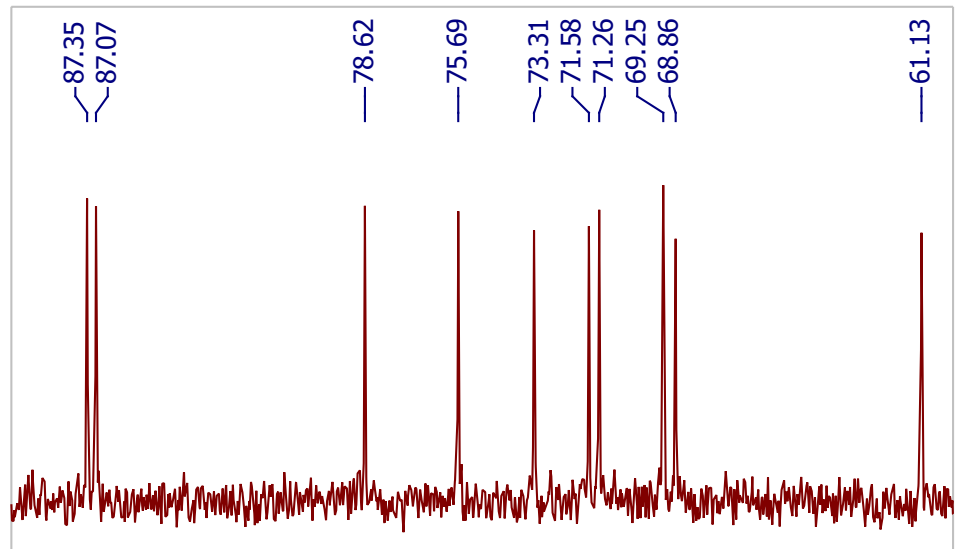

85 


\section{${ }^{1} \mathrm{H}$ NMR, $400 \mathrm{MHz}$, DMSO- $d_{6}$}

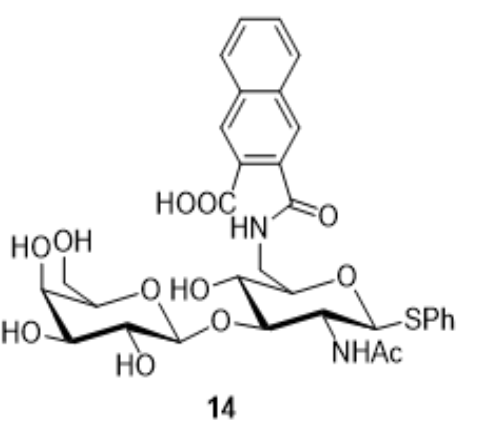

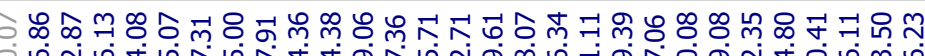

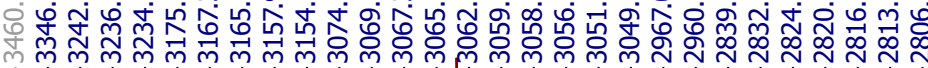

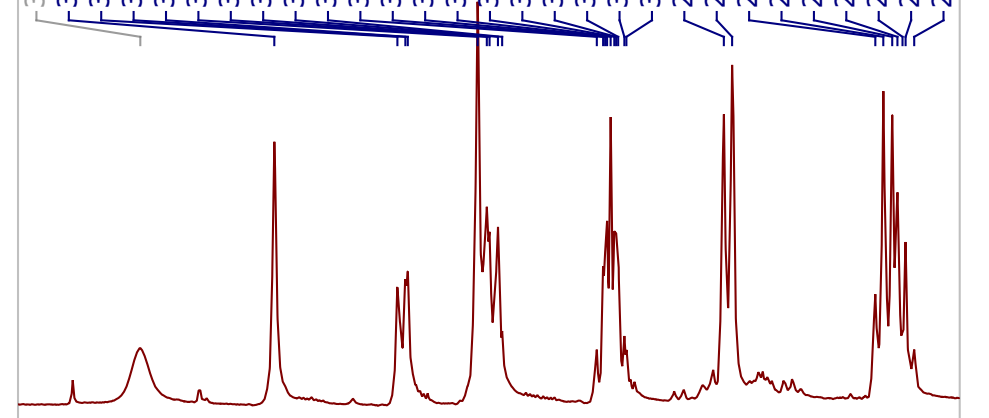

8.5
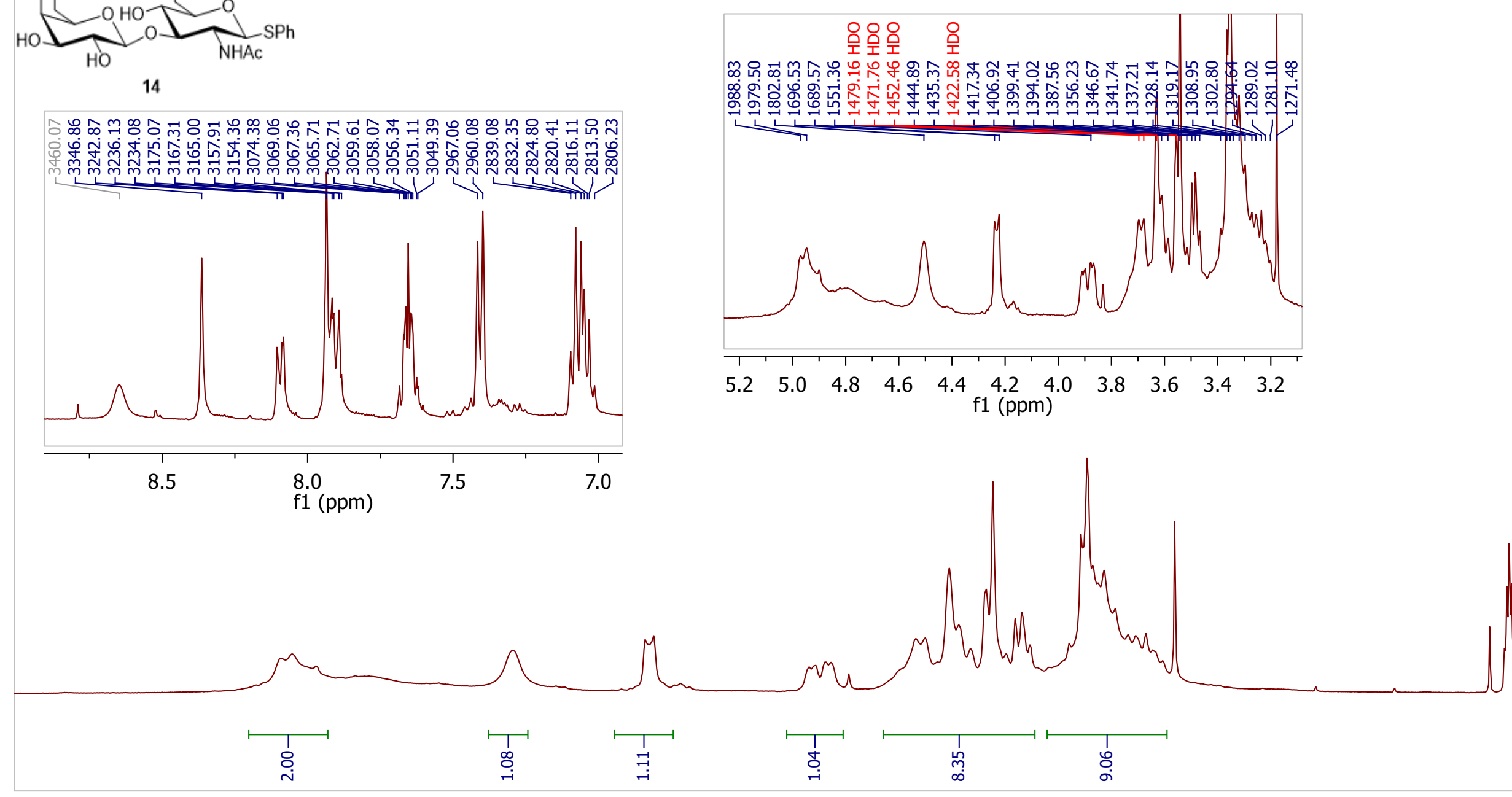


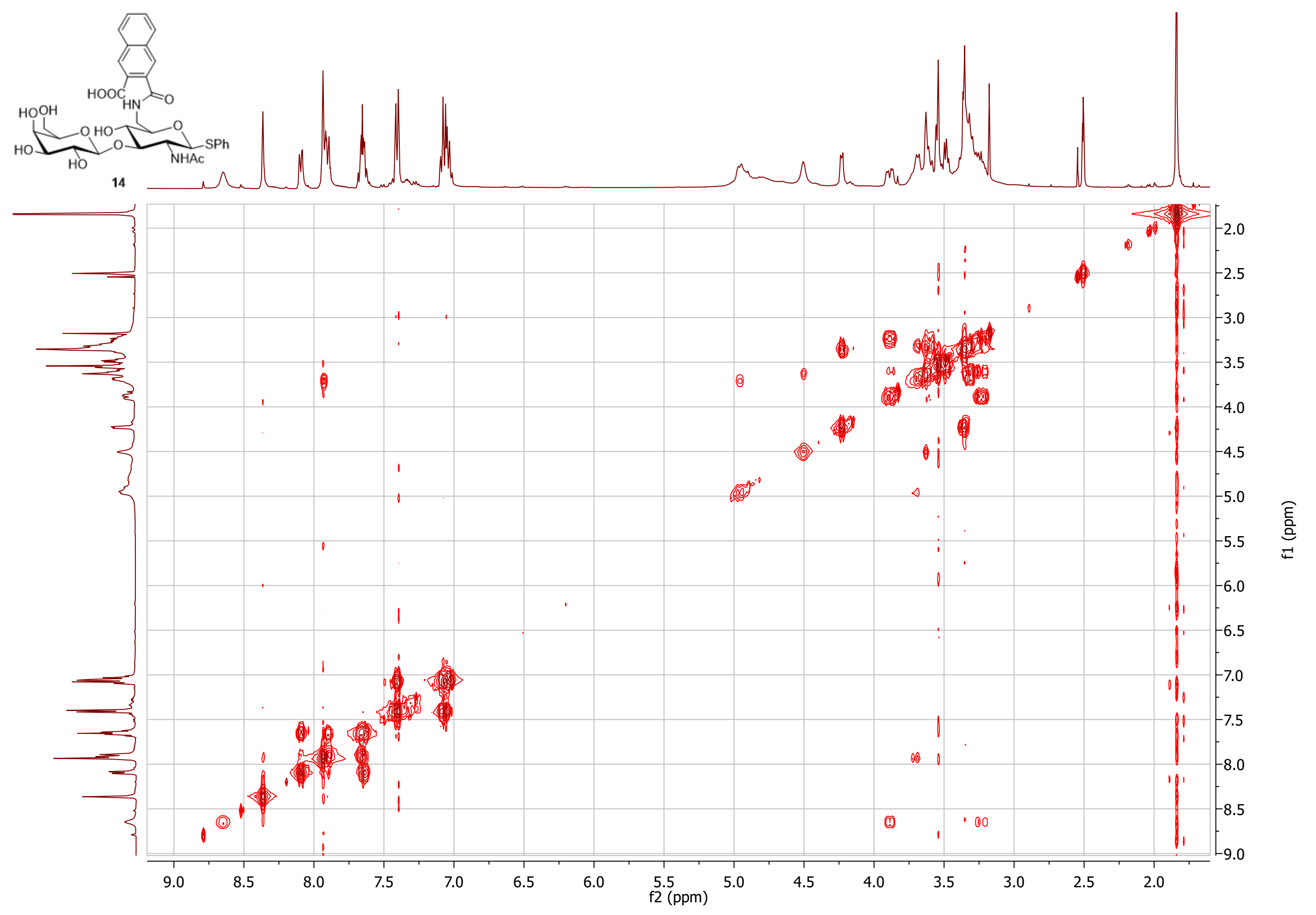




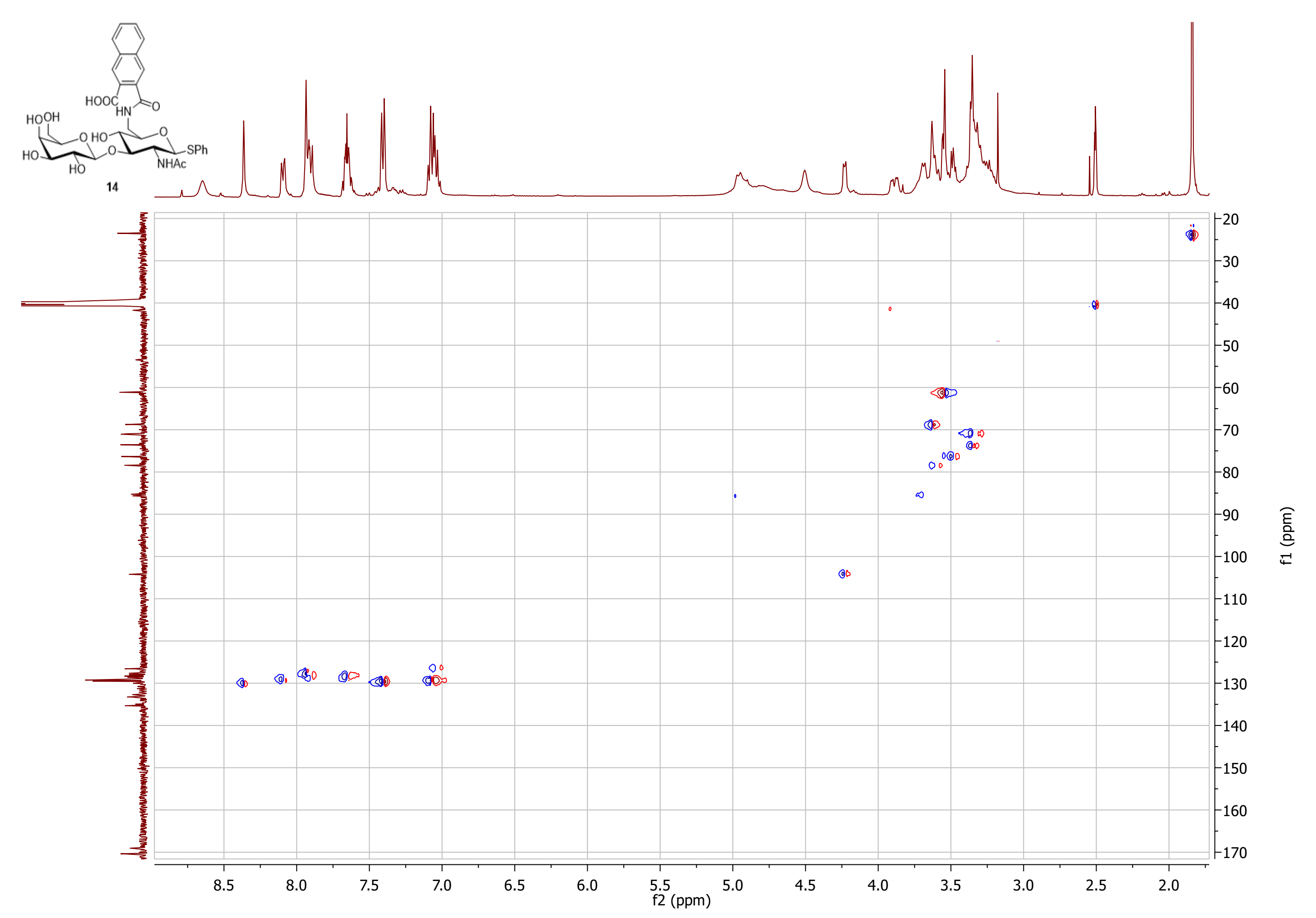




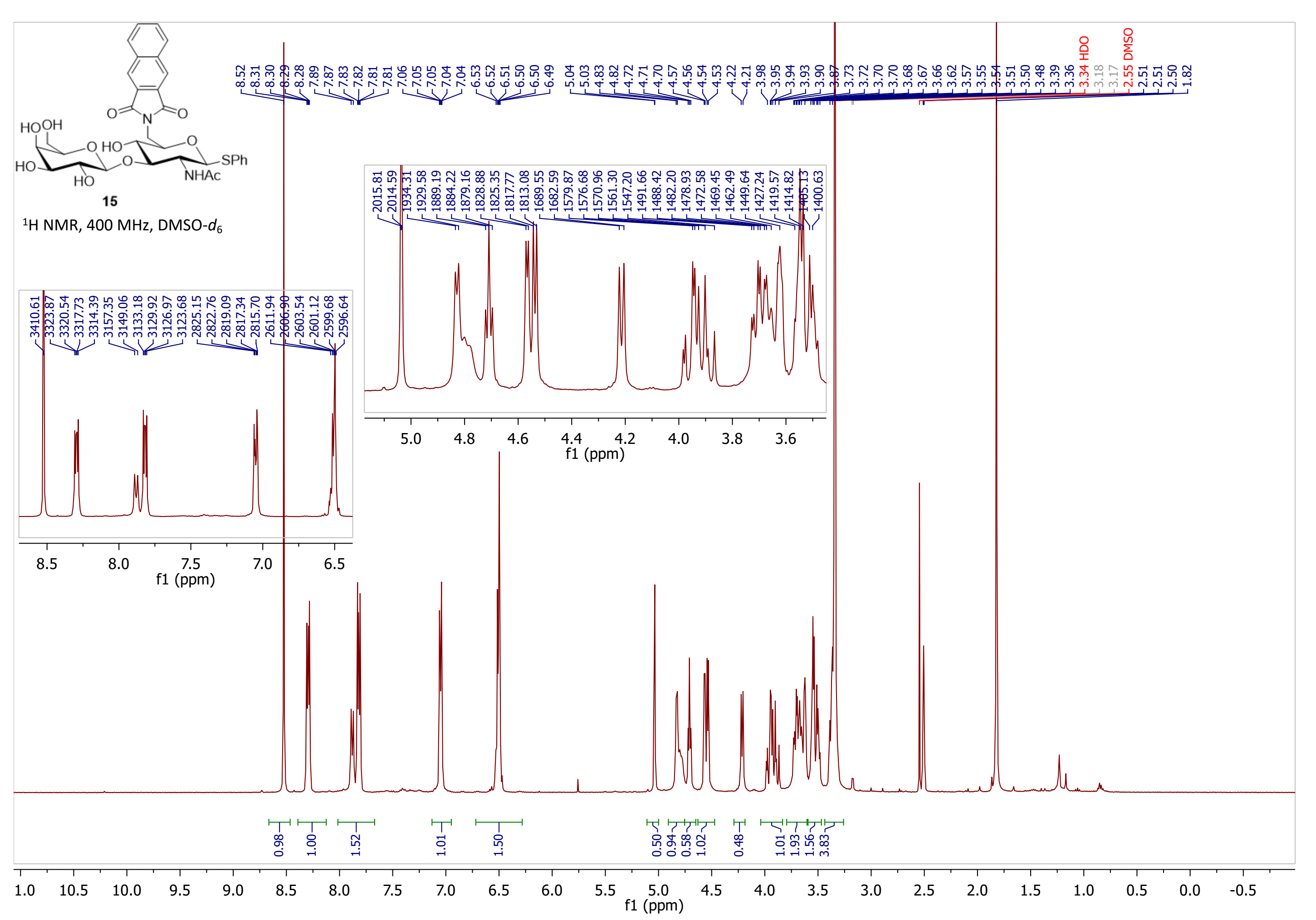




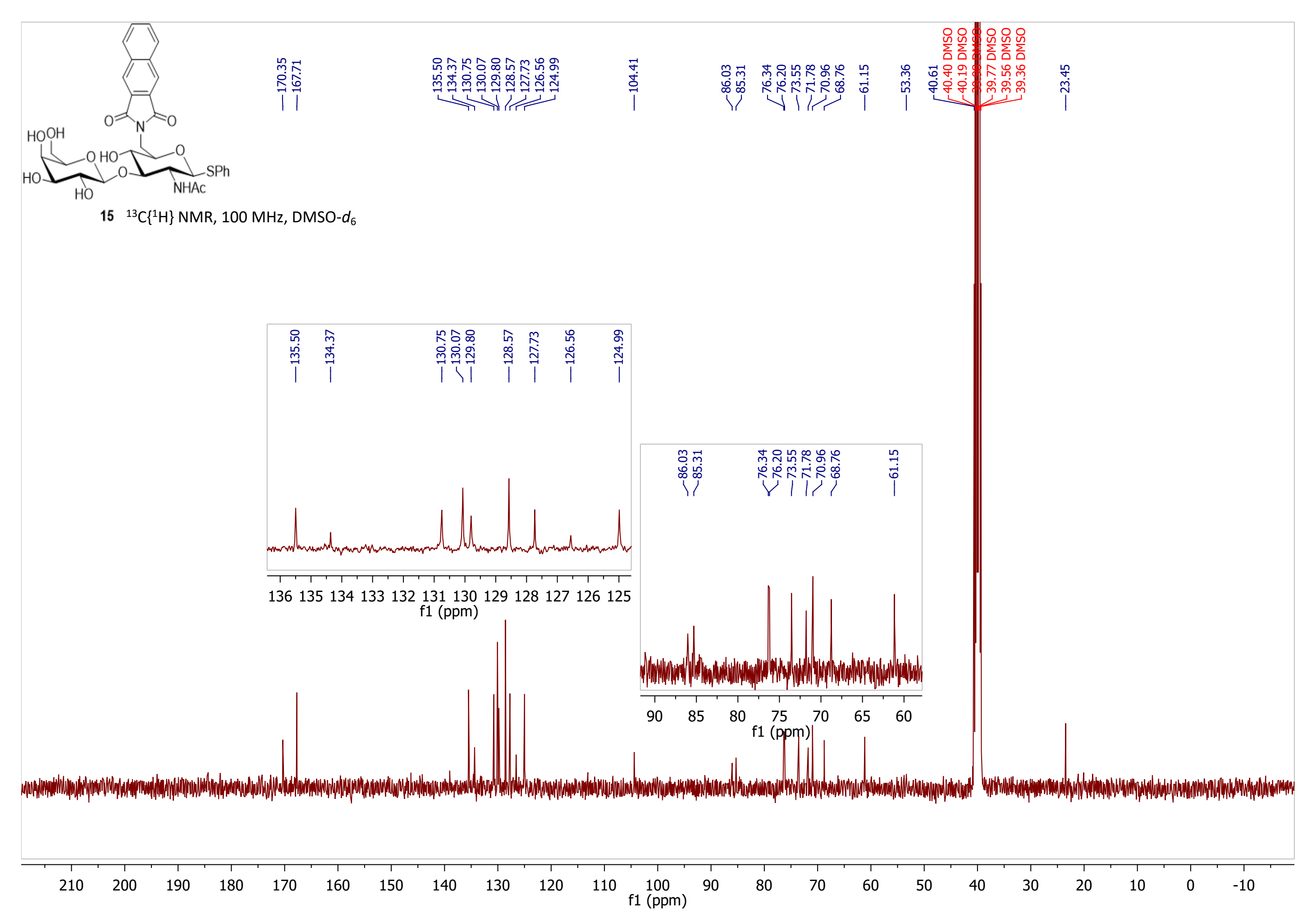




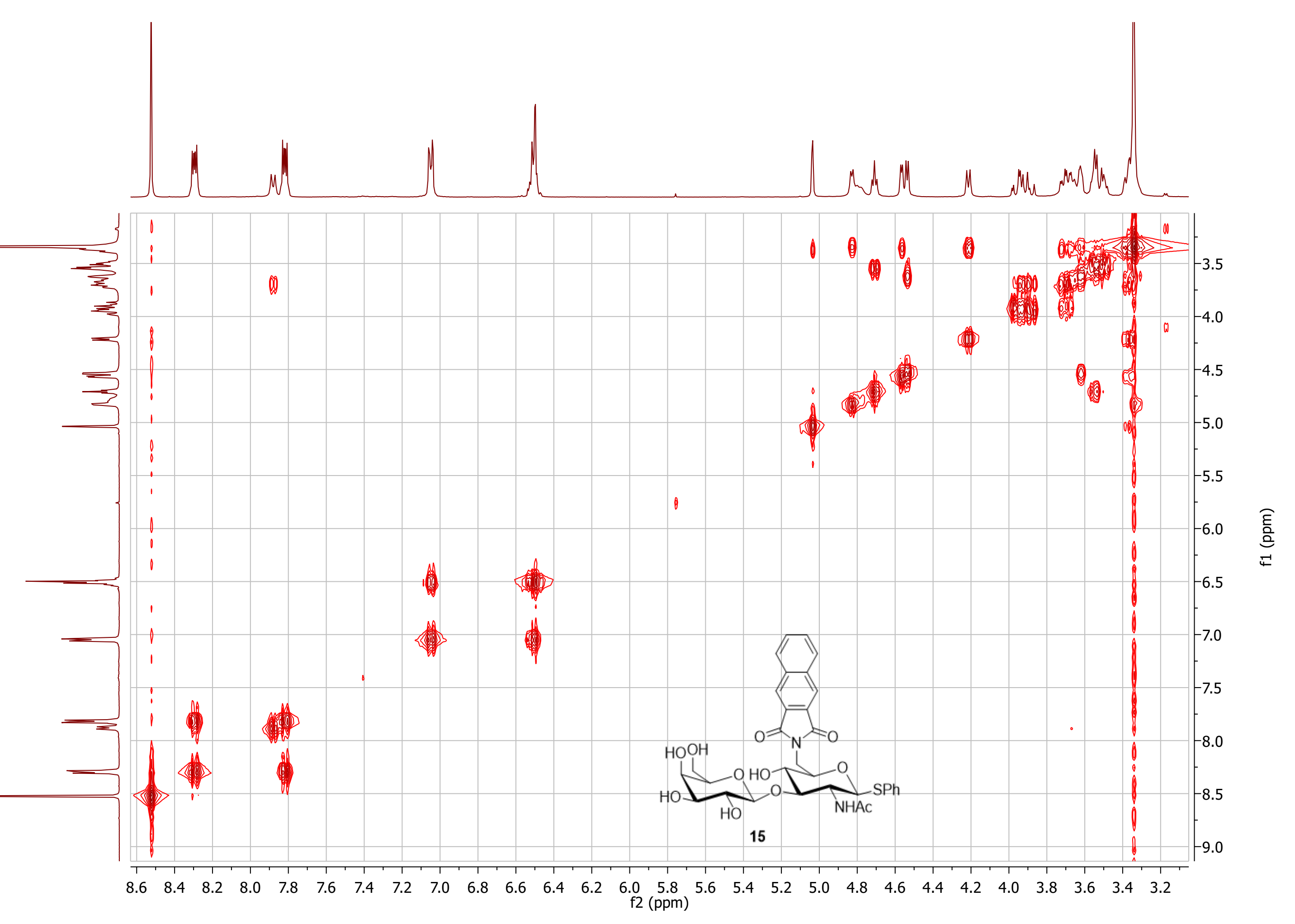




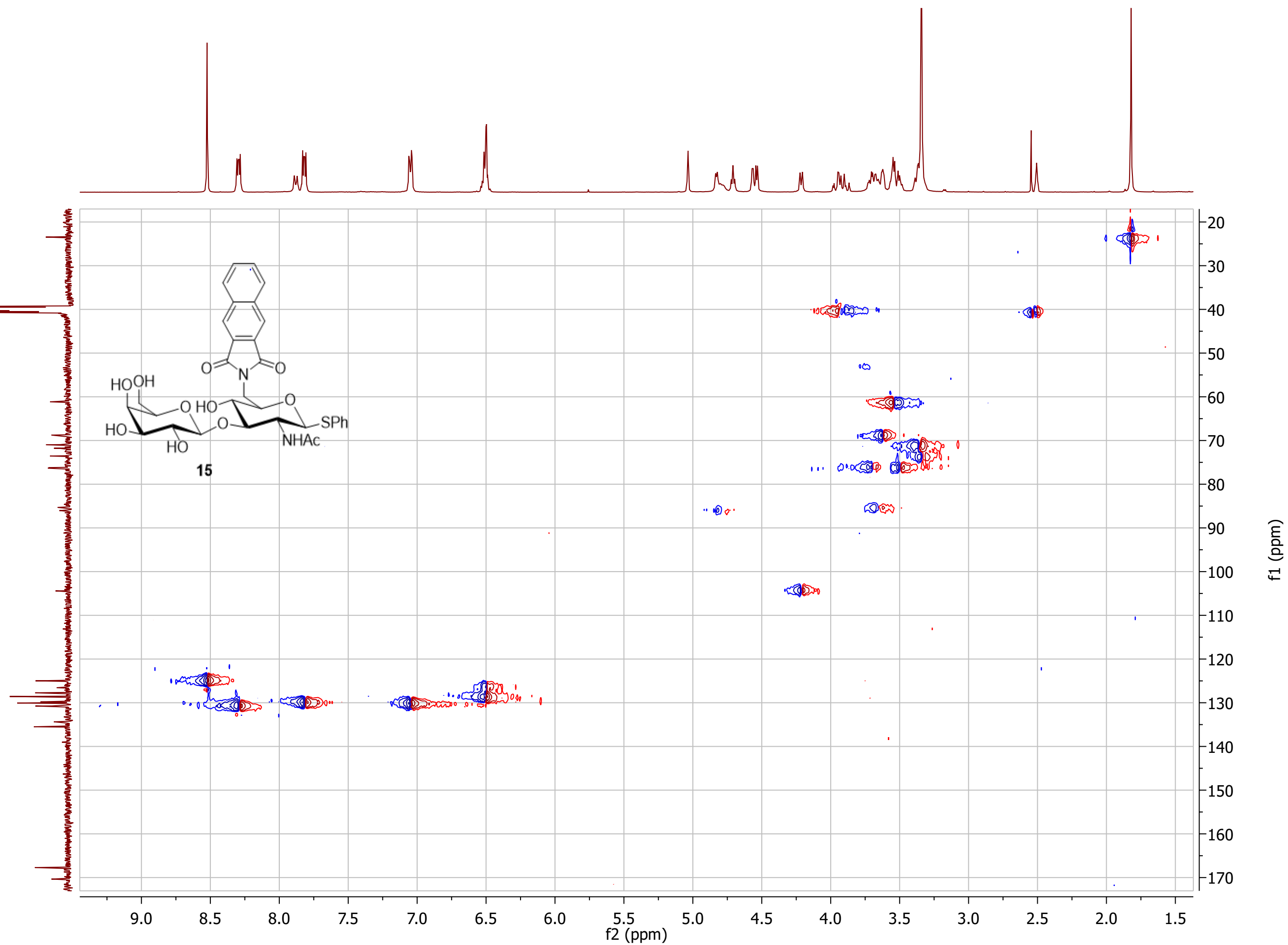




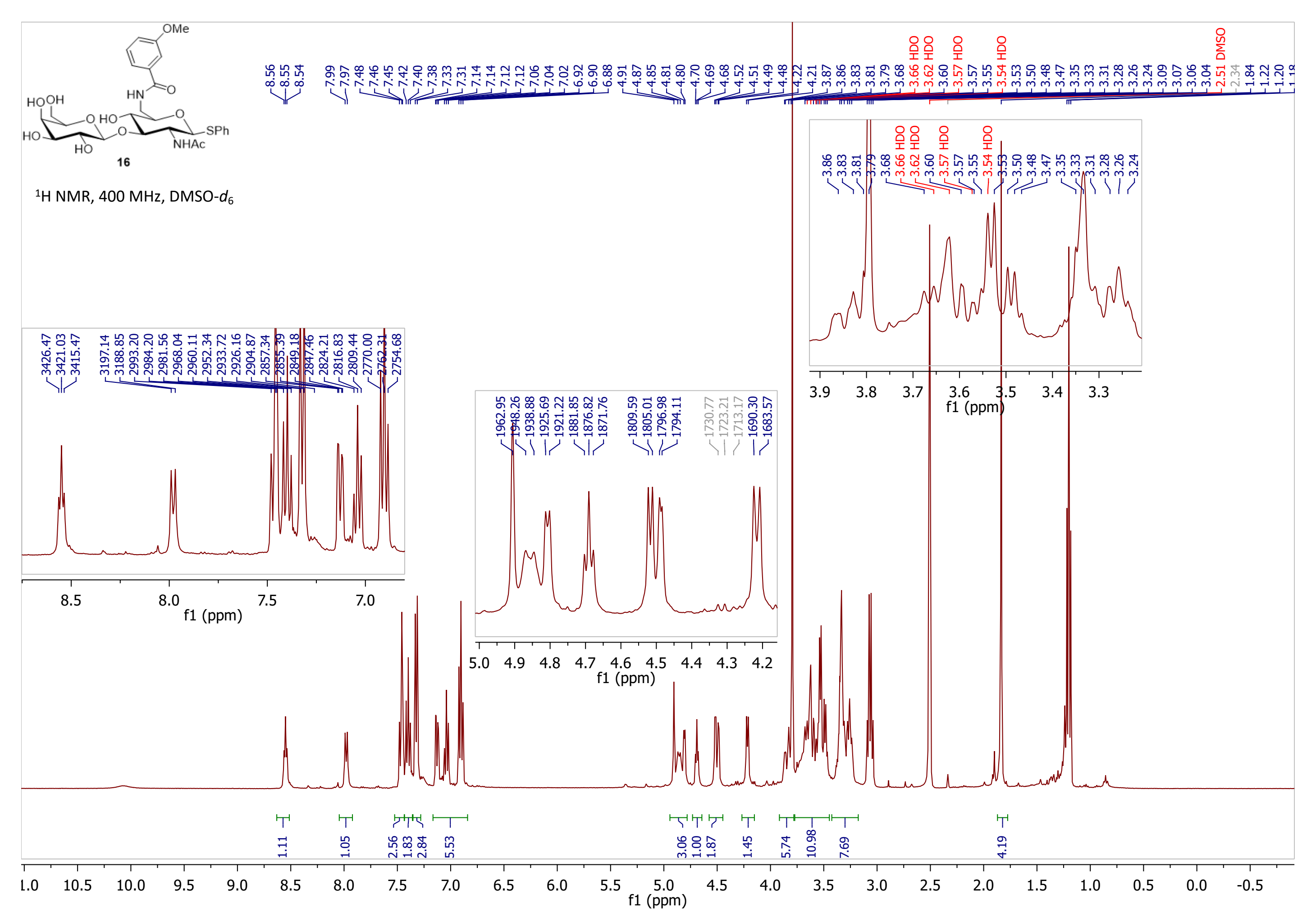




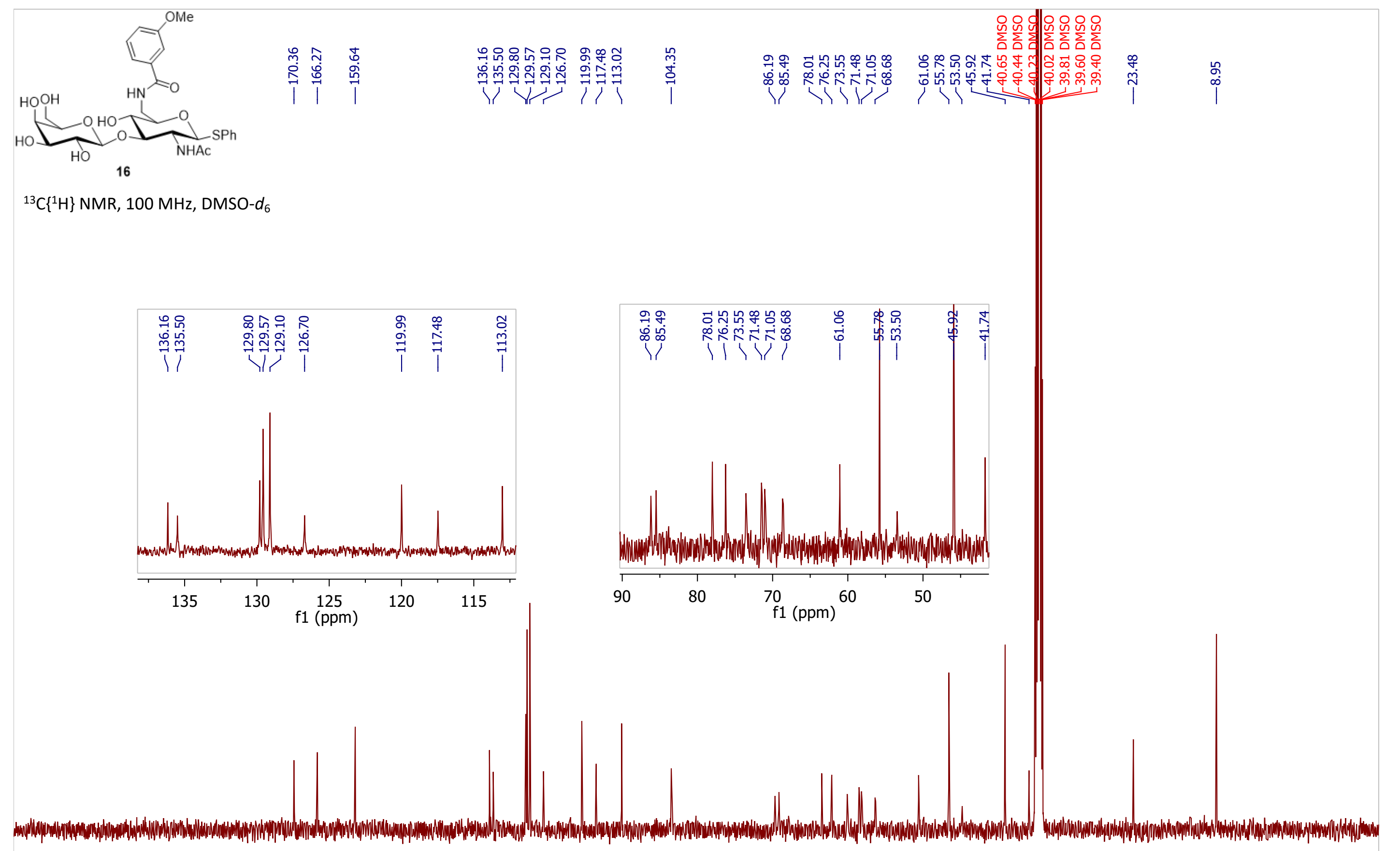




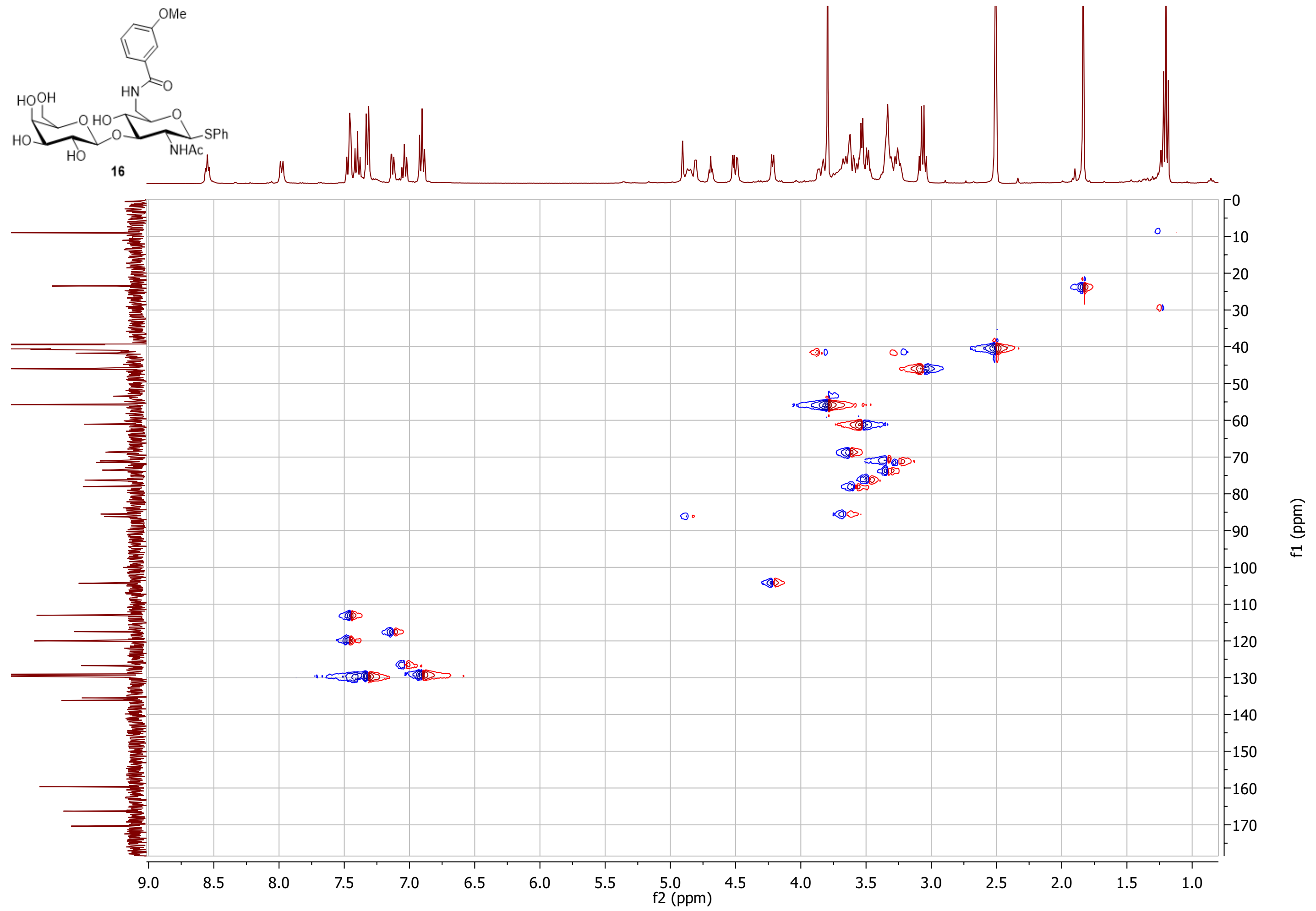




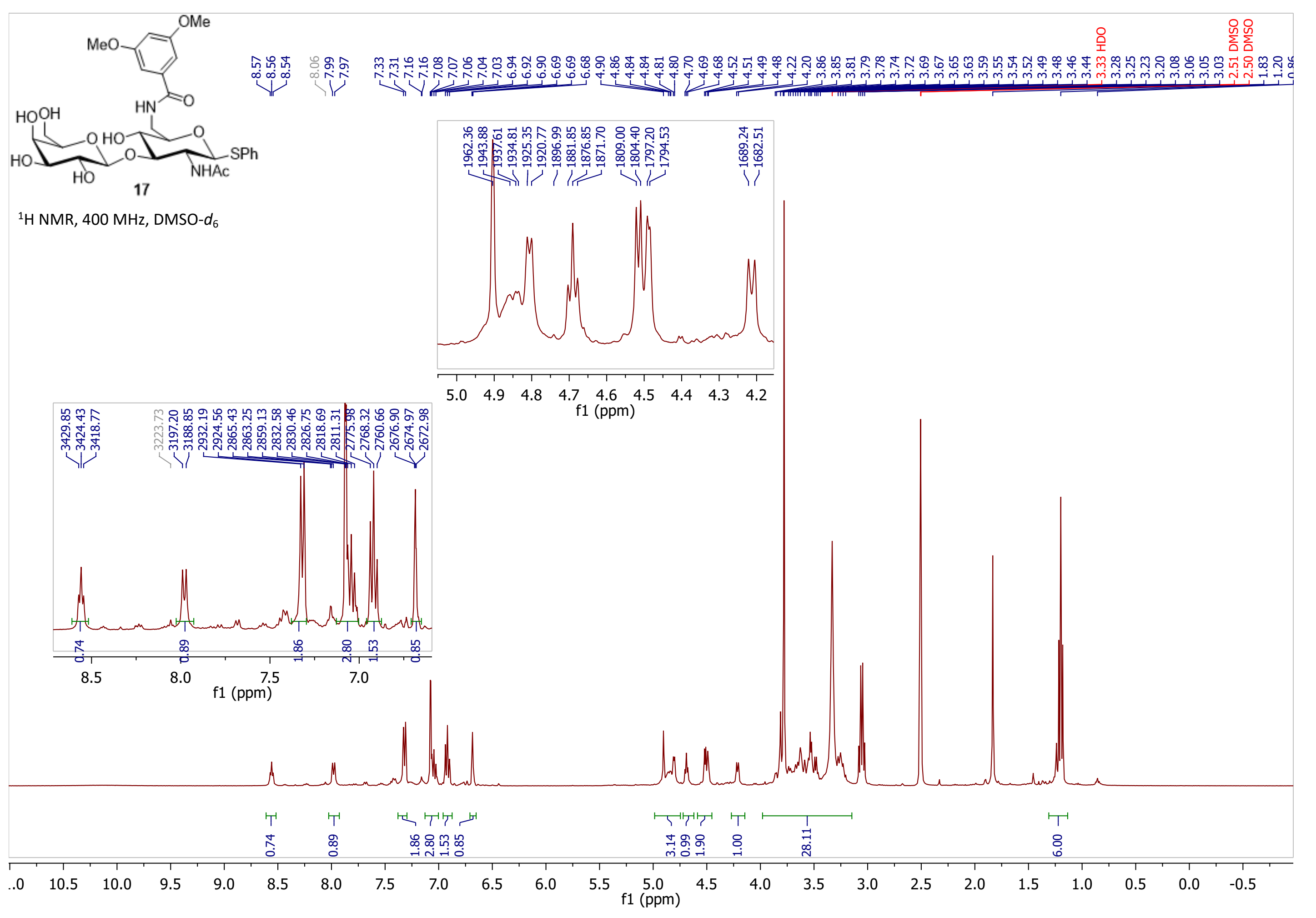


${ }^{13} \mathrm{C}\left\{{ }^{1} \mathrm{H}\right\}$ NMR, $100 \mathrm{MHz}$, DMSO- $d_{6}$

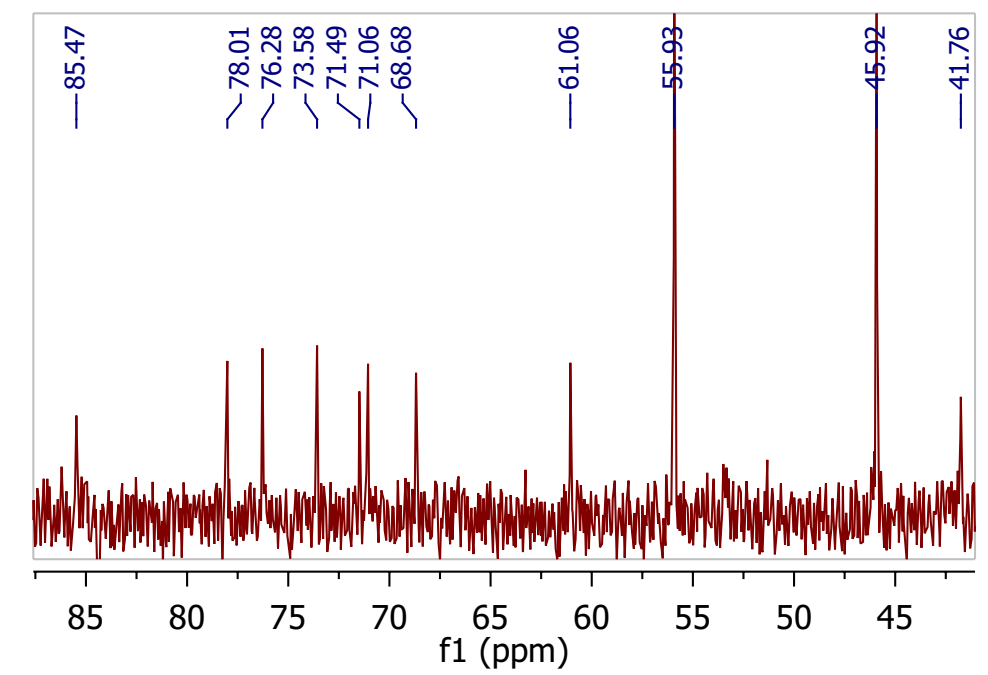

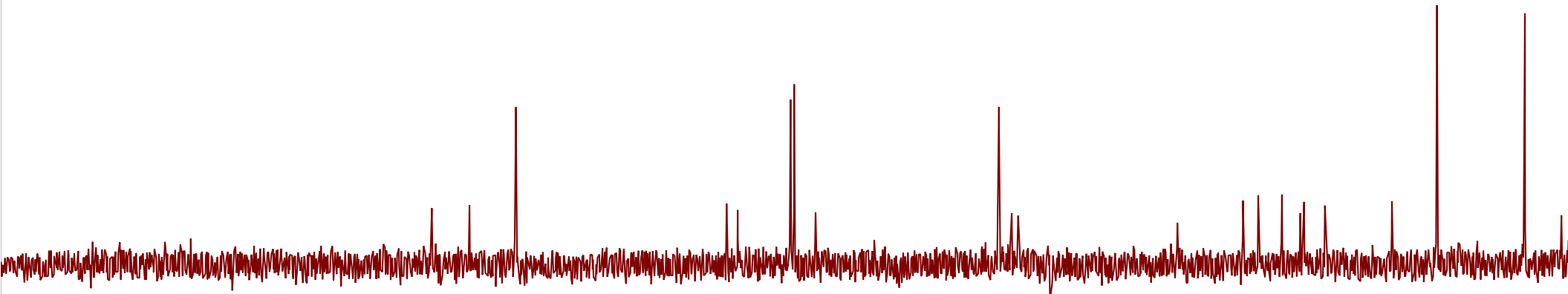



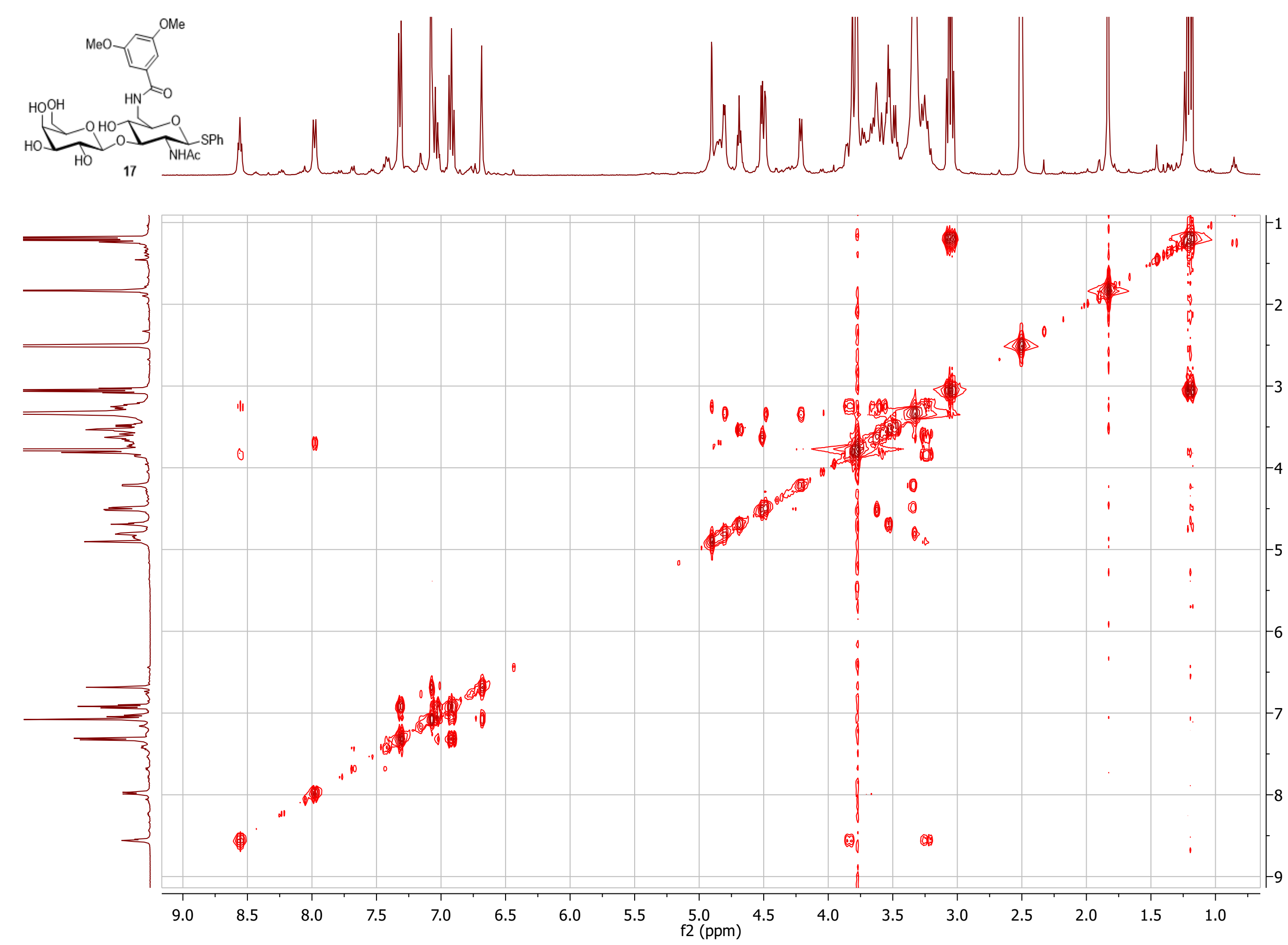

$\underbrace{\widehat{E}}_{\bar{L}}$ 

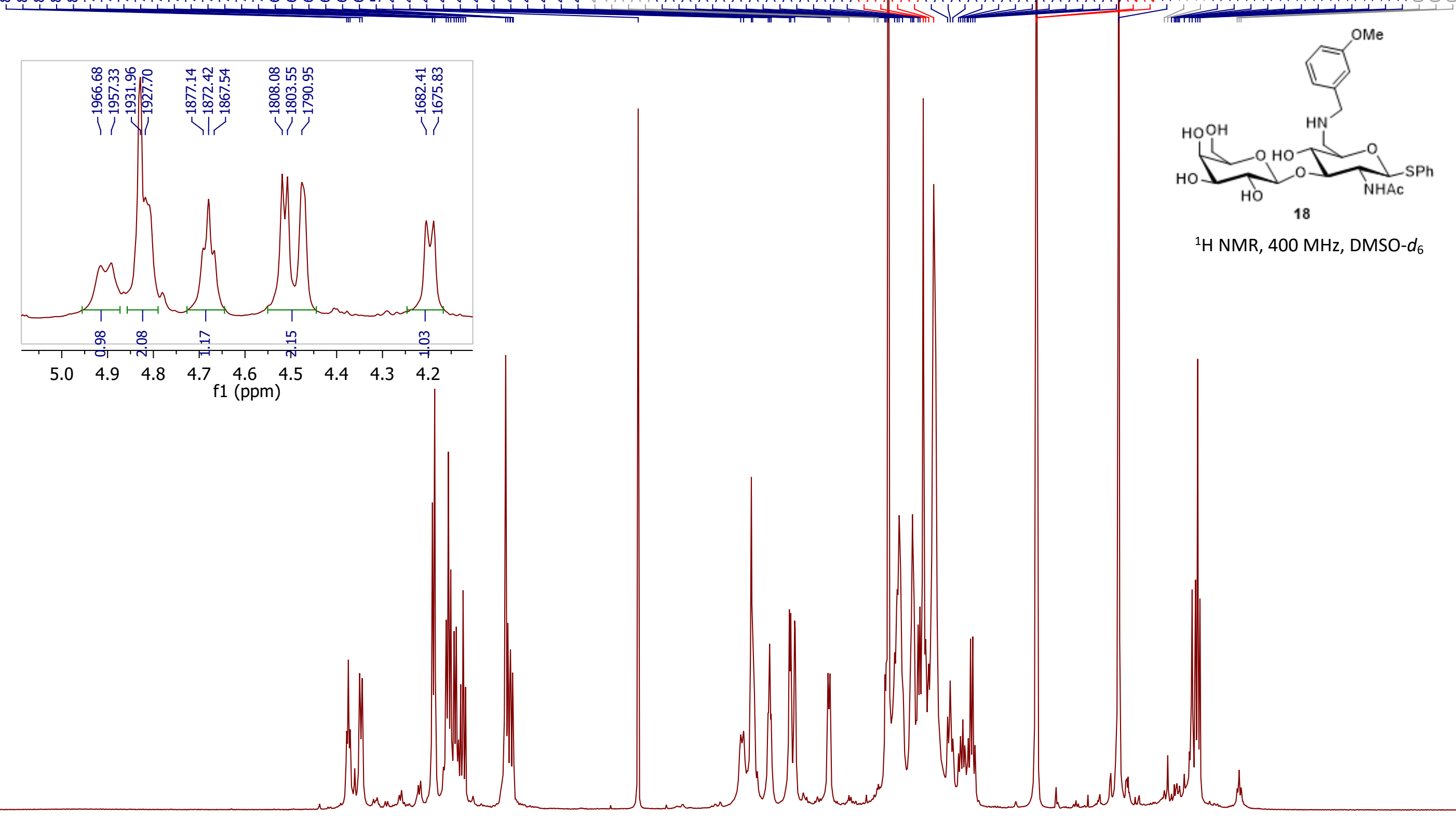

${ }^{1} \mathrm{H}$ NMR, $400 \mathrm{MHz}$, DMSO- $d_{6}$

\begin{tabular}{|c|c|c|c|c|c|c|c|c|c|c|c|c|c|c|c|c|c|c|c|c|c|c|}
\hline & & & & & 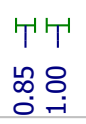 & 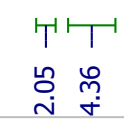 & 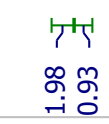 & & & & 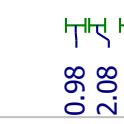 & & $\begin{array}{l}T^{\top} \\
\stackrel{\sim}{\text { Oे }}\end{array}$ & $\begin{array}{l}1 \\
\infty \\
\stackrel{\sim}{N}\end{array}$ & $\begin{array}{l}T \\
\text { ma } \\
\text { in }\end{array}$ & & $\begin{array}{l}T^{\top} \\
\stackrel{0}{m} \\
m\end{array}$ & & & & & \\
\hline 10.5 & 10.0 & 9.5 & 9.0 & 8.5 & 8.0 & 7.5 & 7.0 & 6.5 & 6.0 & 5.5 & $\begin{array}{c}5.0 \\
1(\mathrm{ppm})\end{array}$ & 4.5 & 4.0 & 3.5 & 3.0 & 2.5 & 2.0 & 1.5 & 1.0 & 0.5 & 0.0 & -0.5 \\
\hline
\end{tabular}




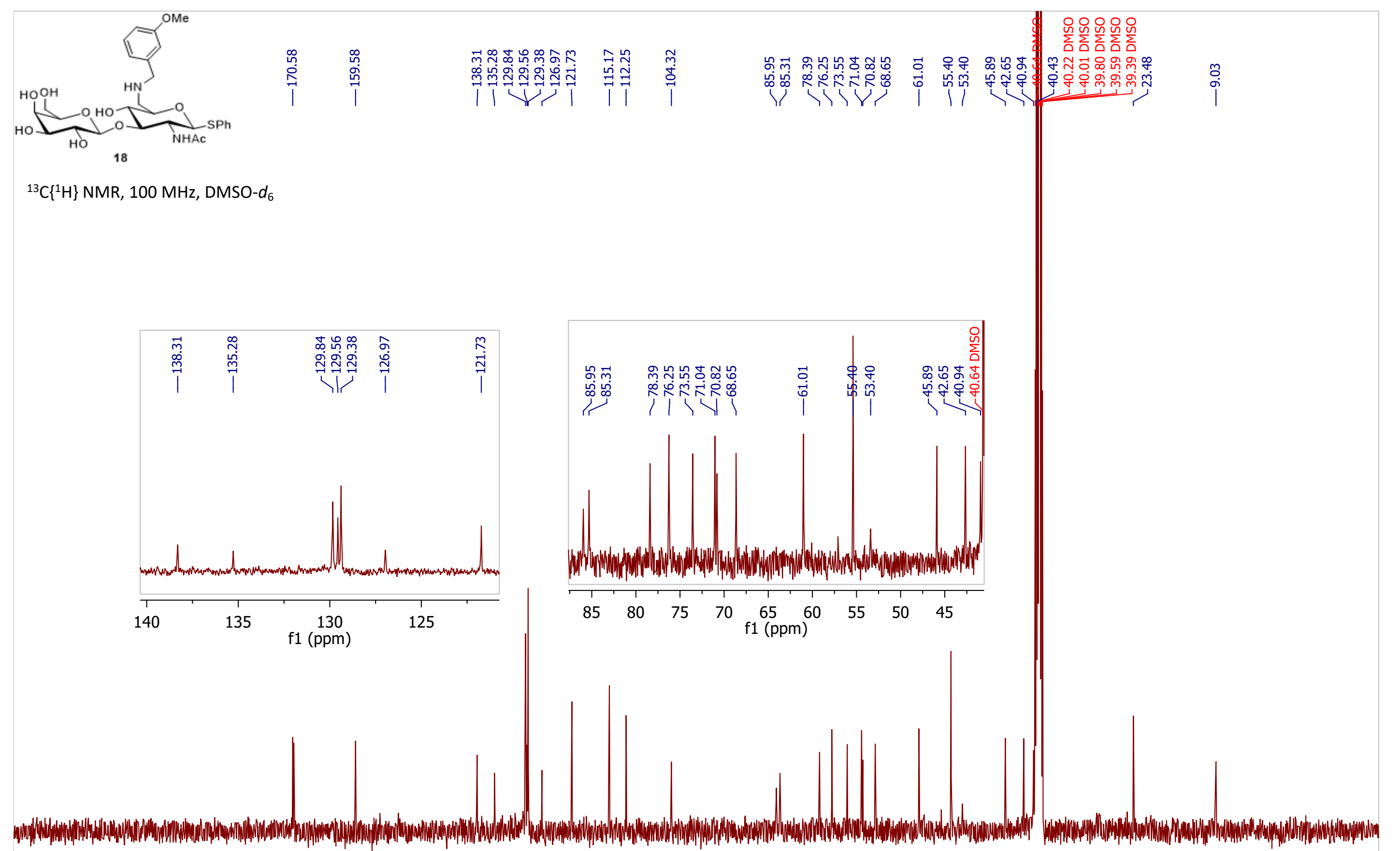




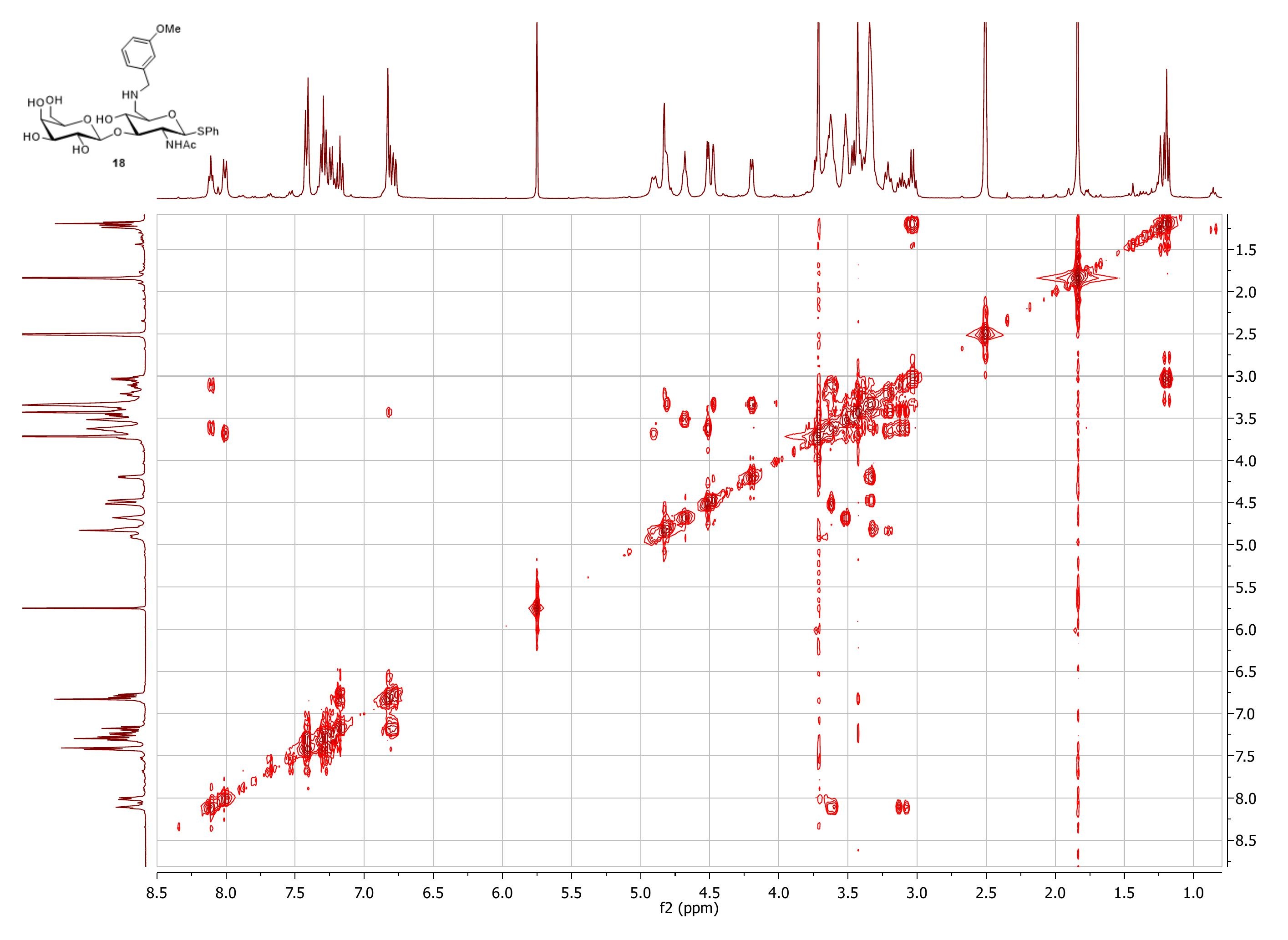




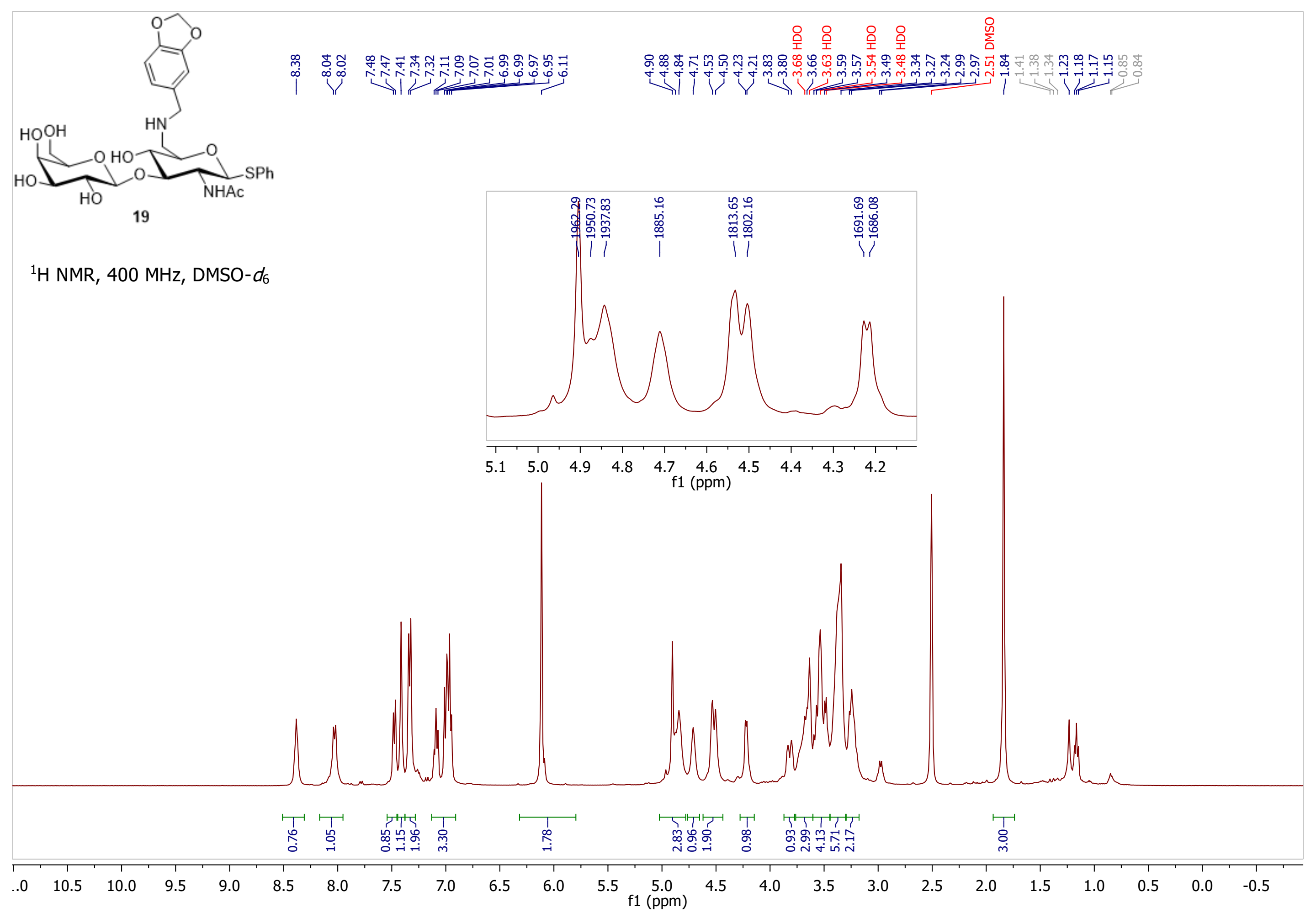




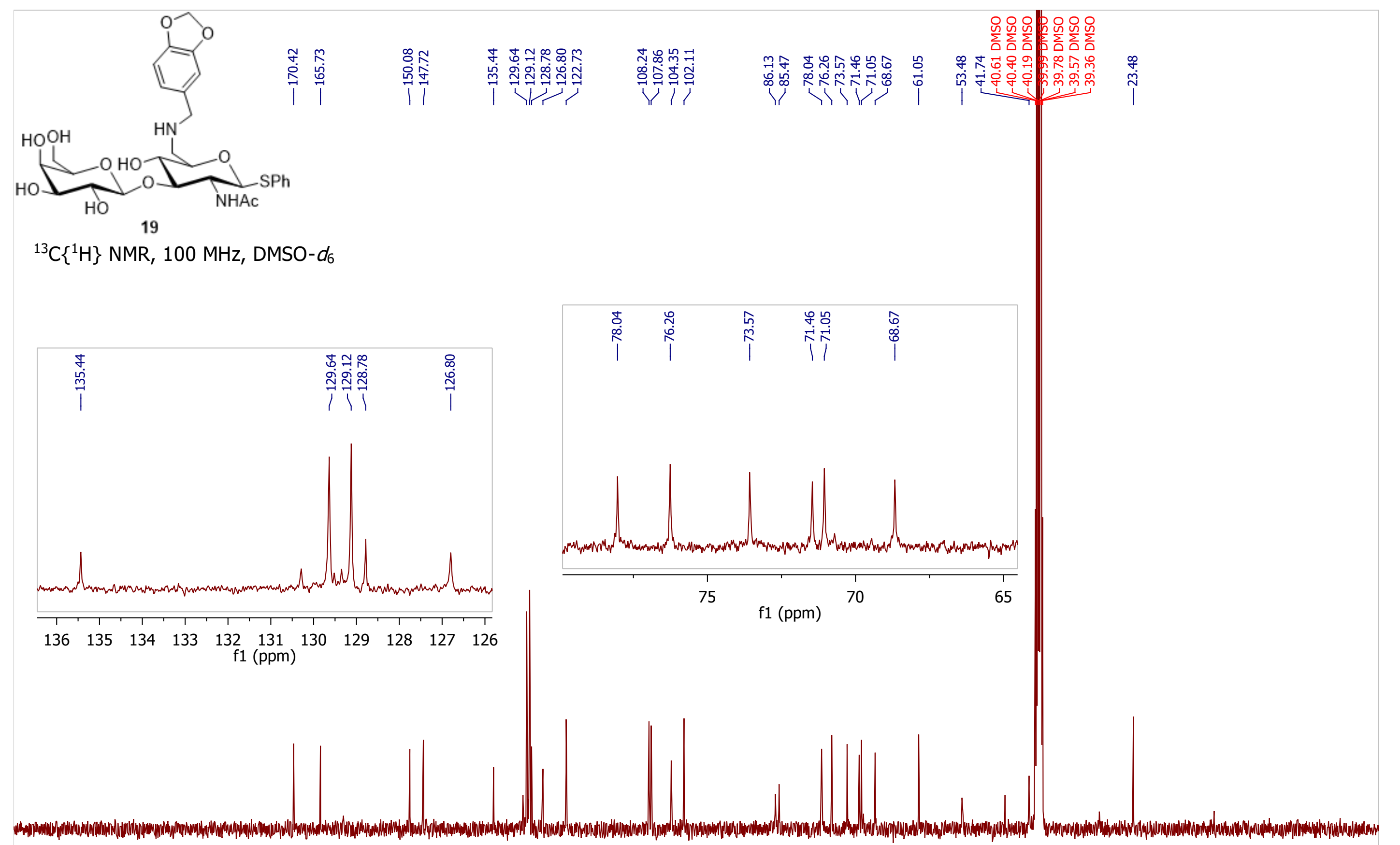




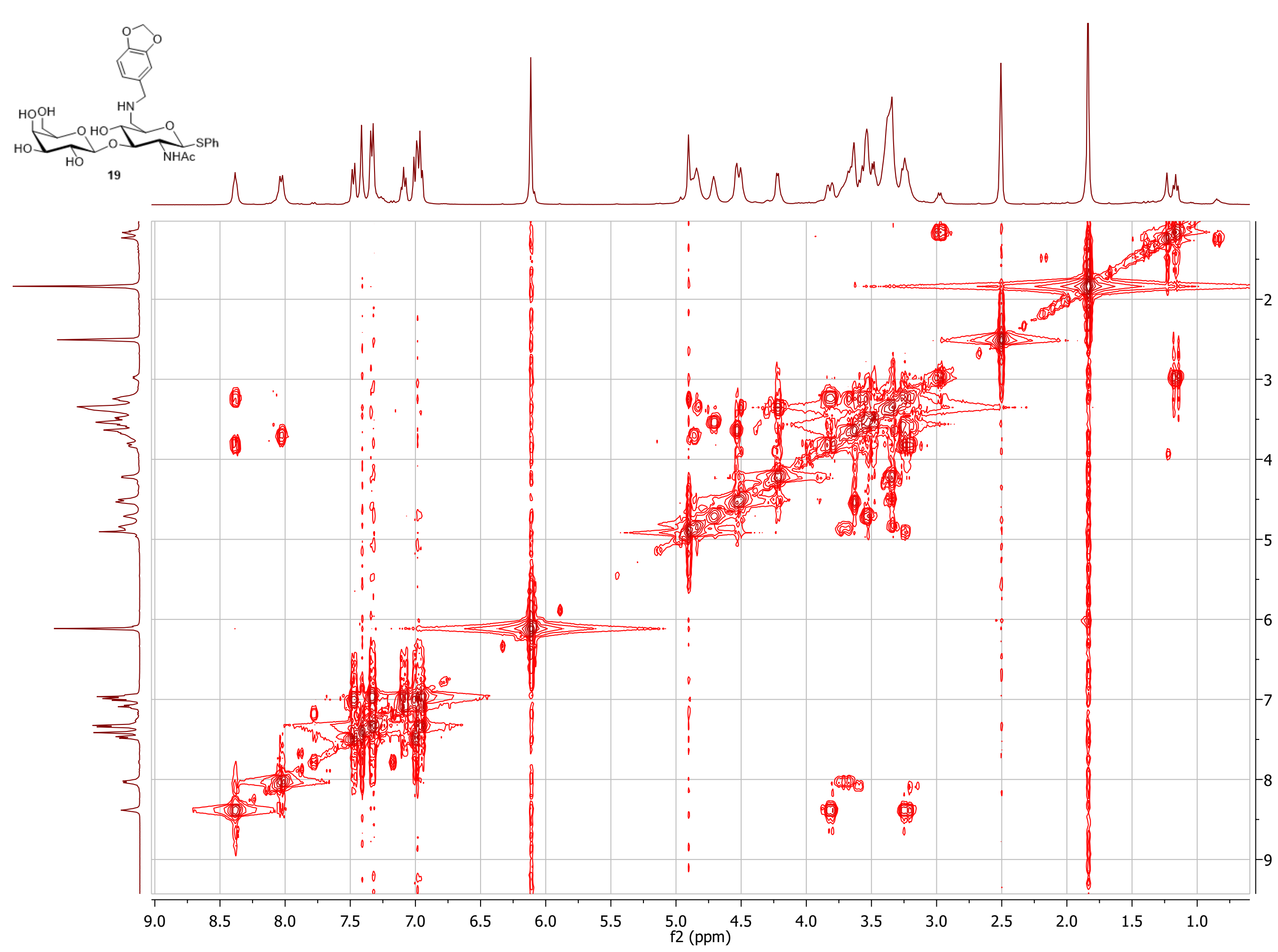

$\underbrace{\widehat{c}}_{\bar{L}}$ 


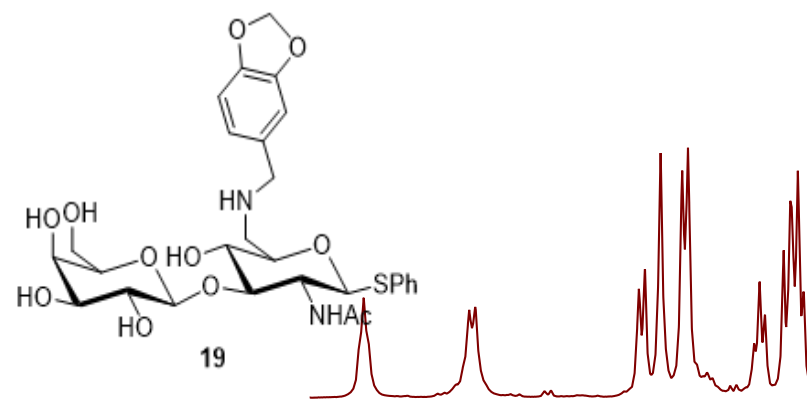

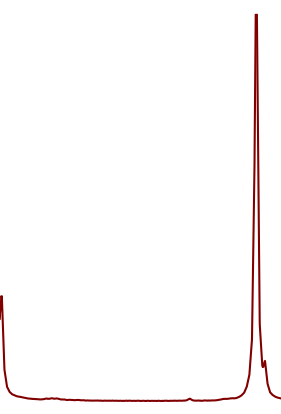

$$
\underbrace{4}
$$

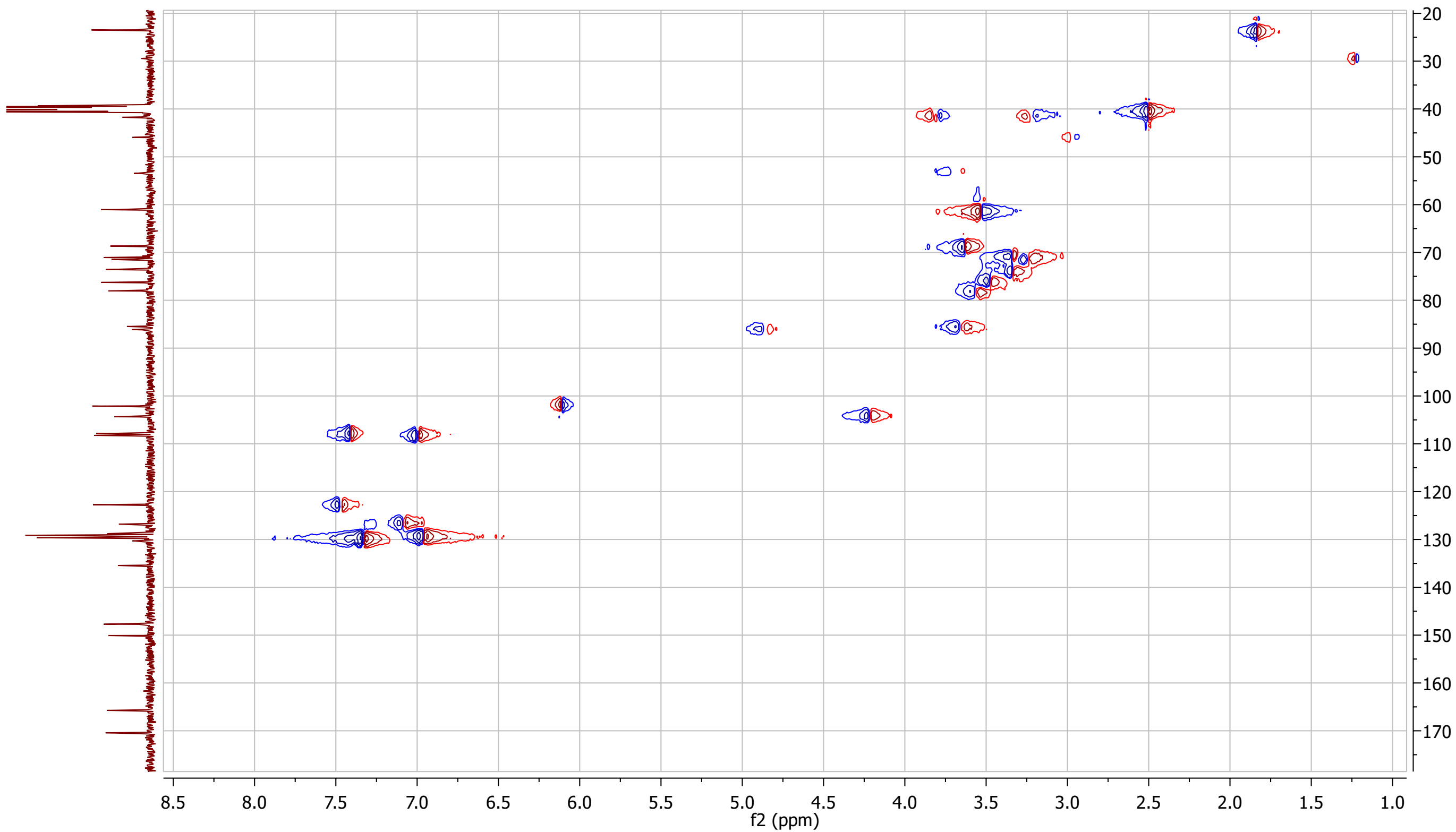




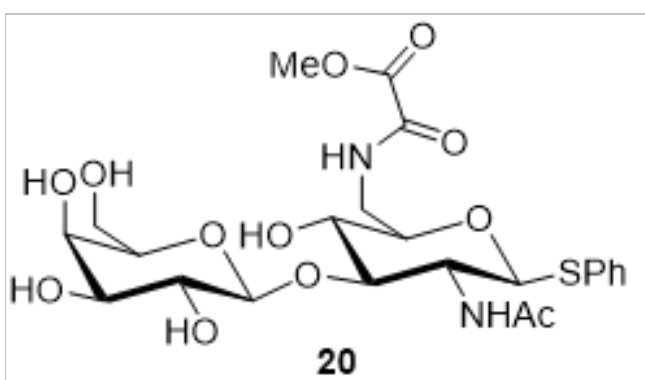

${ }^{1} \mathrm{H}$ NMR, $400 \mathrm{MHz}$, DMSO- $d_{6}$
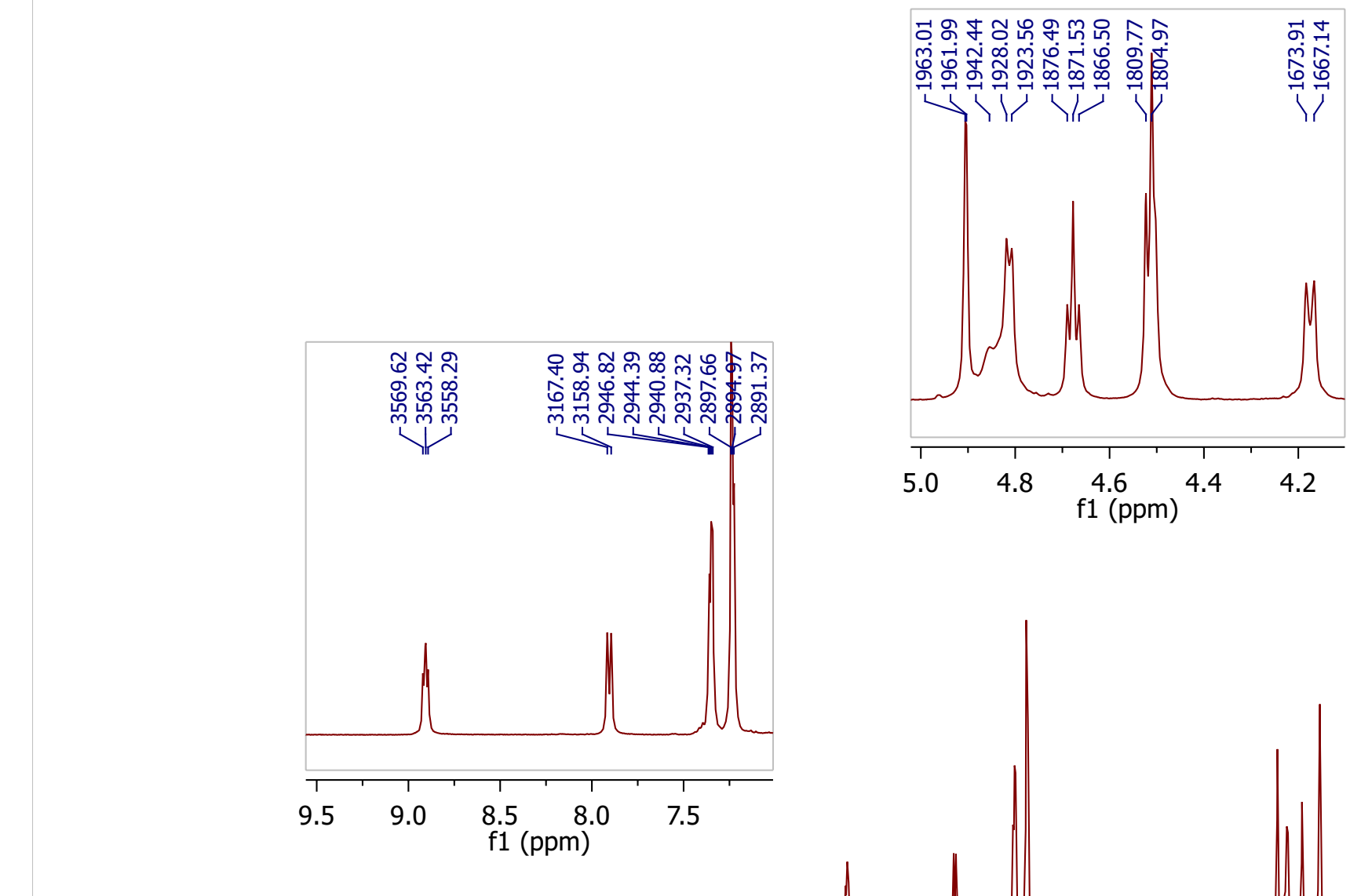

\section{오}

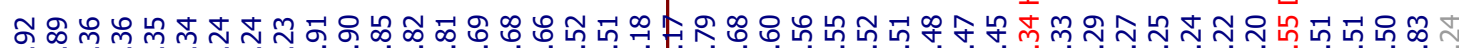

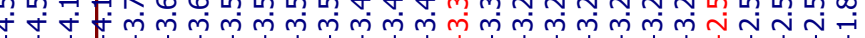

Y
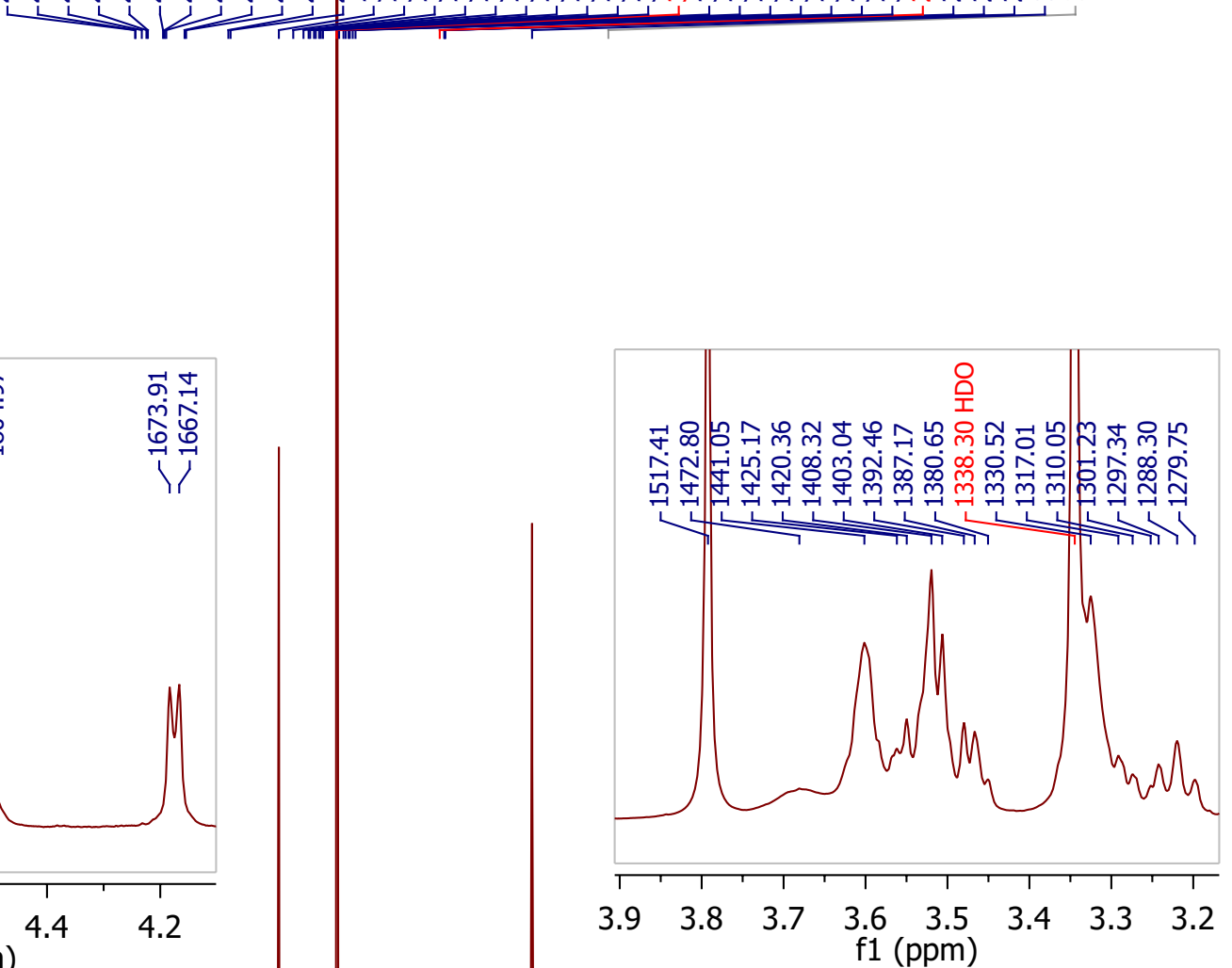

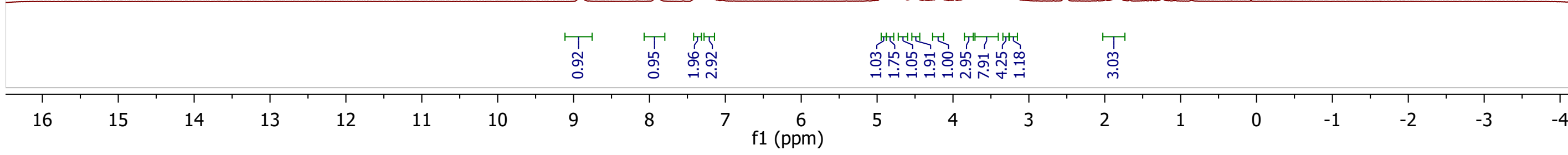




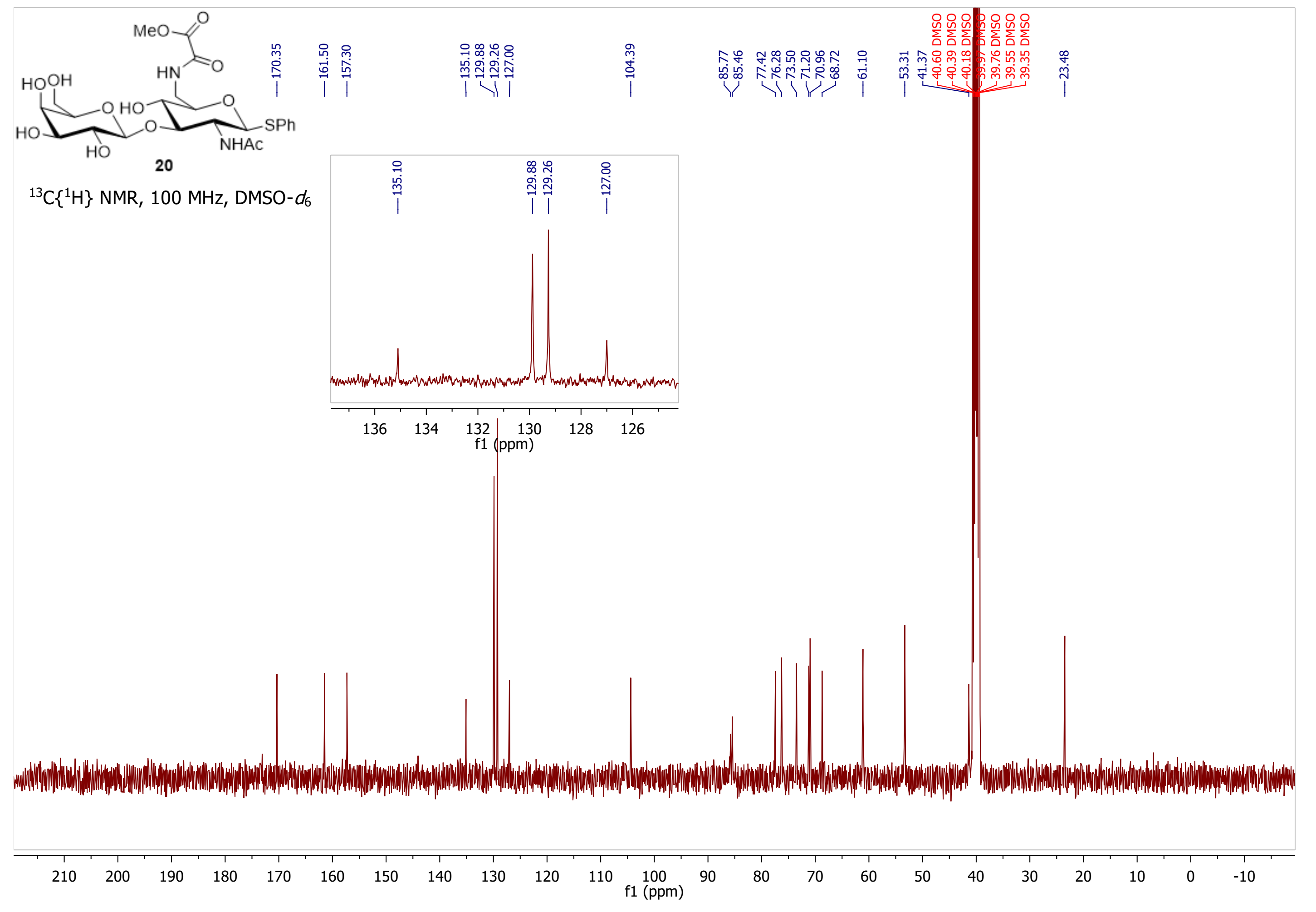




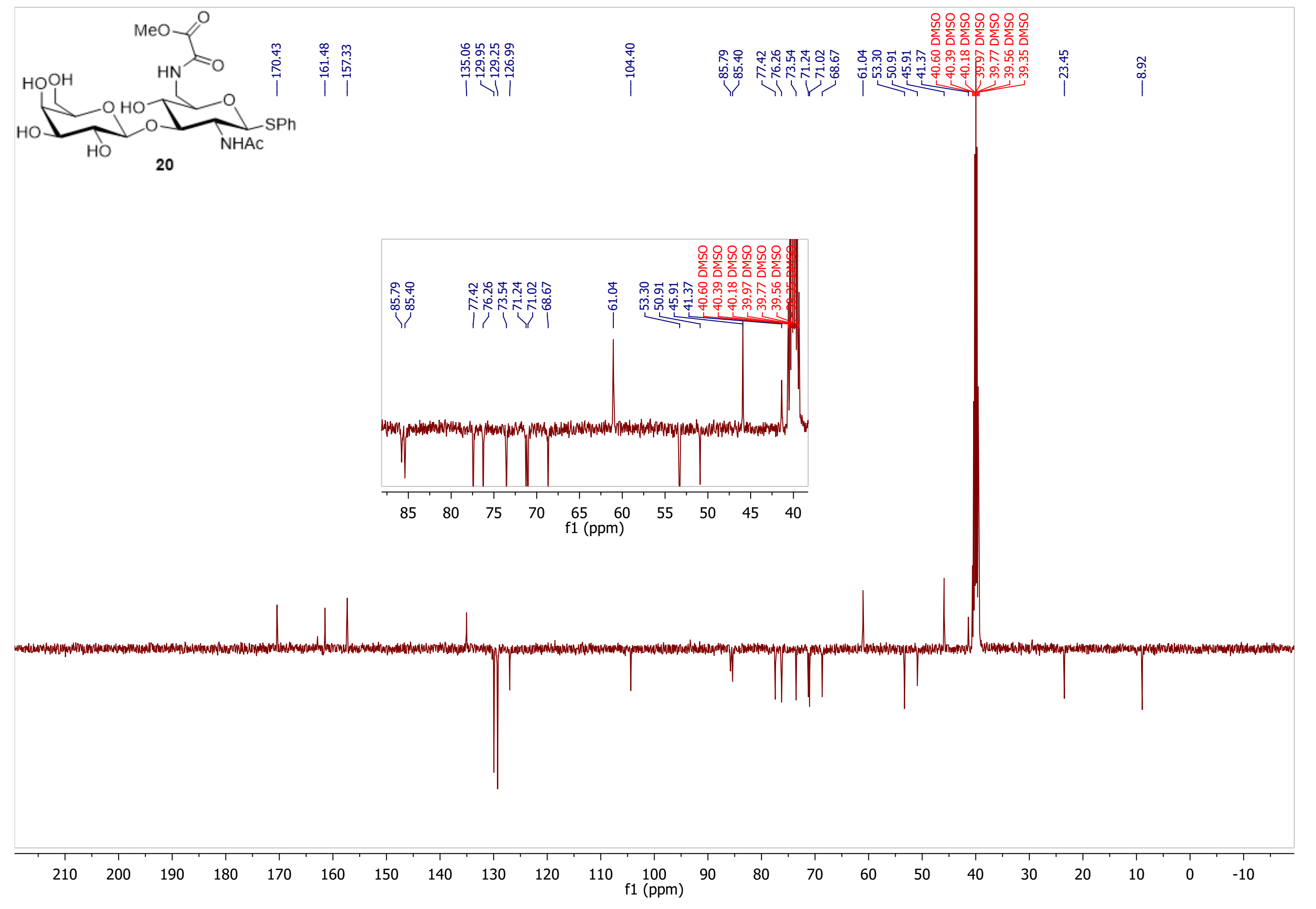




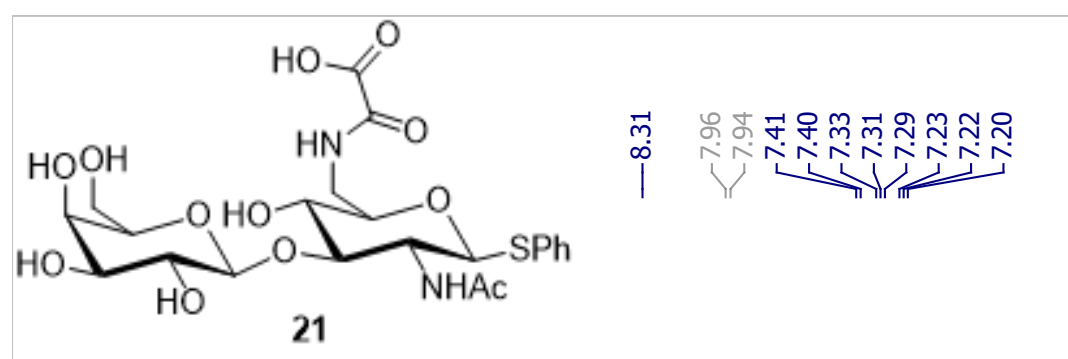

${ }^{1} \mathrm{H}$ NMR, 400 MHz, DMSO-d

f1 (ppm)
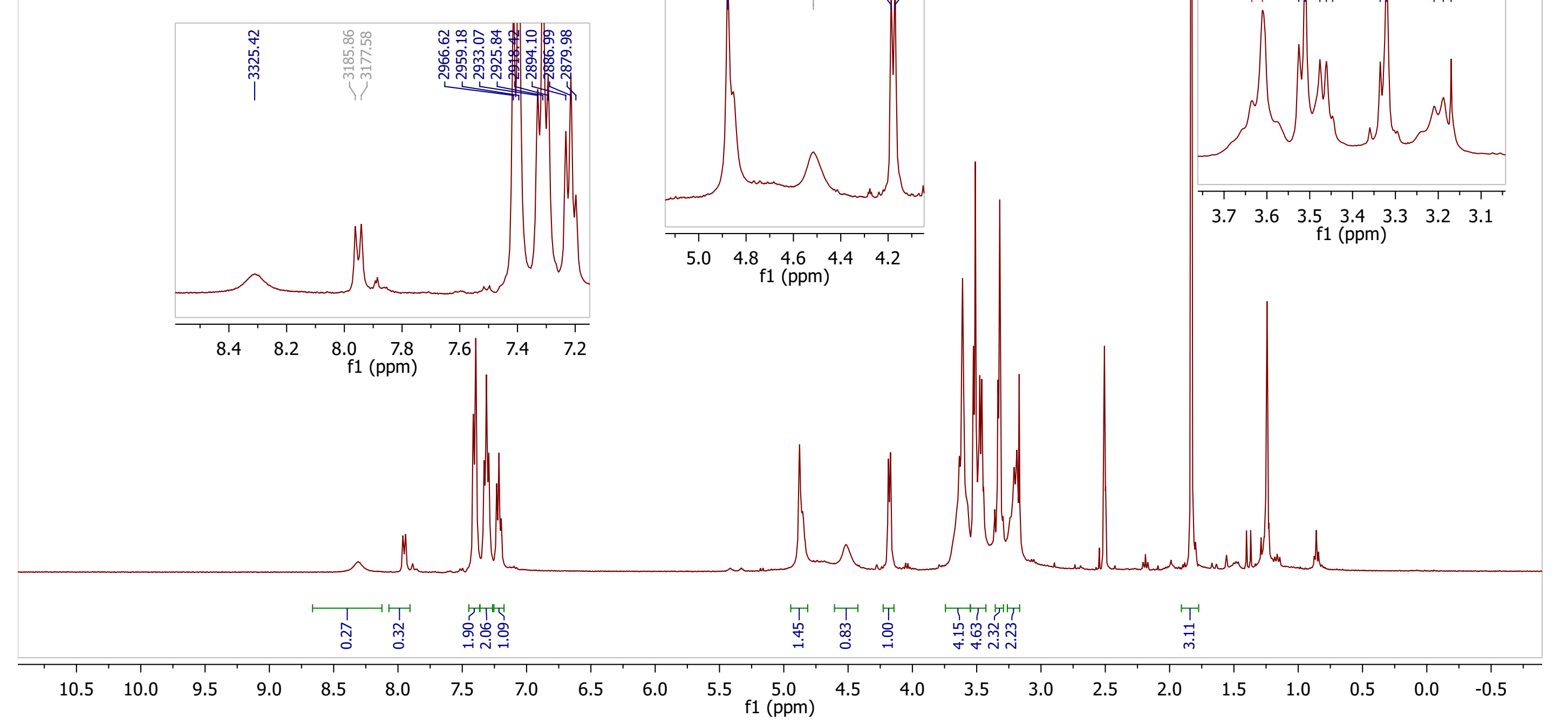

f1 (ppm)

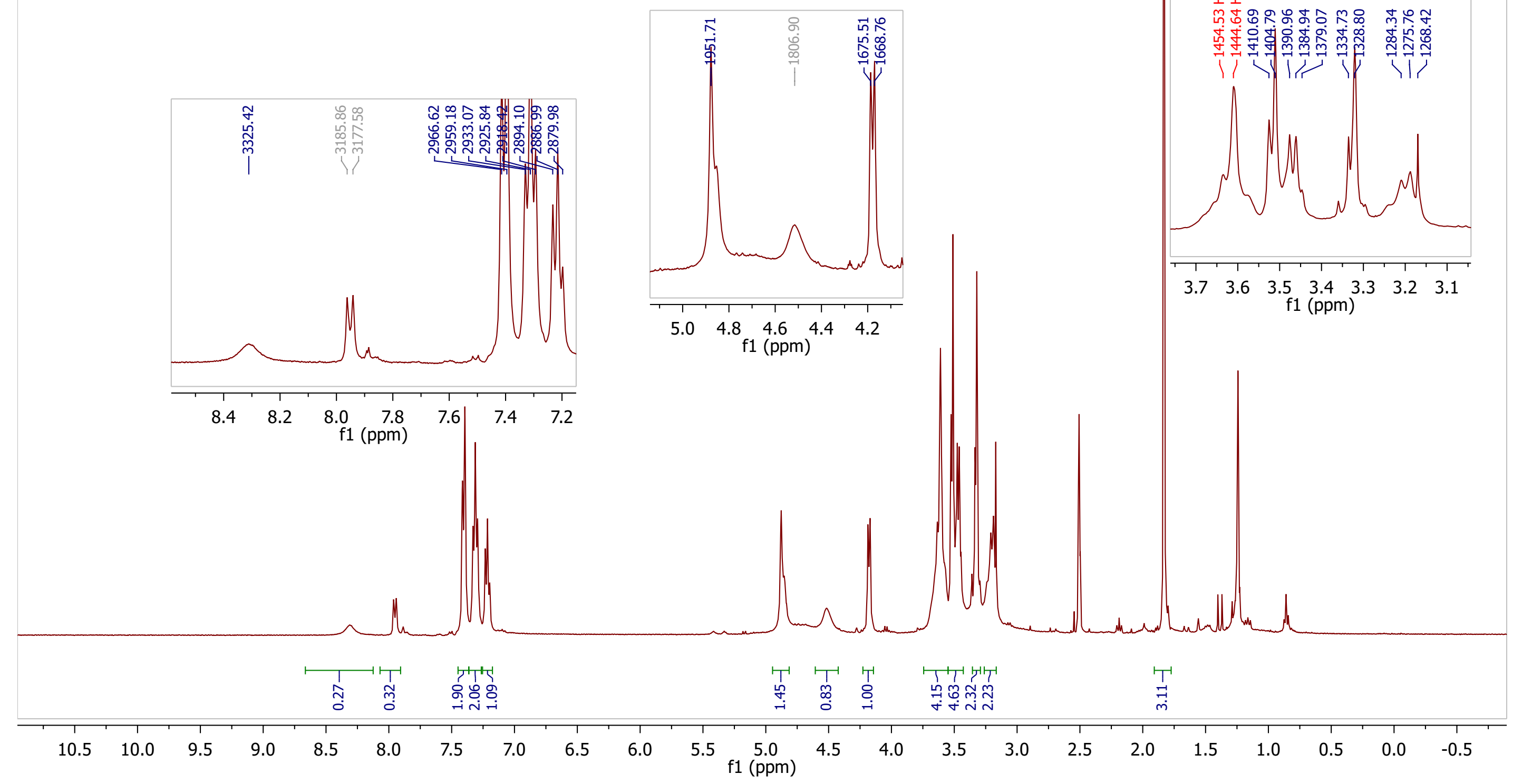




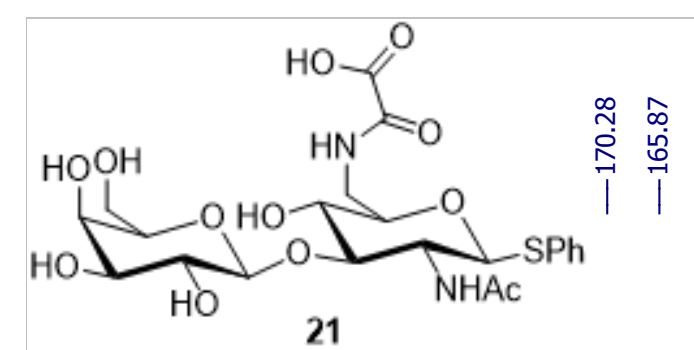

${ }^{13} \mathrm{C}\left\{{ }^{1} \mathrm{H}\right\}$ NMR, $100 \mathrm{MHz}$, DMSO- $d_{6}$

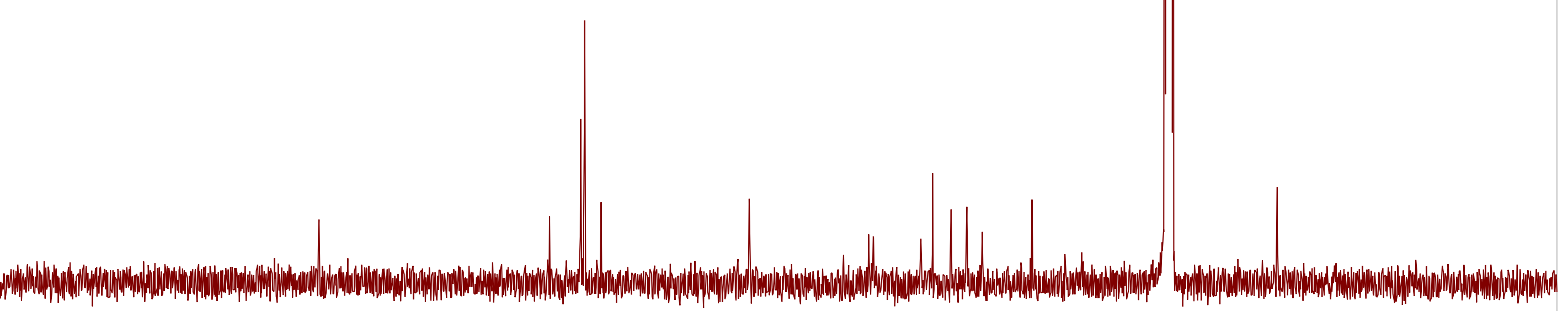




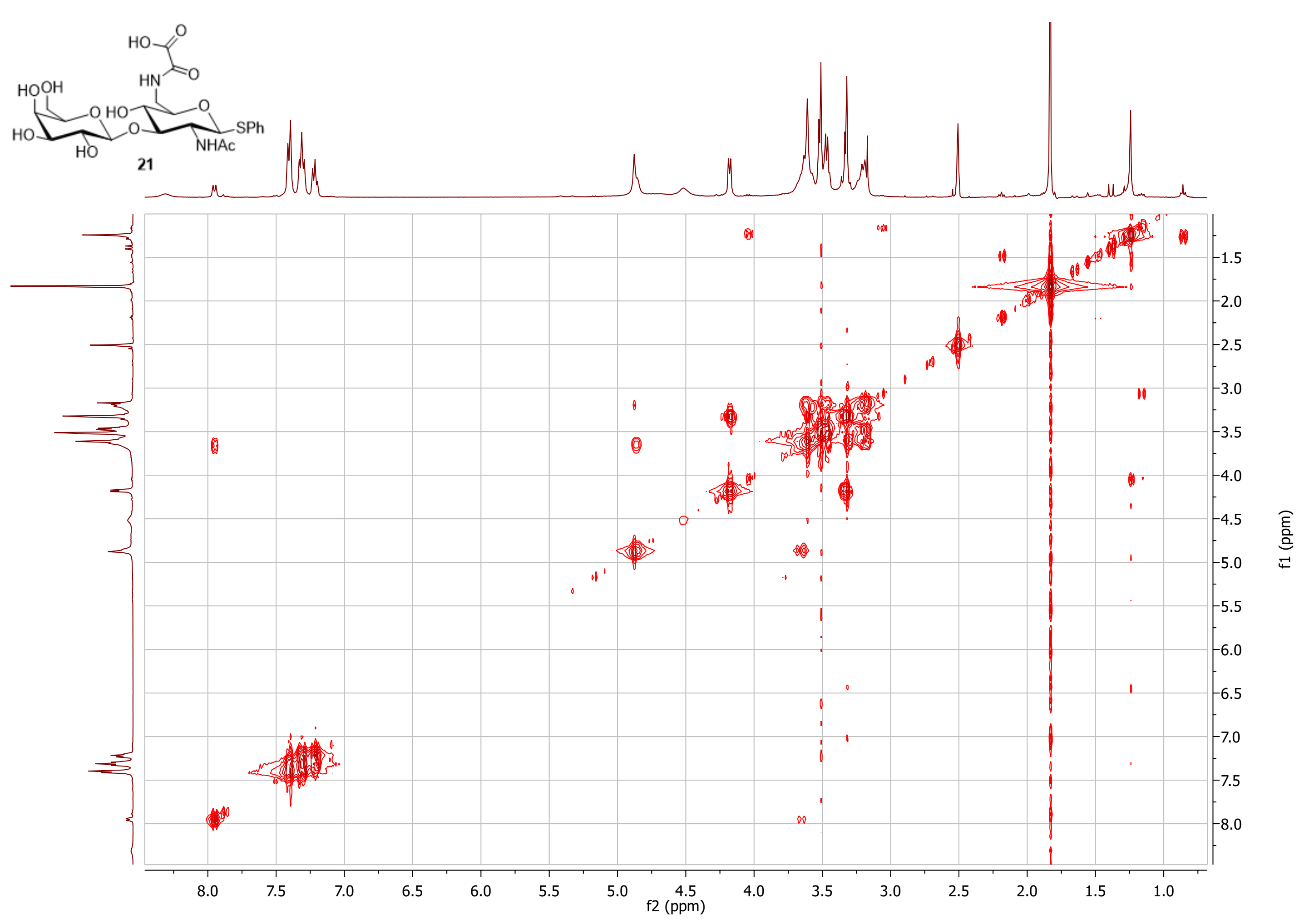




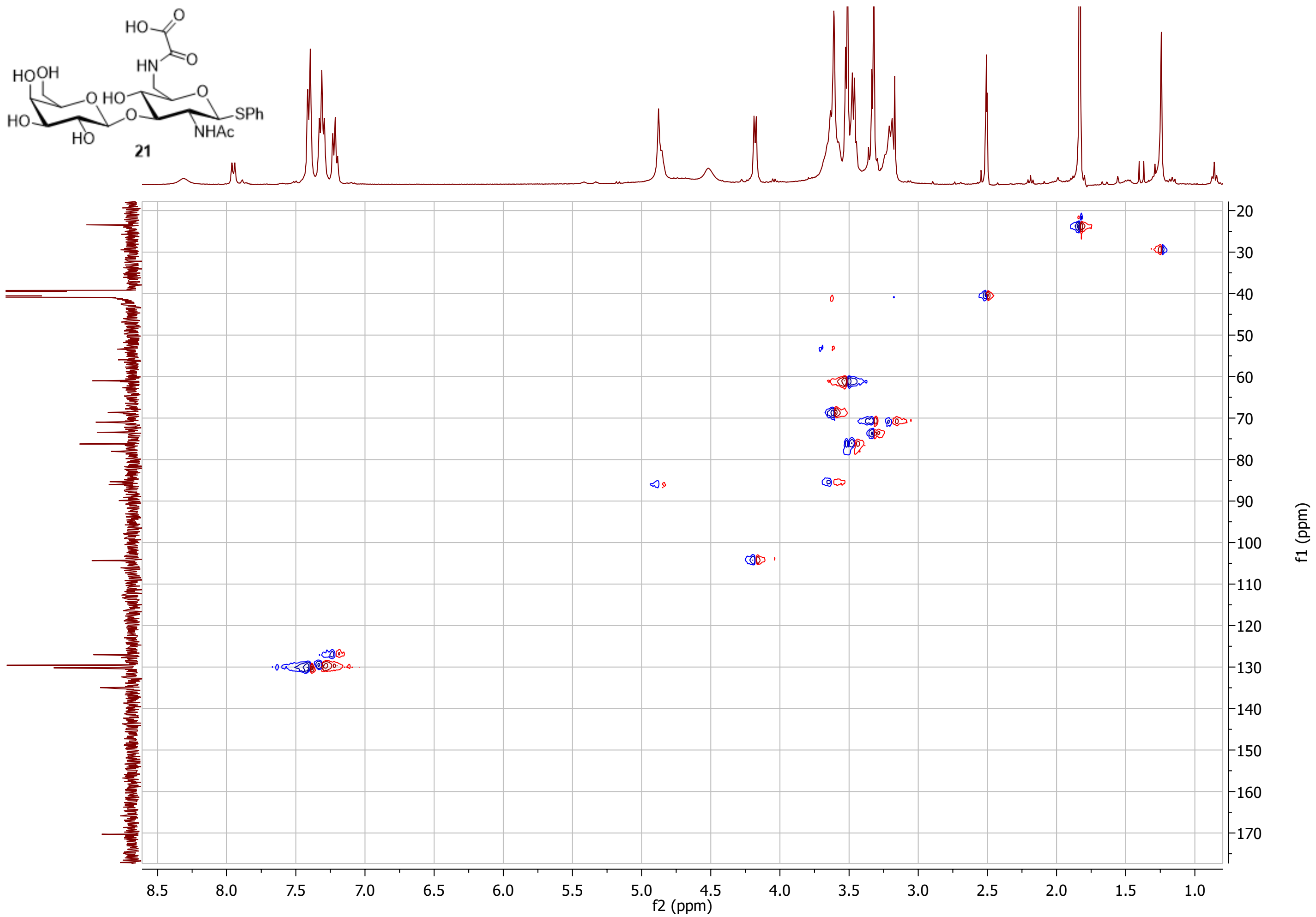




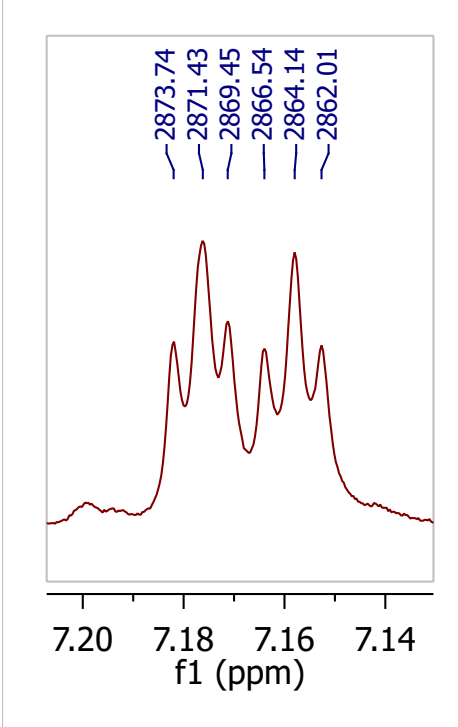

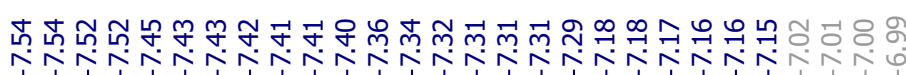

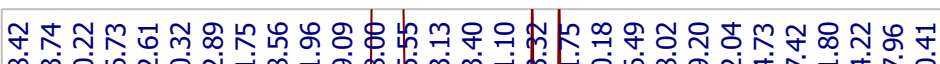

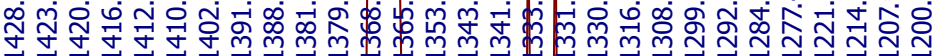
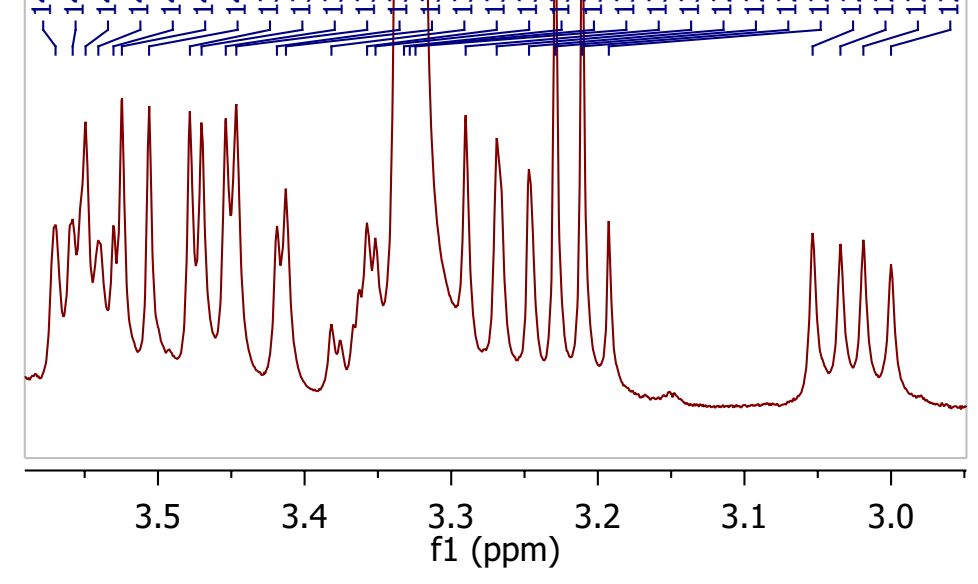

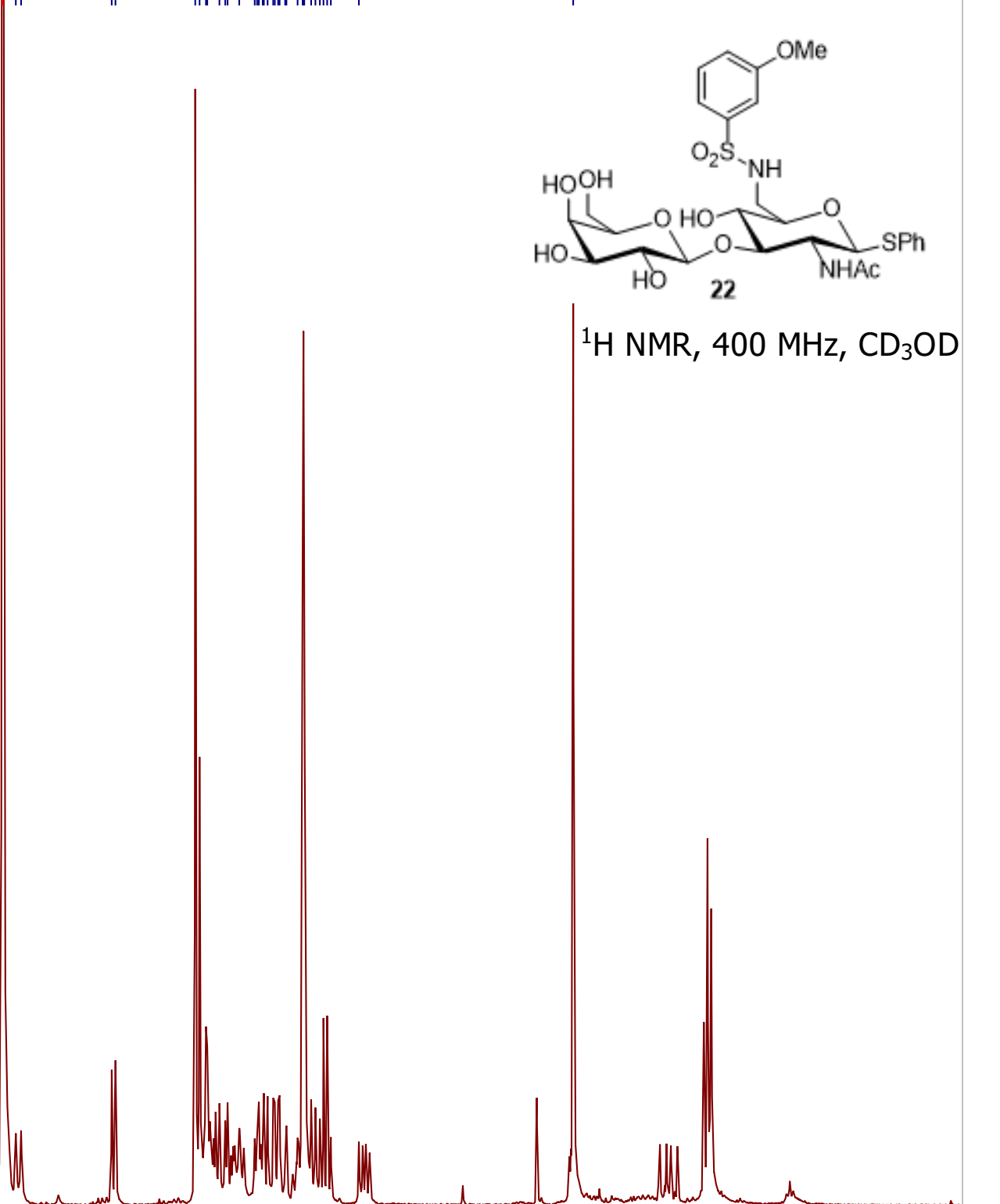

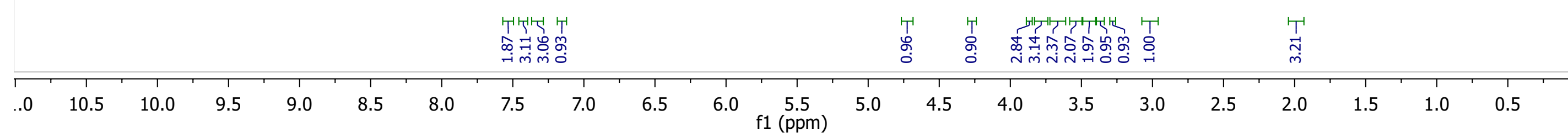




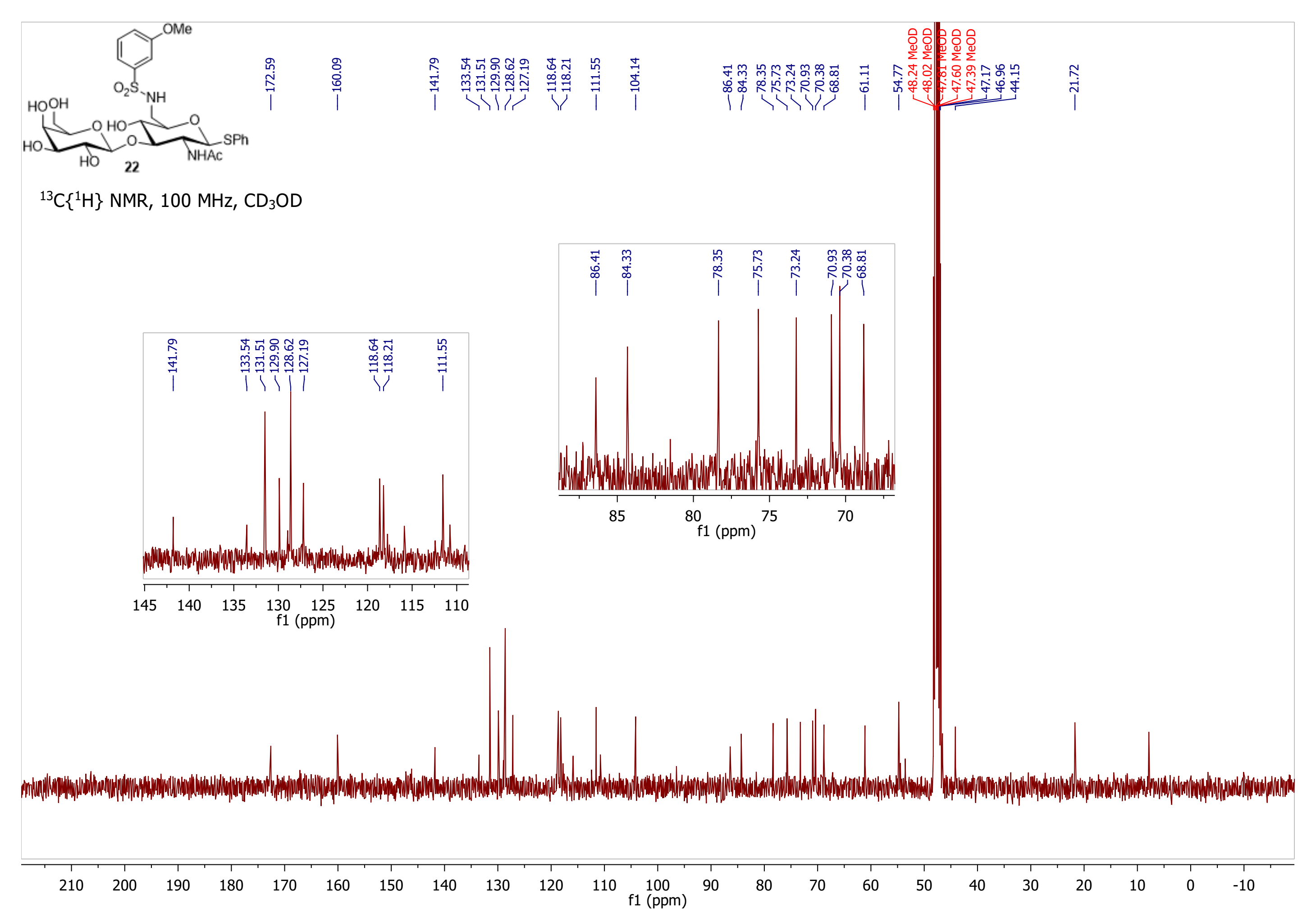




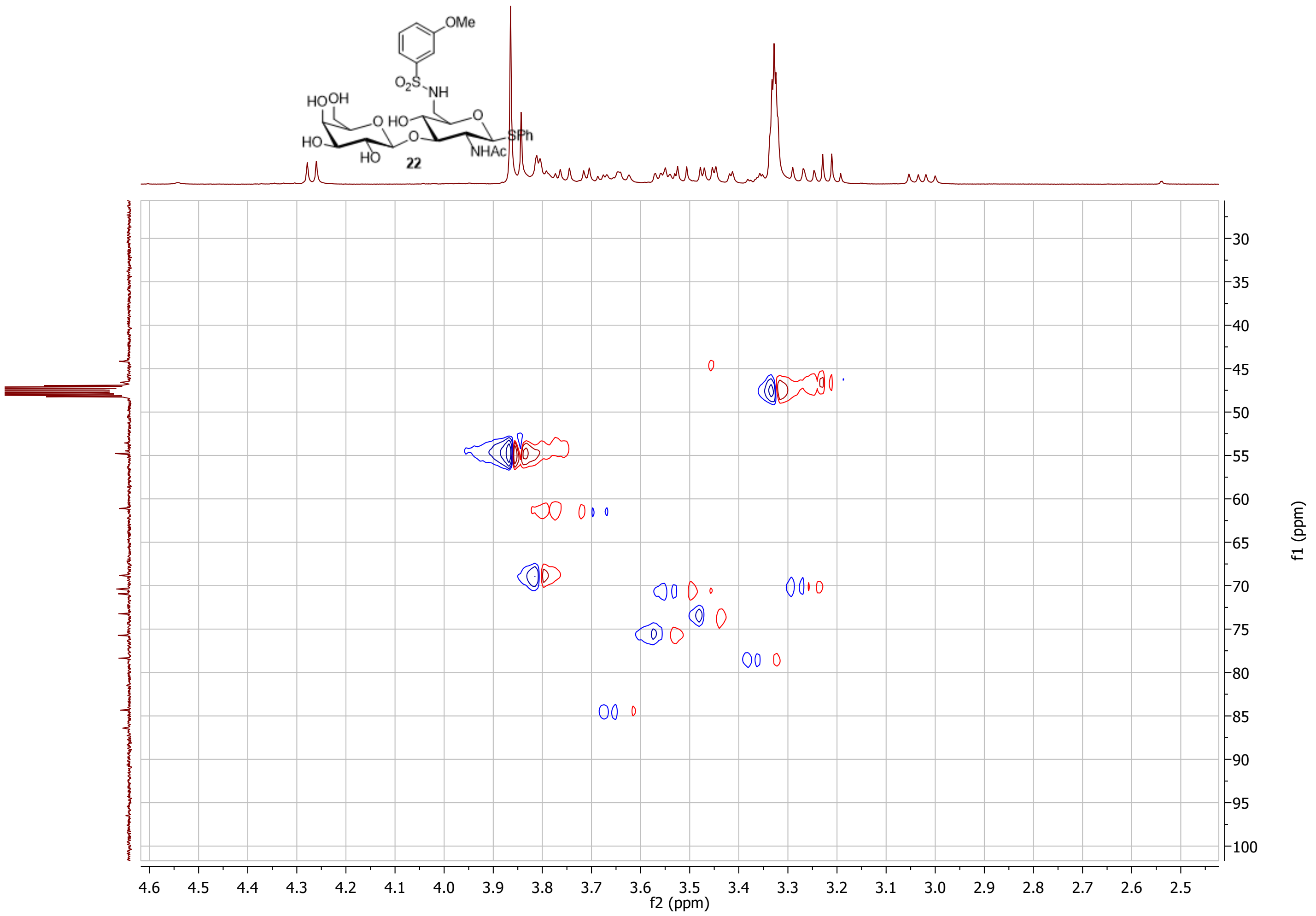




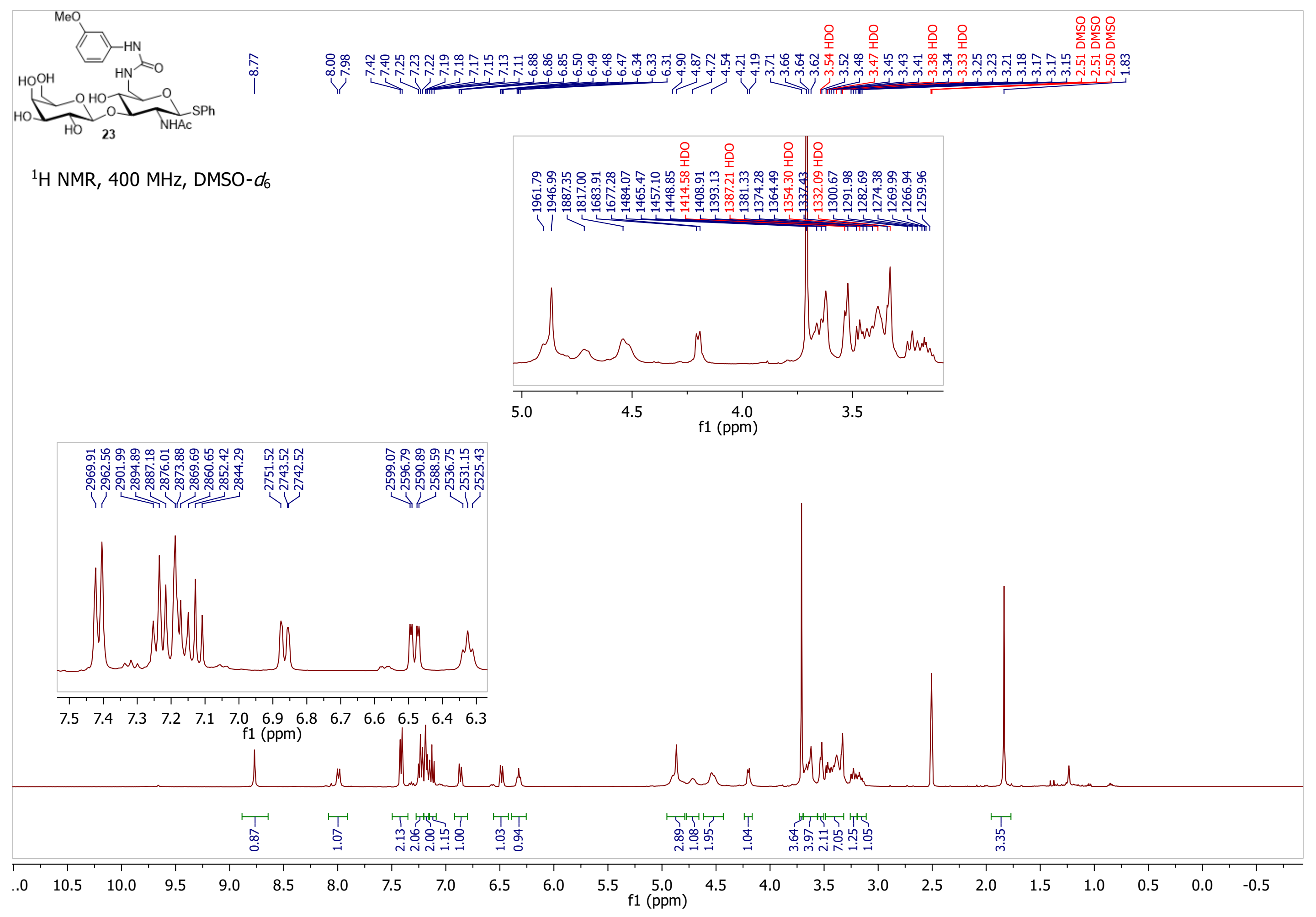




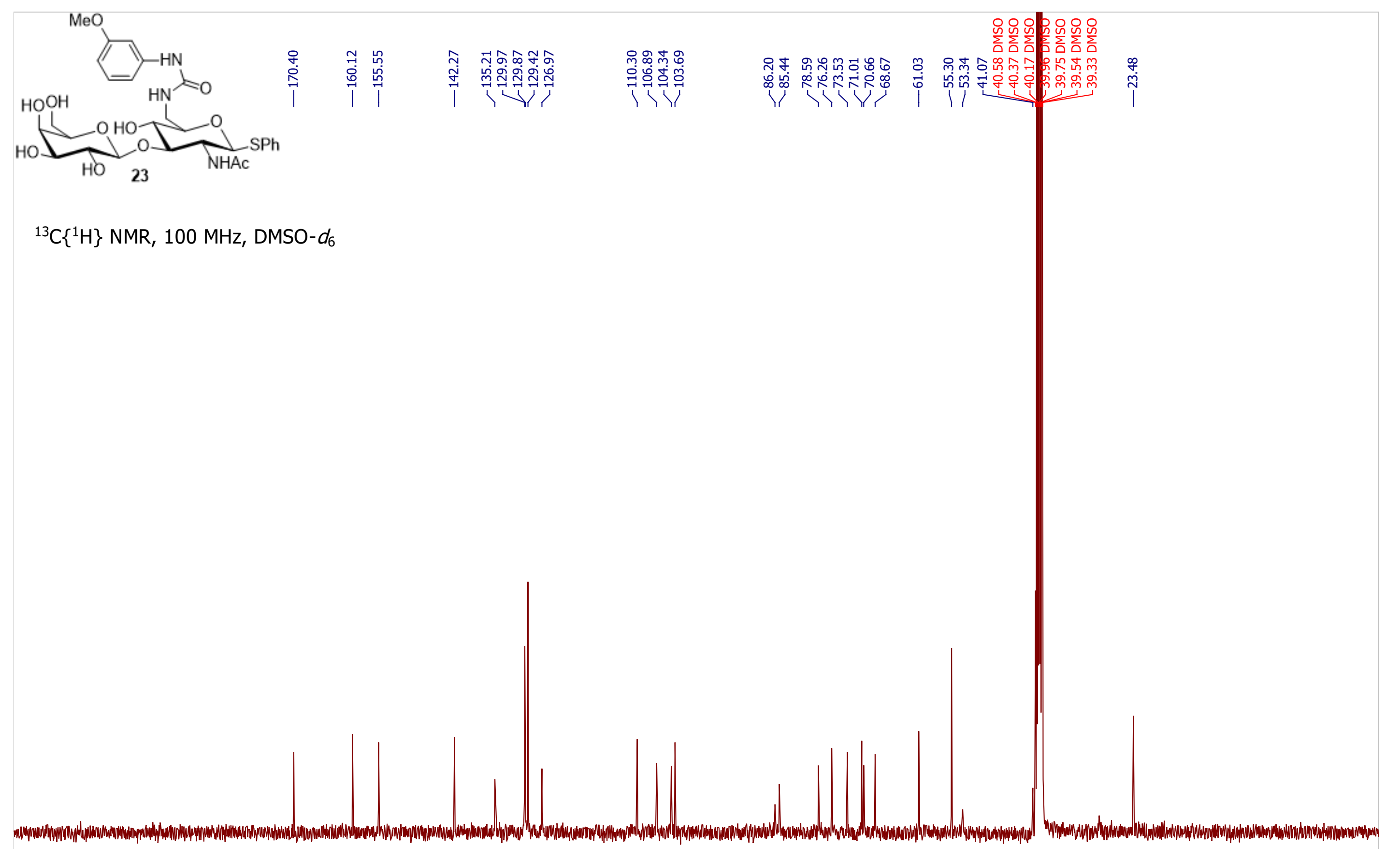




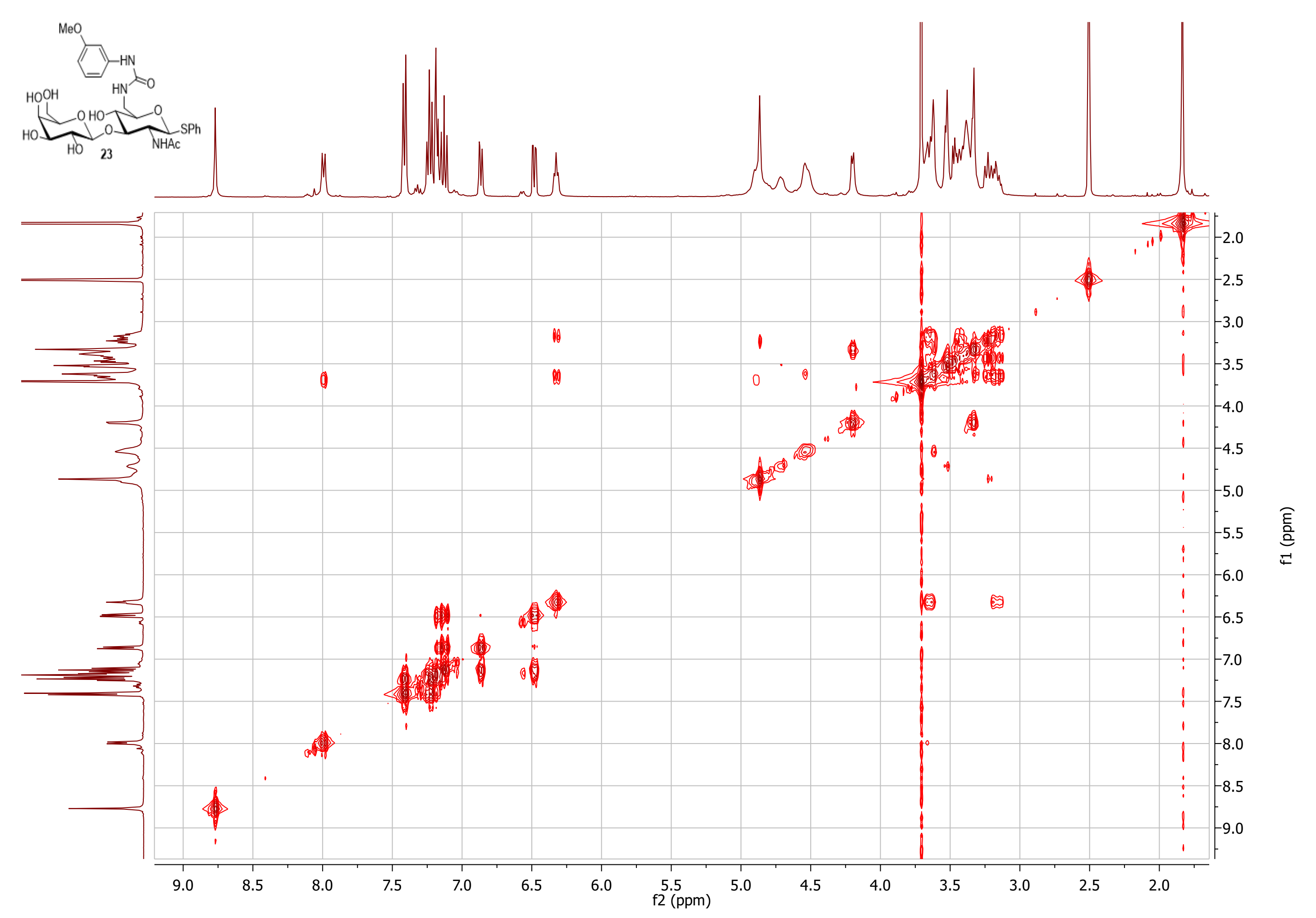




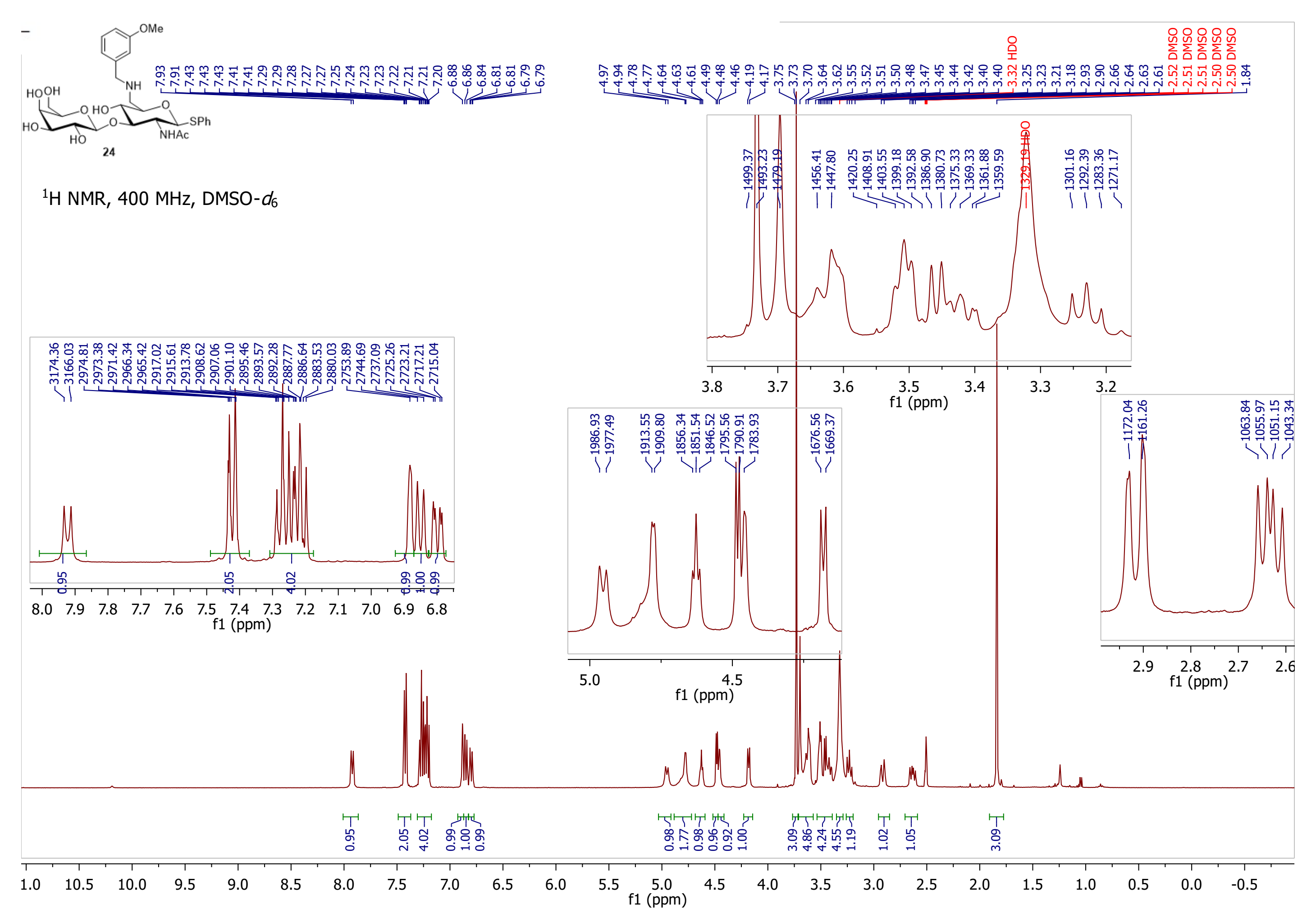




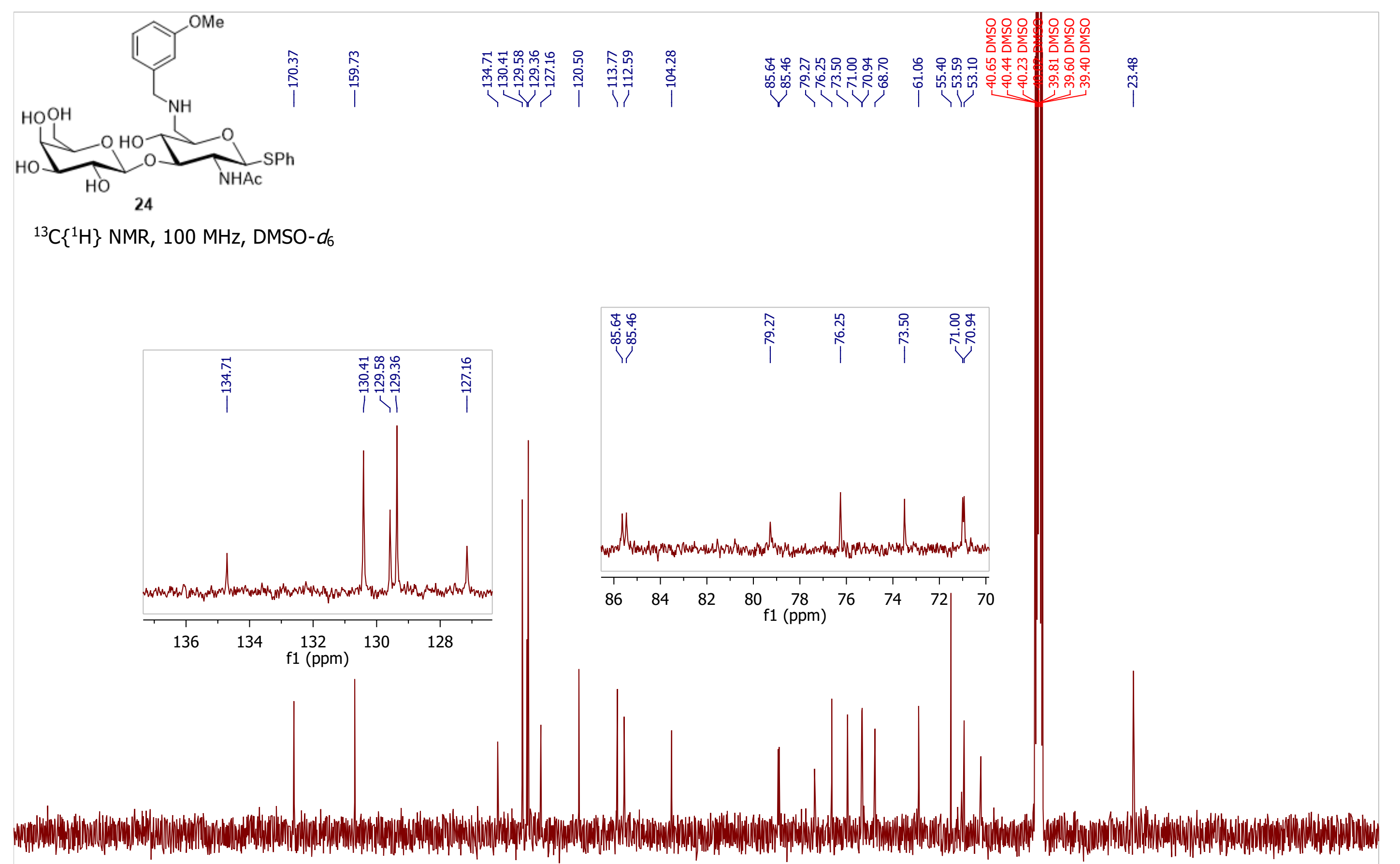

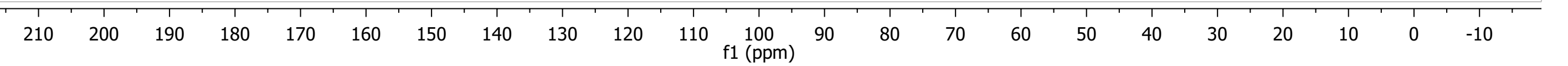




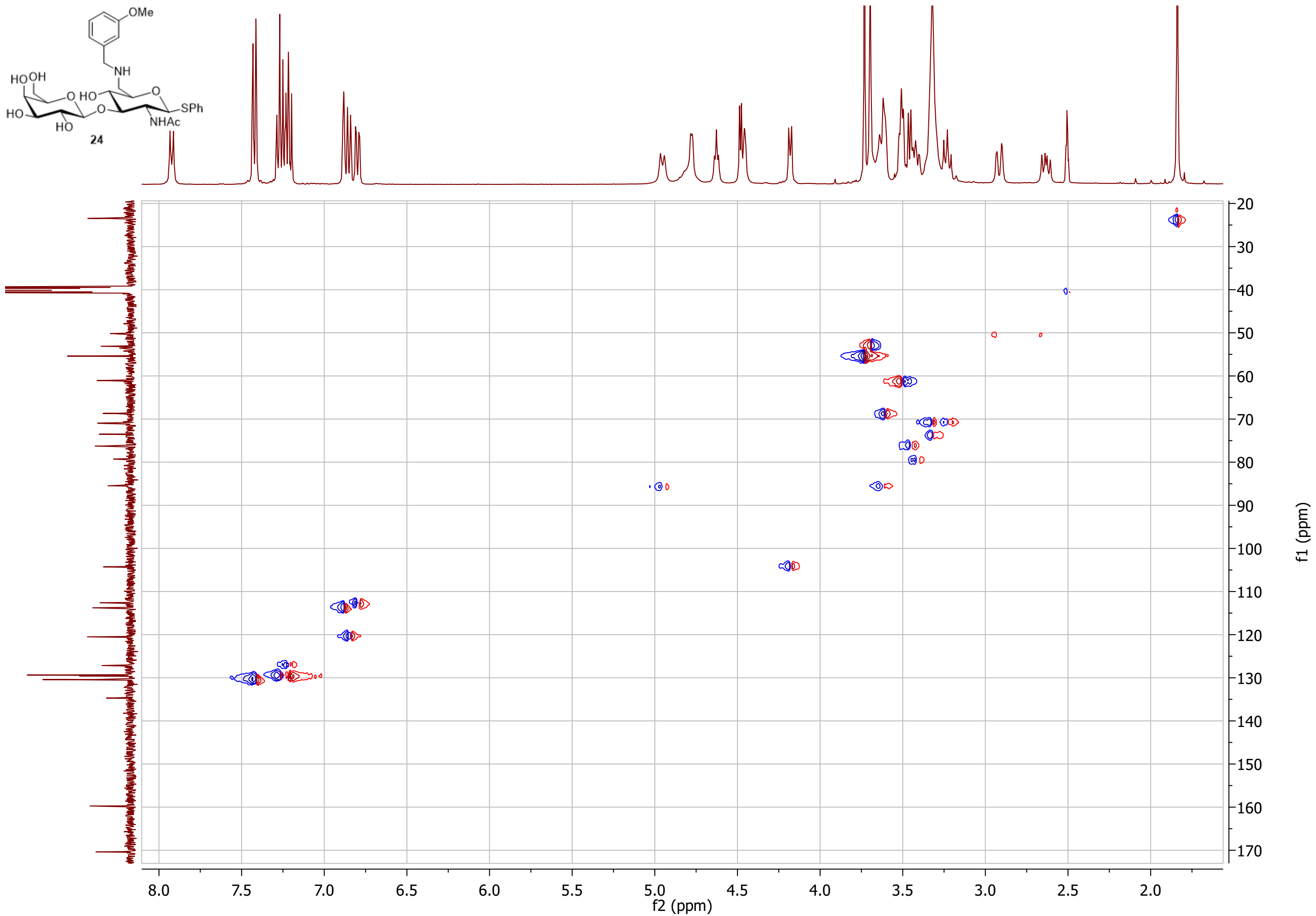




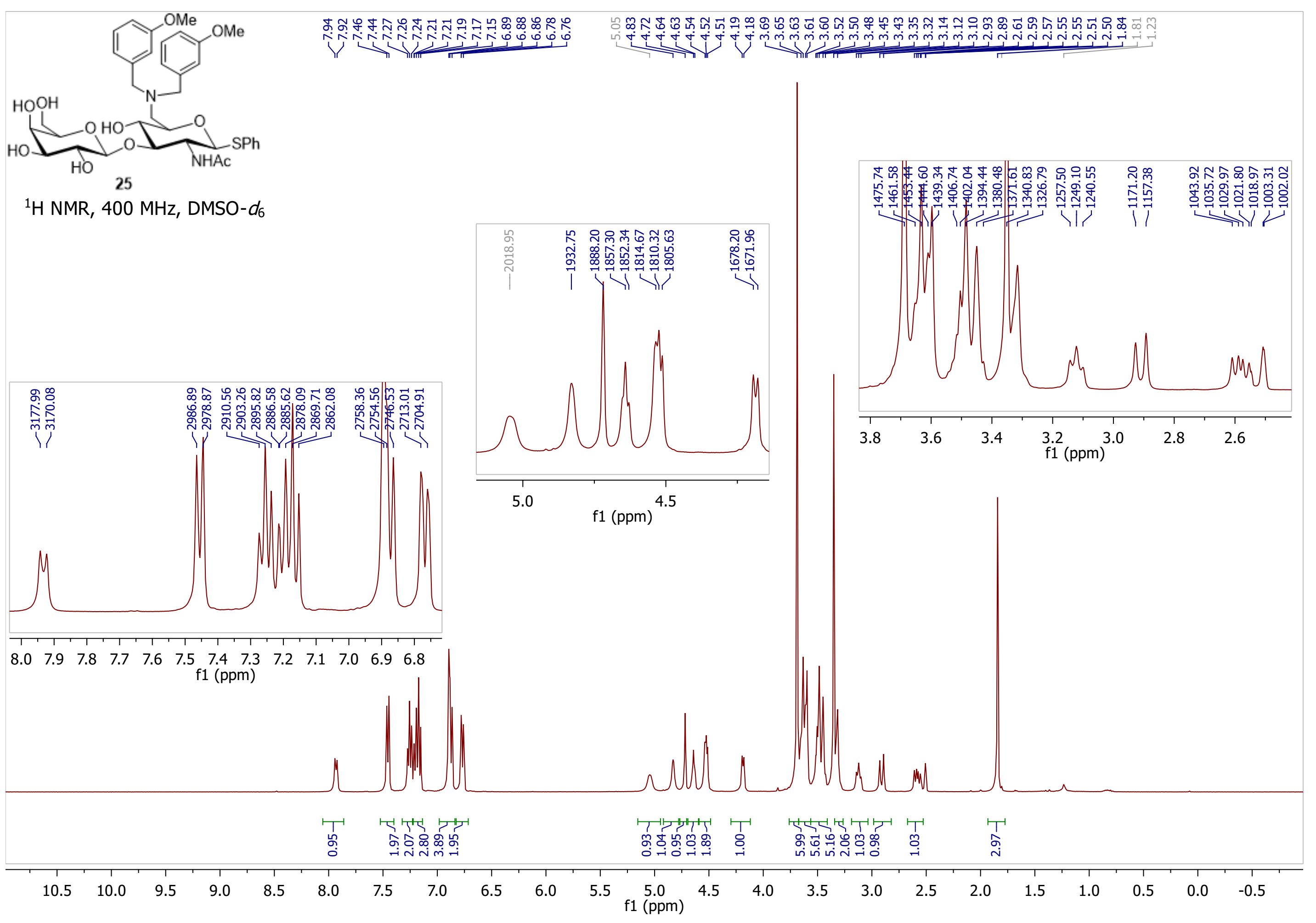




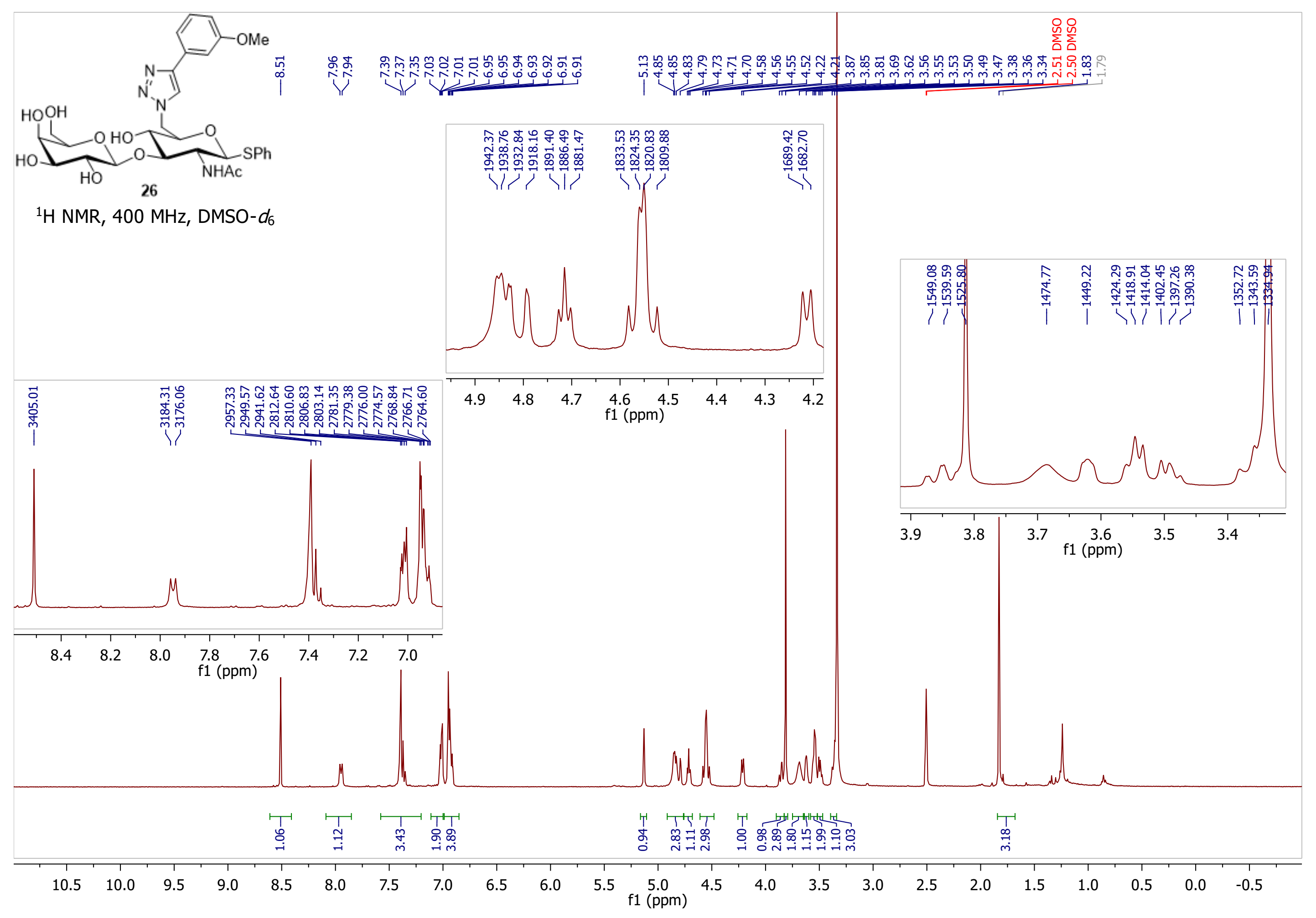




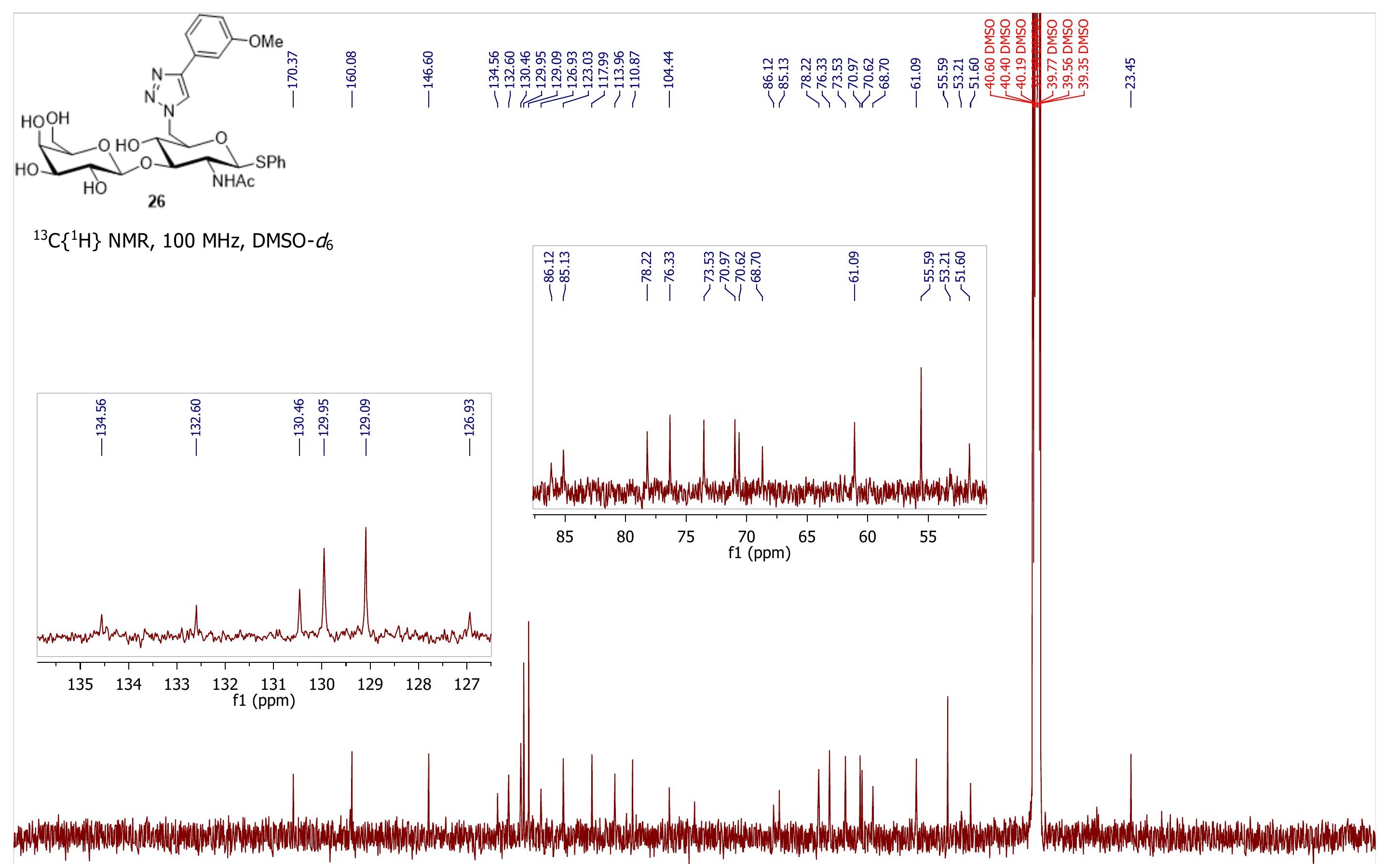

\begin{tabular}{|c|c|c|c|c|c|c|c|c|c|c|c|c|c|c|c|}
\hline 210 & 200 & 190 & 18 & 170 & 160 & 150 & 140 & 130 & 120 & 110 & $\begin{array}{c}100 \\
\mathrm{f} 1(\mathrm{ppm})\end{array}$ & 90 & 80 & 7 & -10 \\
\hline
\end{tabular}




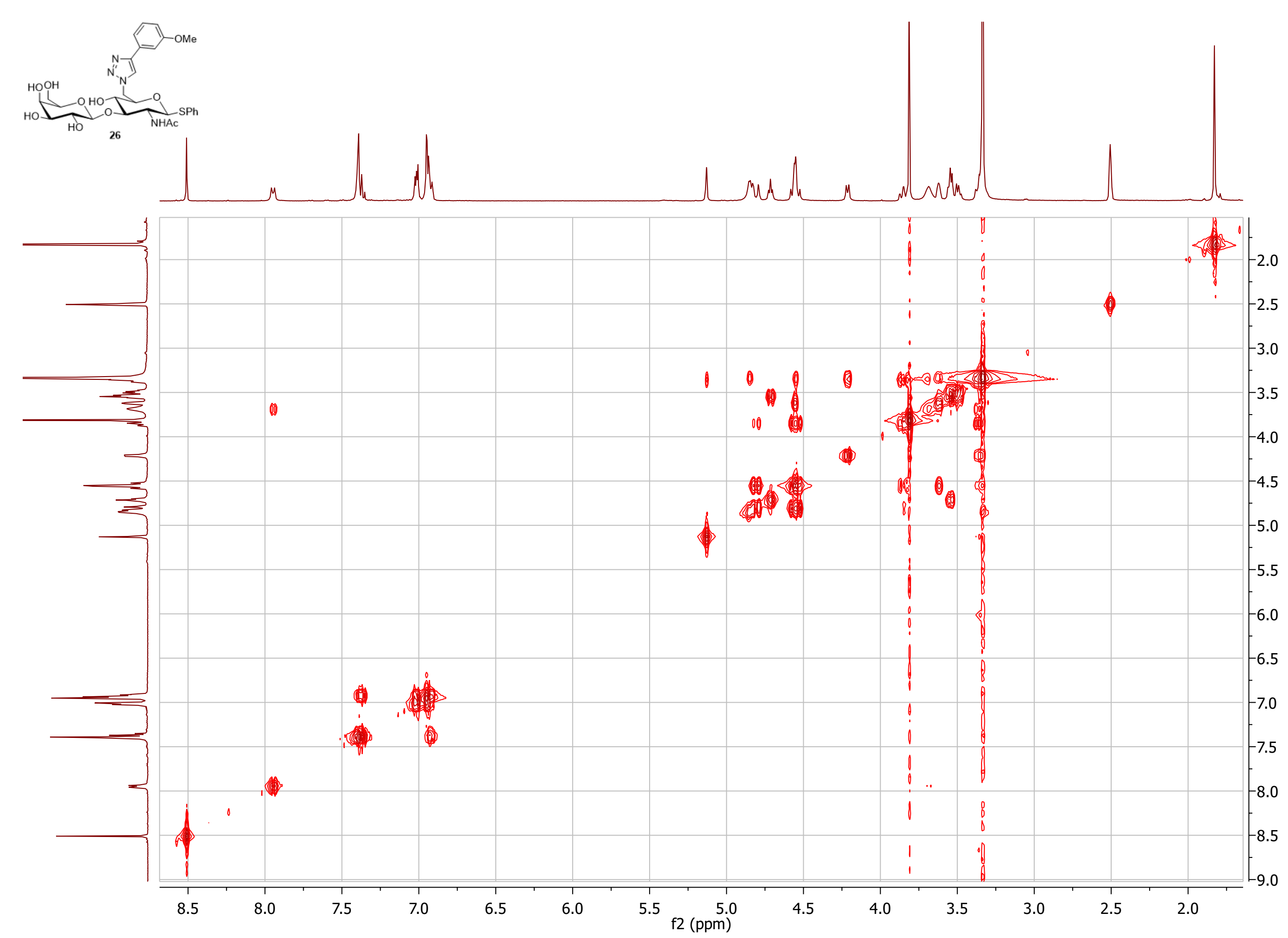




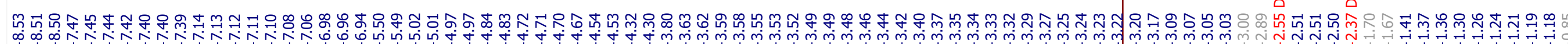

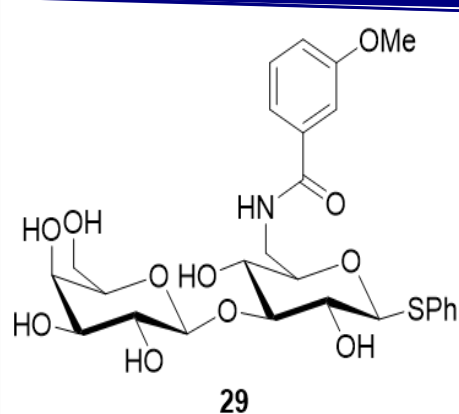

${ }^{1} \mathrm{H}$ NMR, $400 \mathrm{MHz}$, DMSO- $d_{6}$

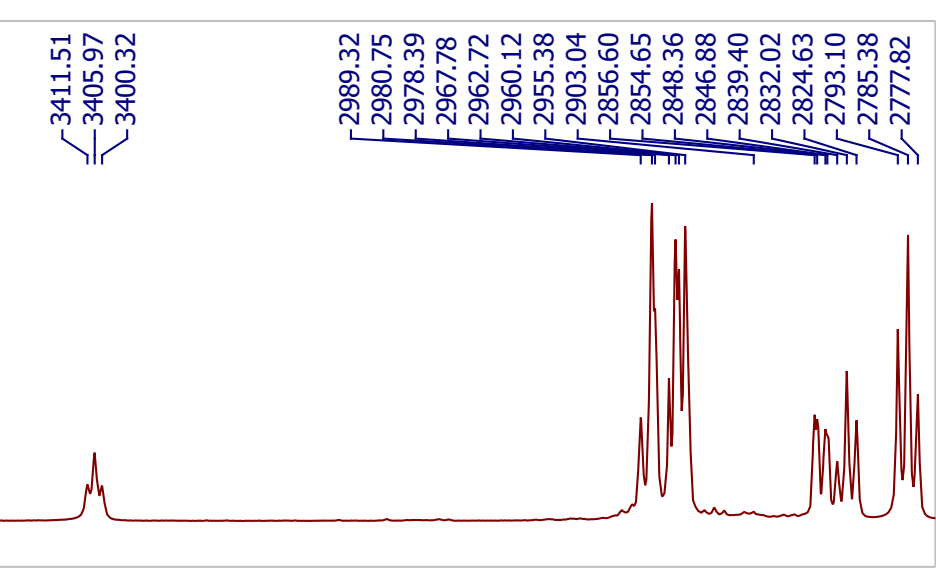
$8.6 \quad 8.4 \quad 8.2$$$
\text { f1 } 7.8 \text { (ppm) } 7.6
$$

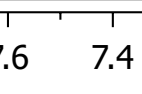
7.2

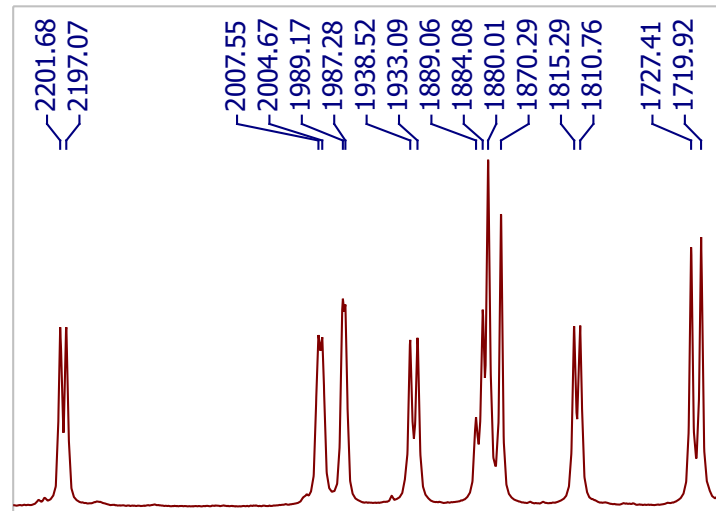

$\begin{array}{lllll}5.4 & 5.2 & \begin{array}{lll}5.0 & 4.8 \\ \mathrm{f} 1(\mathrm{ppm})\end{array} & 4.6 & 4.4\end{array}$

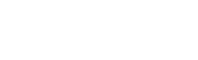

$$
8 .
$$
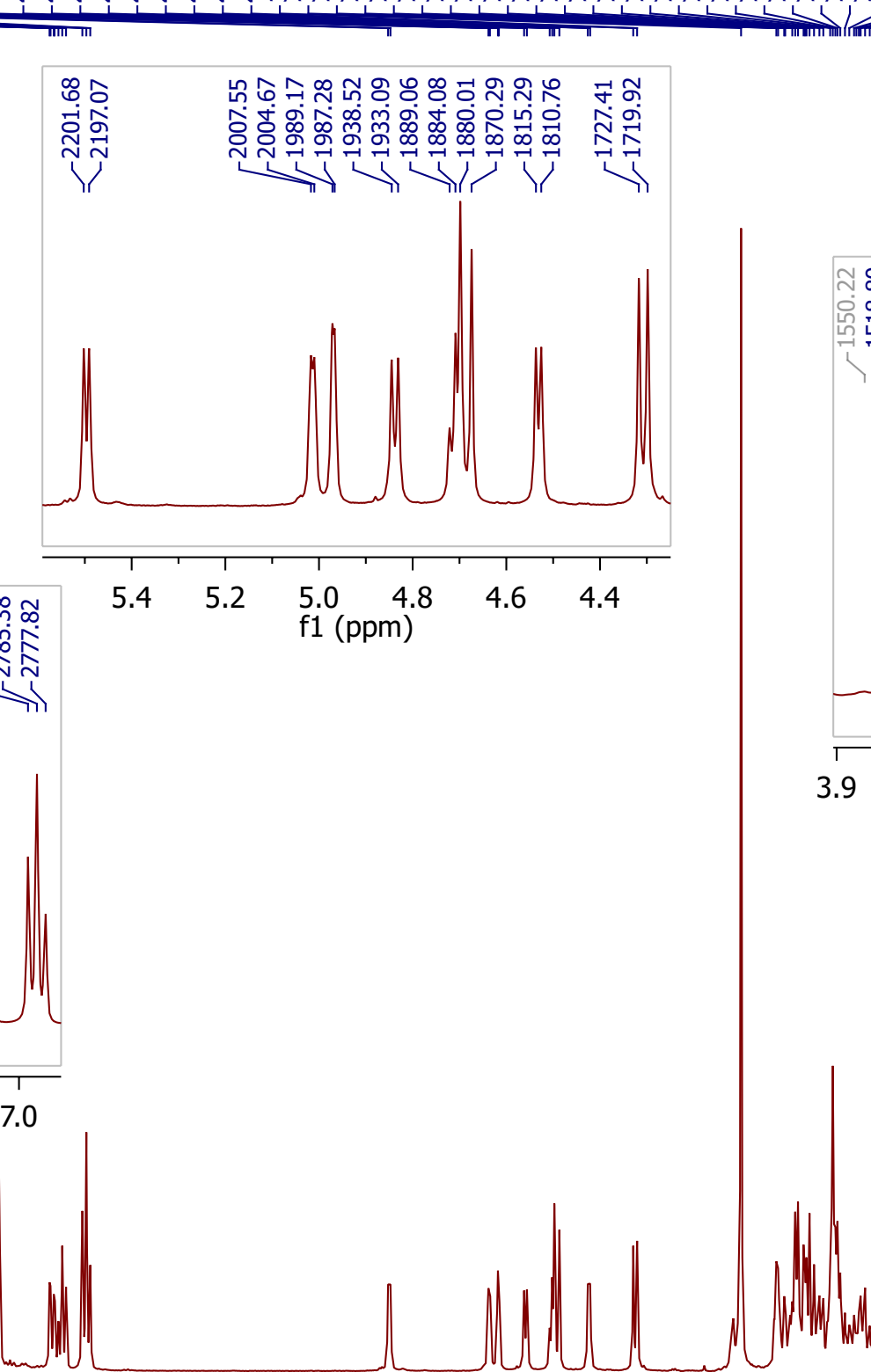

ताTाIIII

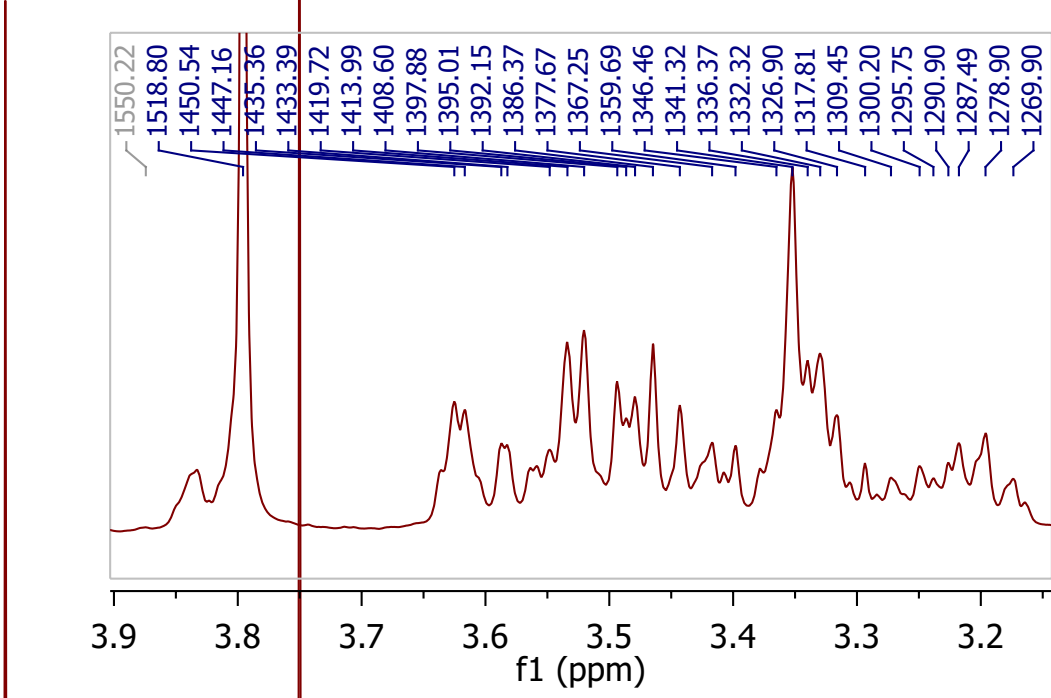

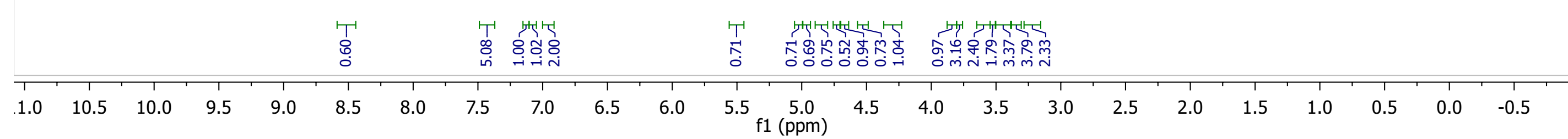




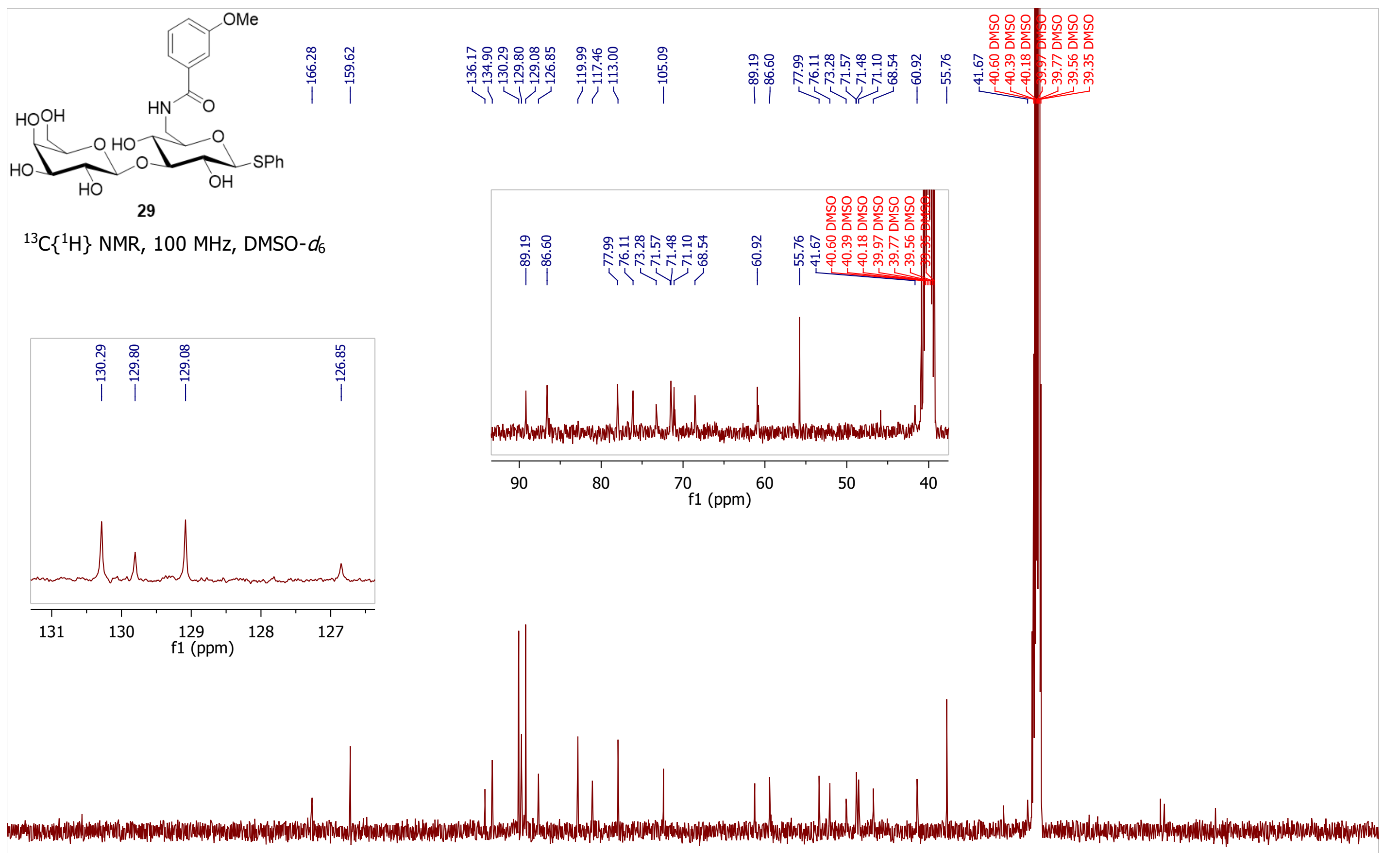

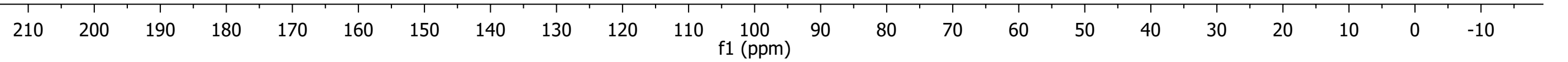




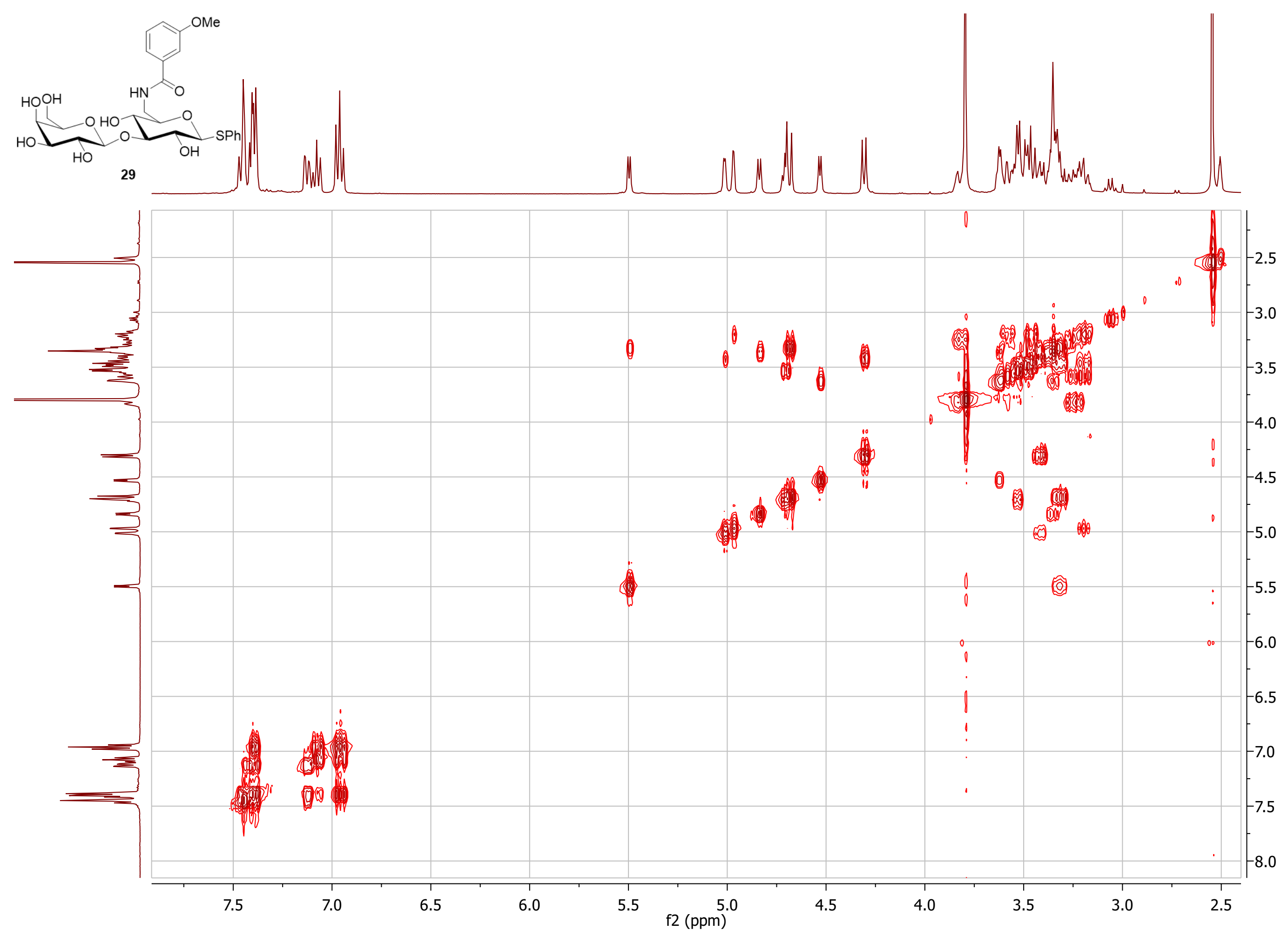

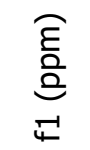




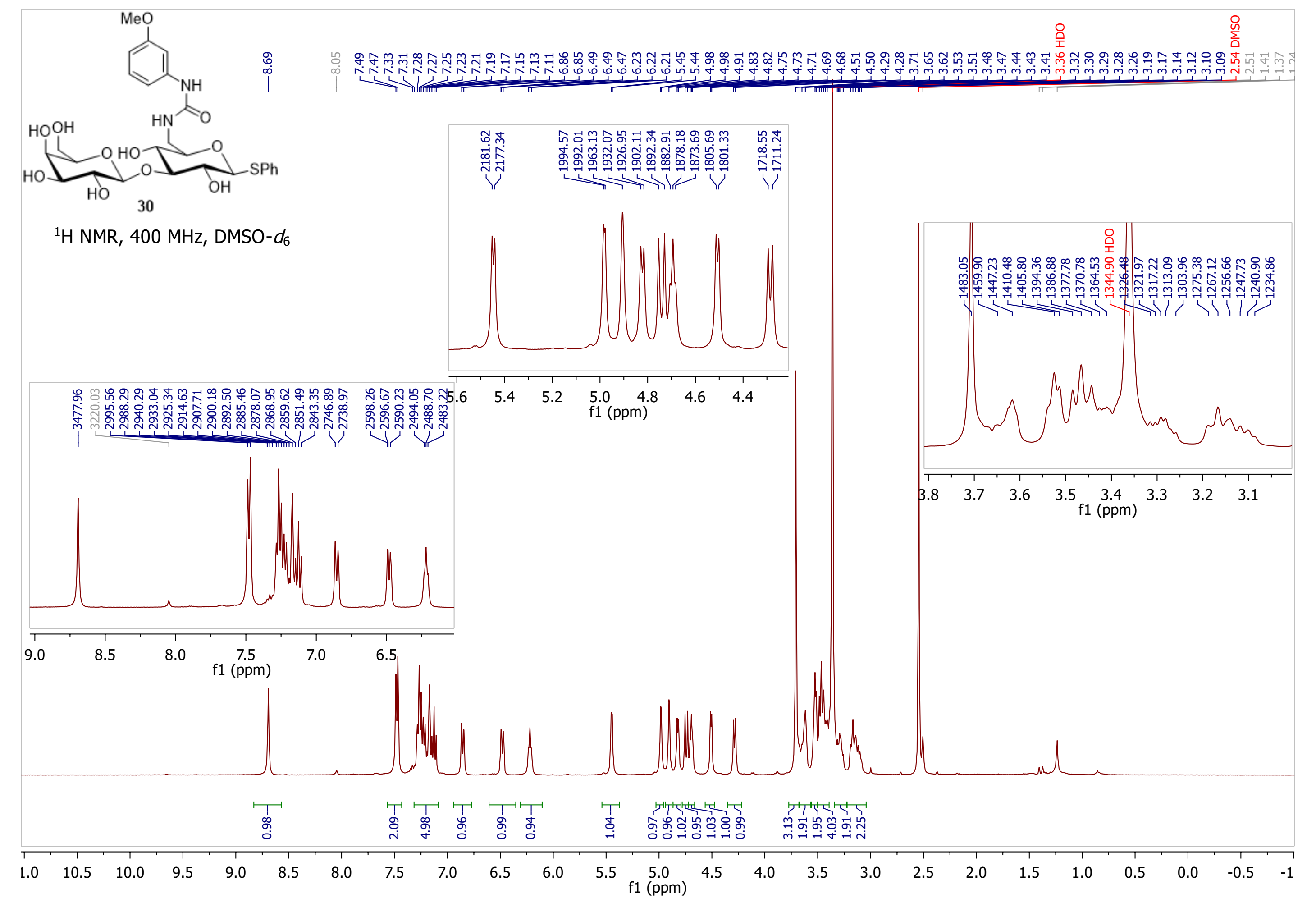




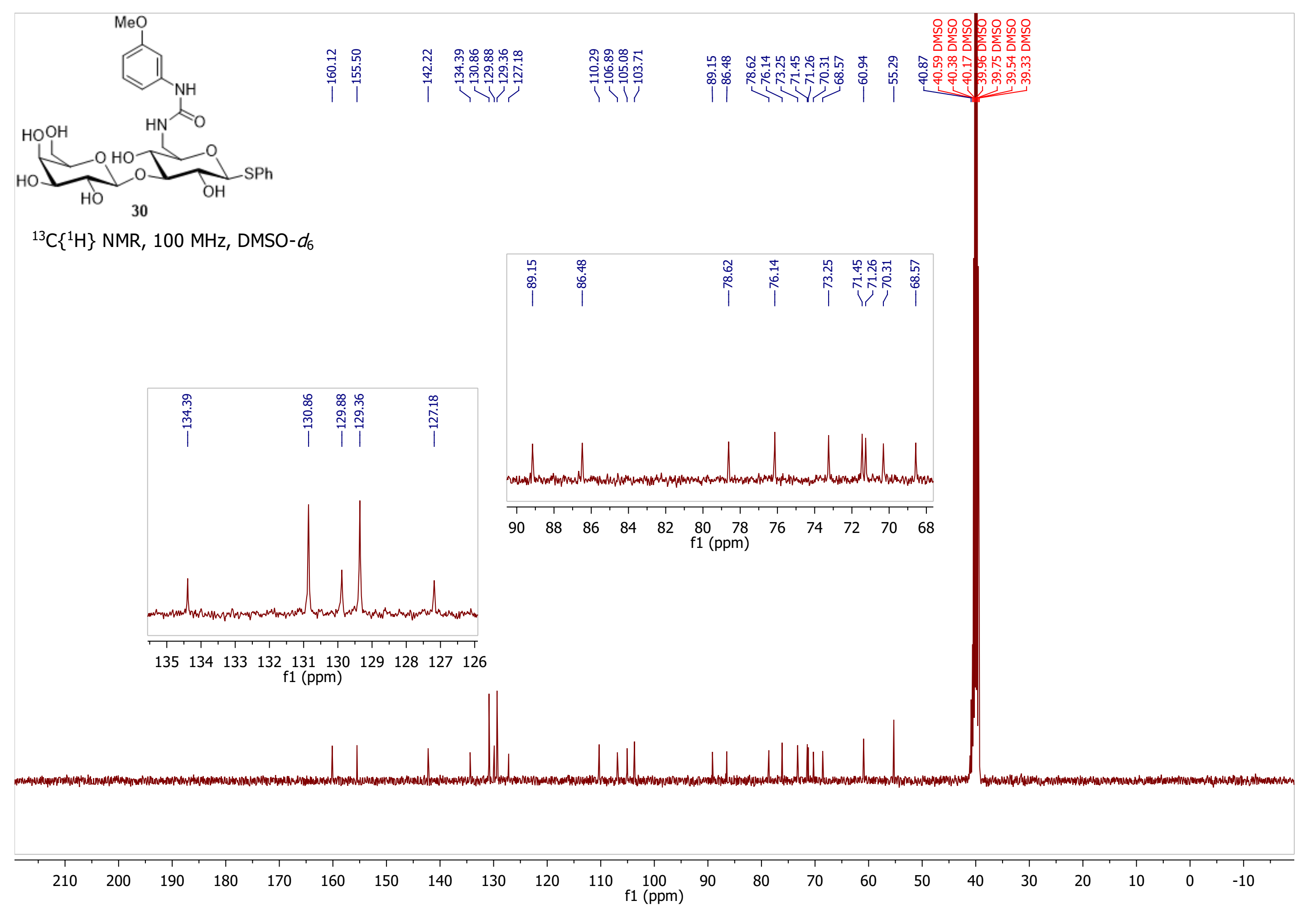




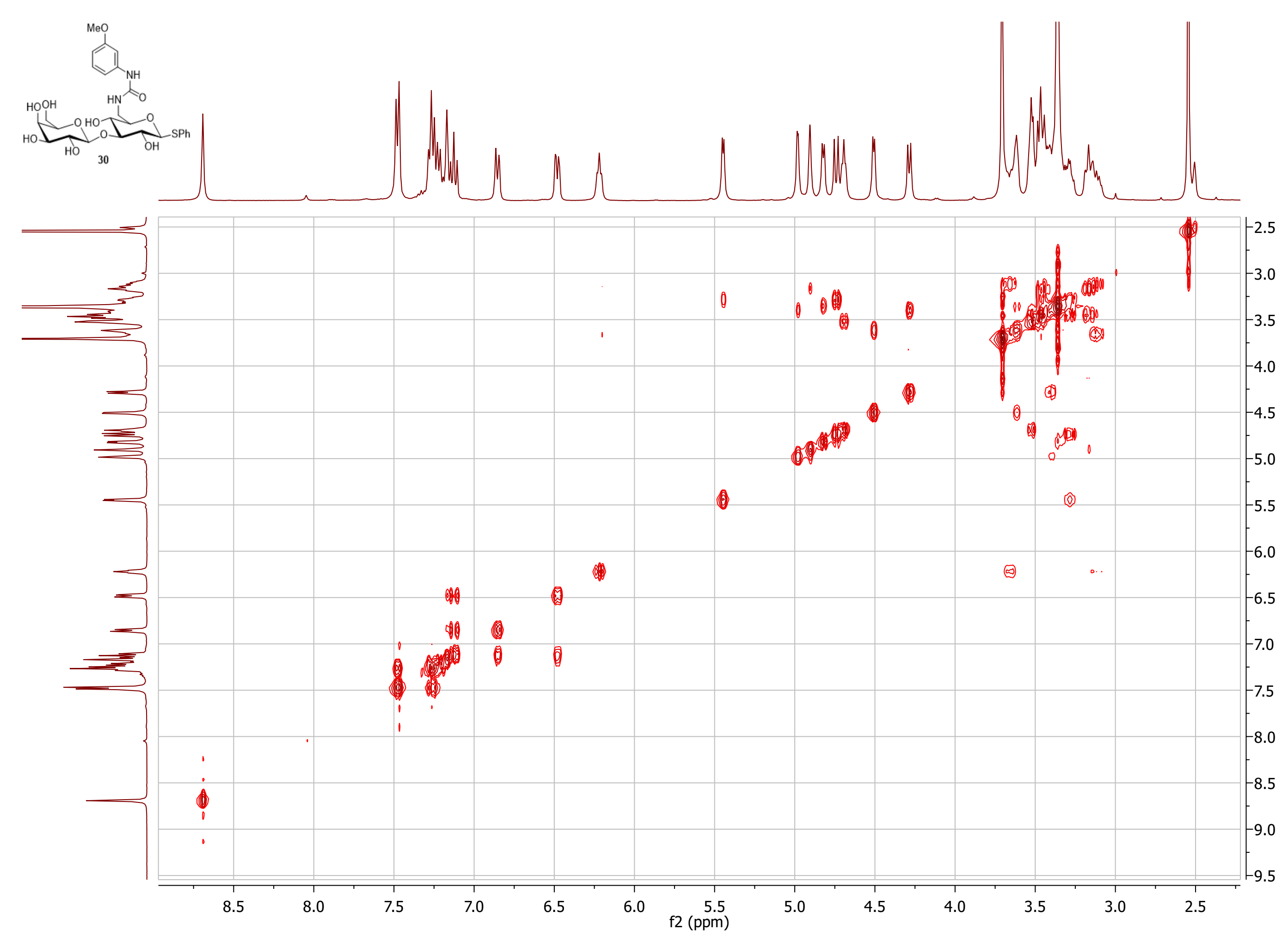




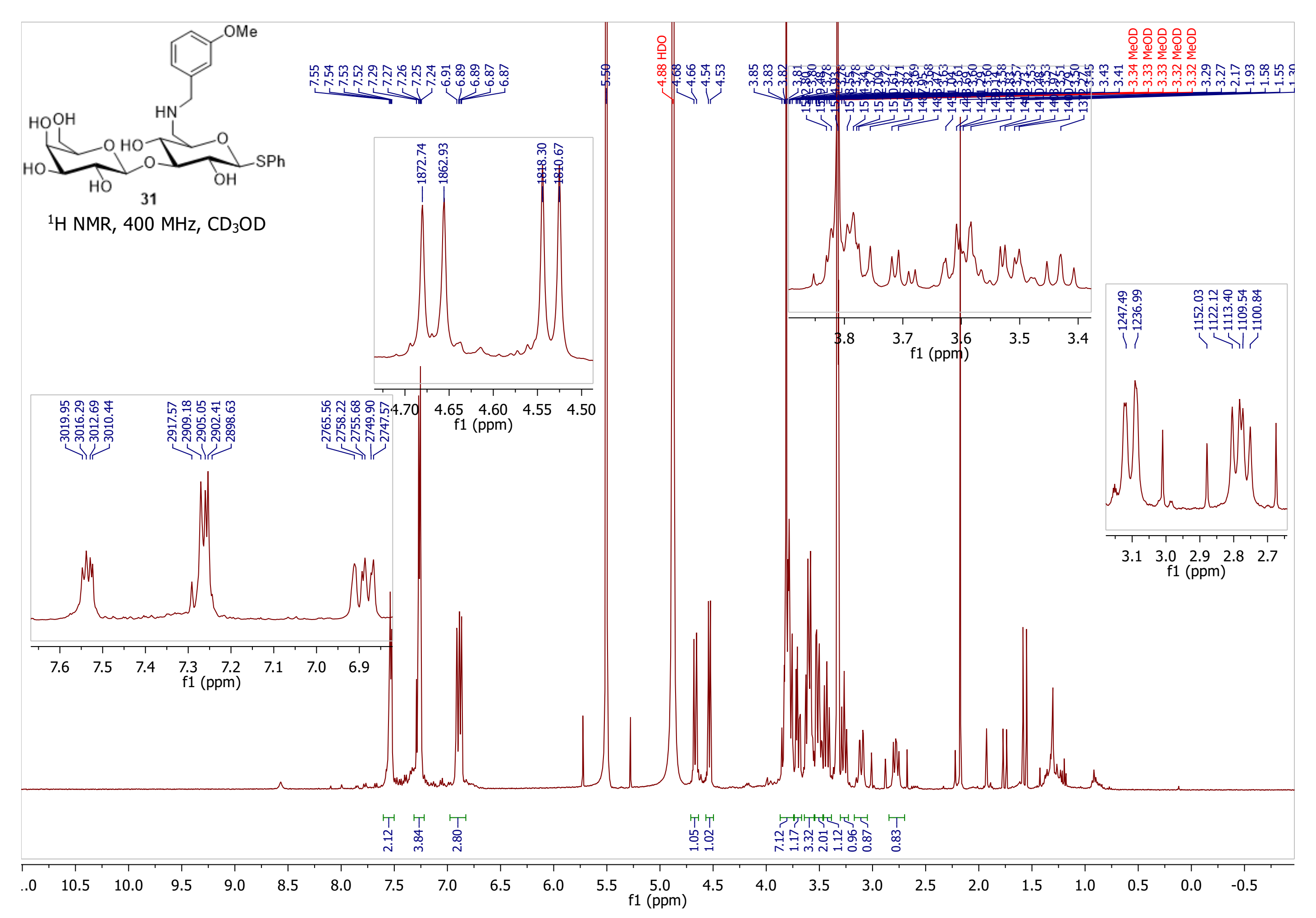




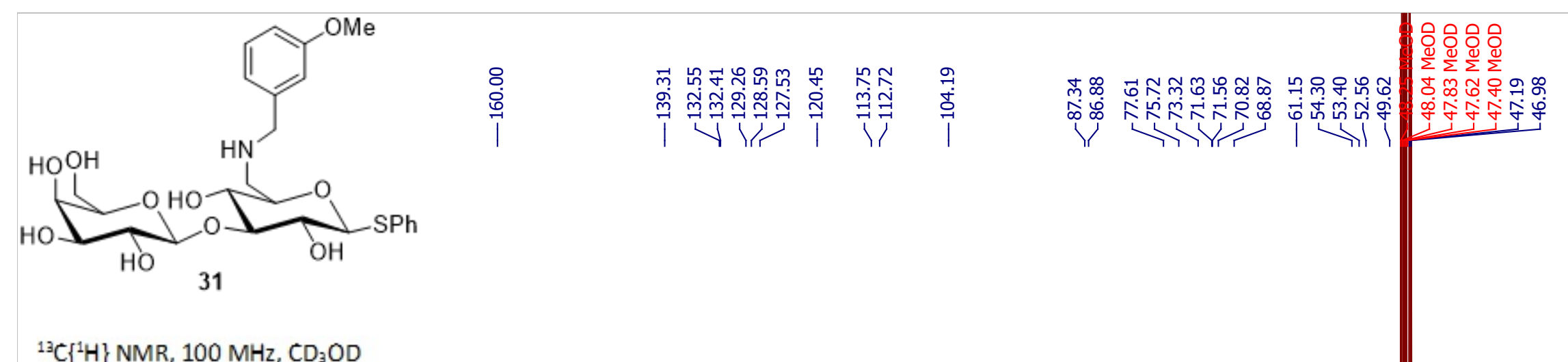

${ }^{13} \mathrm{C}\left\{{ }^{1} \mathrm{H}\right\} \mathrm{NMR}, 100 \mathrm{MHz}, \mathrm{CD}_{3} \mathrm{OD}$
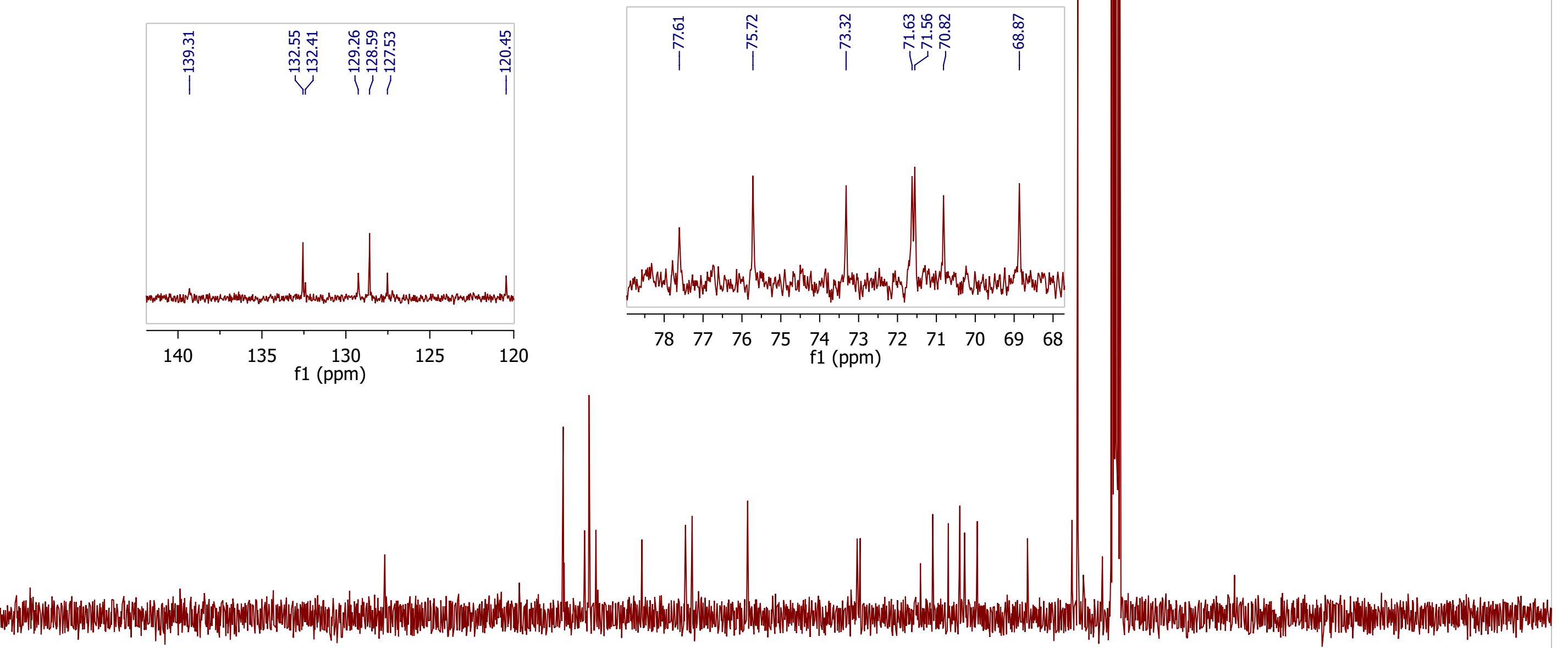

$\begin{array}{lllllllllllllllllllllllll}210 & 200 & 190 & 180 & 170 & 160 & 150 & 140 & 130 & 120 & 110 & \begin{array}{c}100 \\ \mathrm{f} 1(\mathrm{ppm})\end{array} & 90 & 80 & 70 & 60 & 50 & 40 & 30 & 20 & 10 & 0 & -10 & \end{array}$




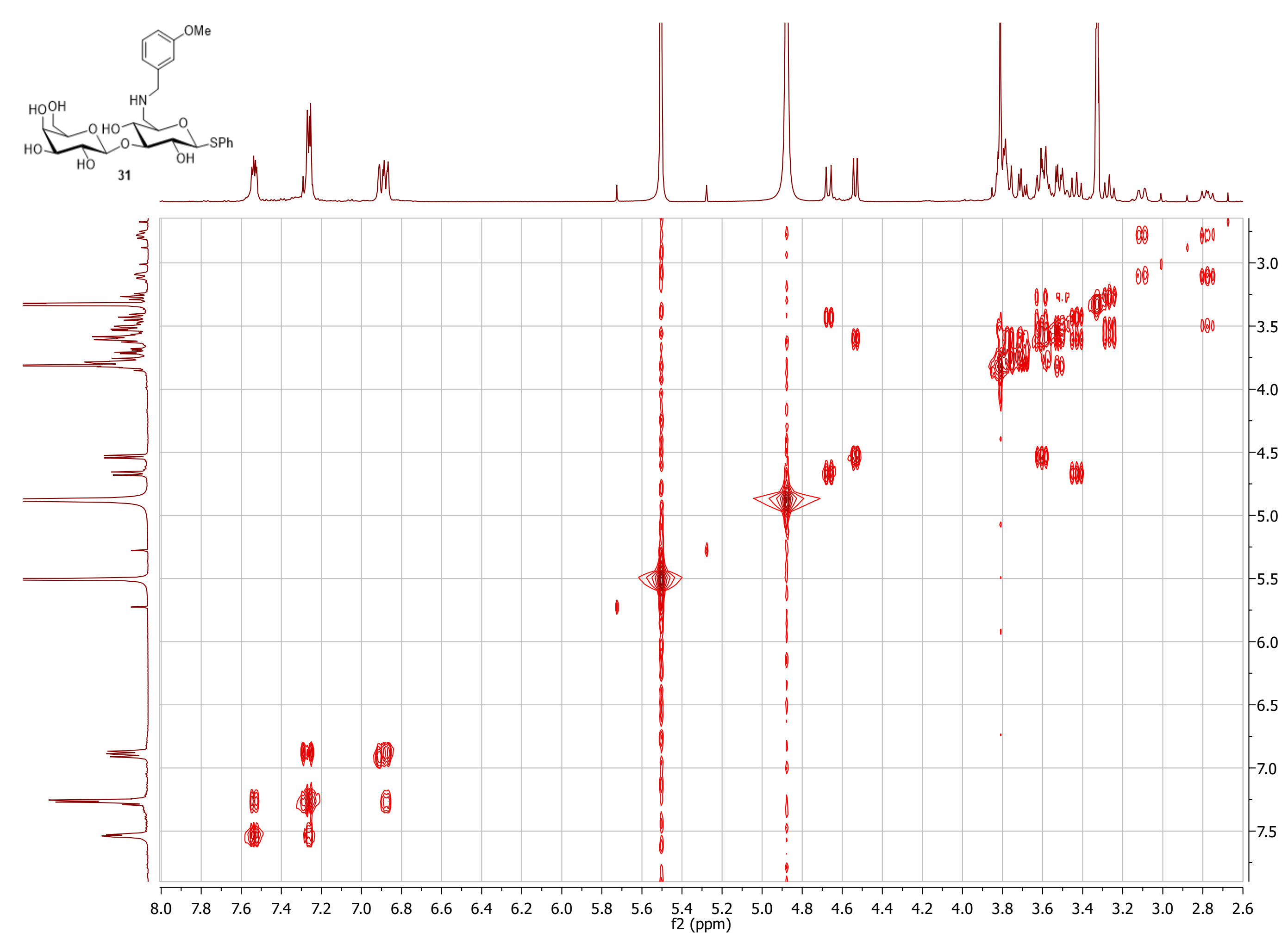

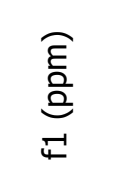




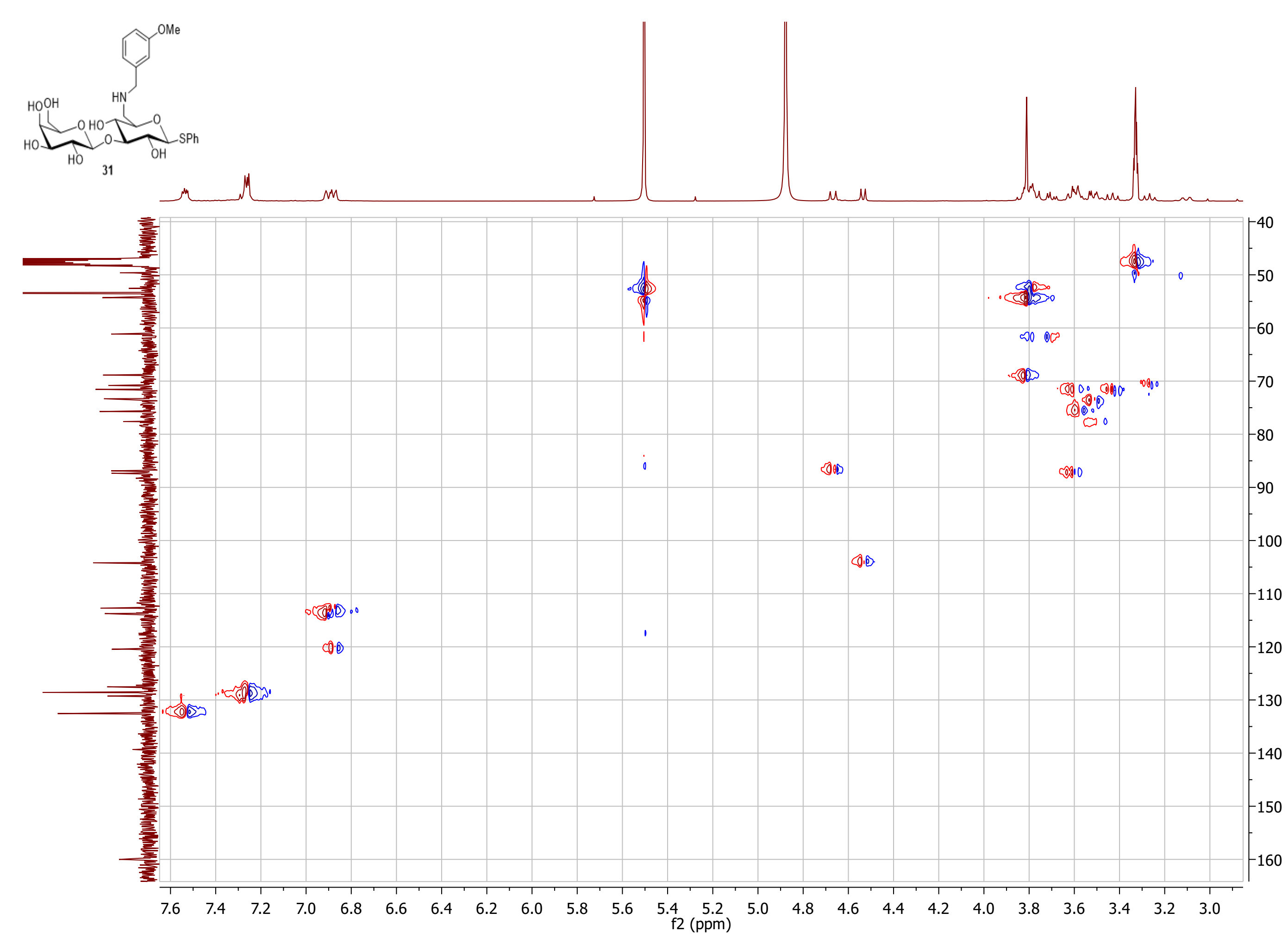




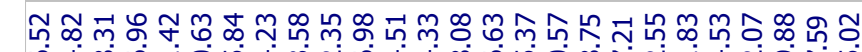

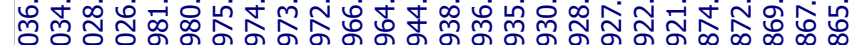

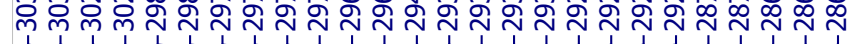
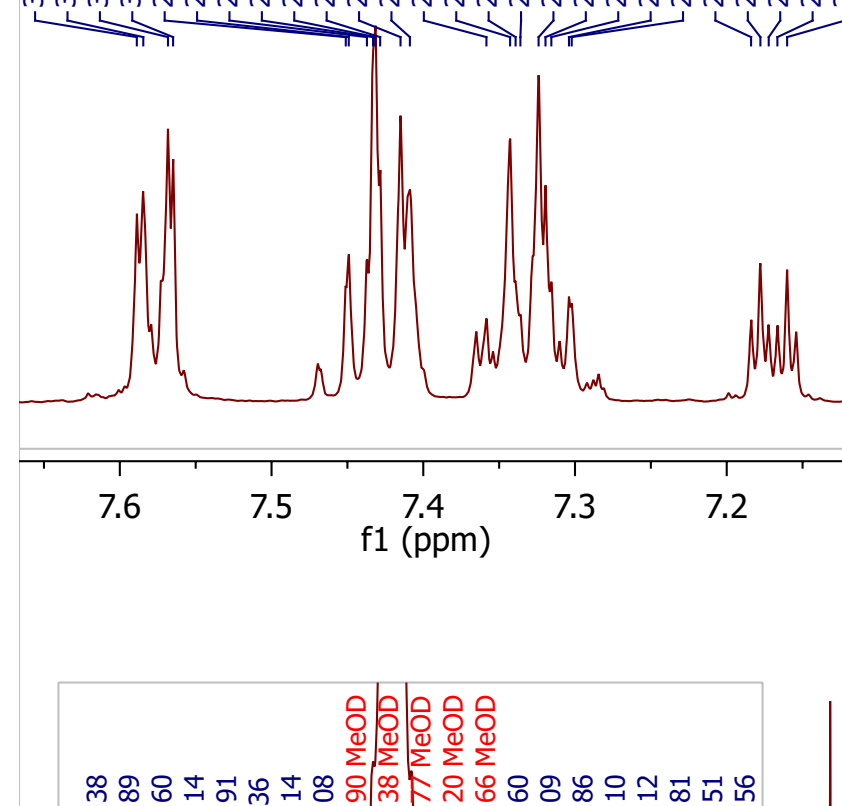

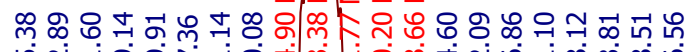
苮 (

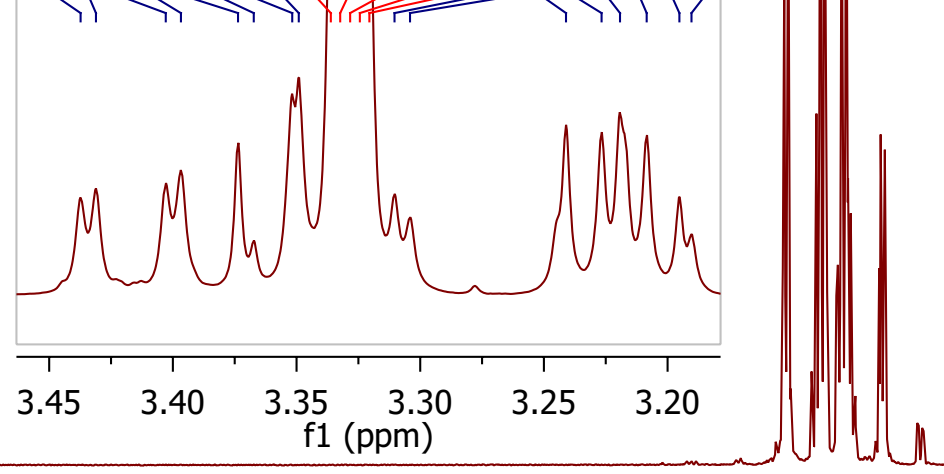

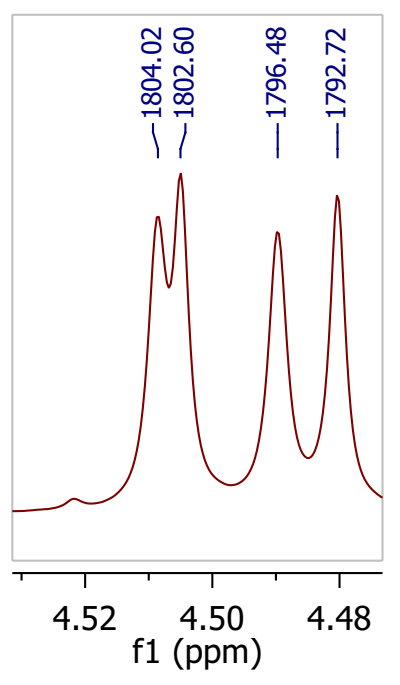

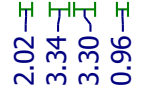

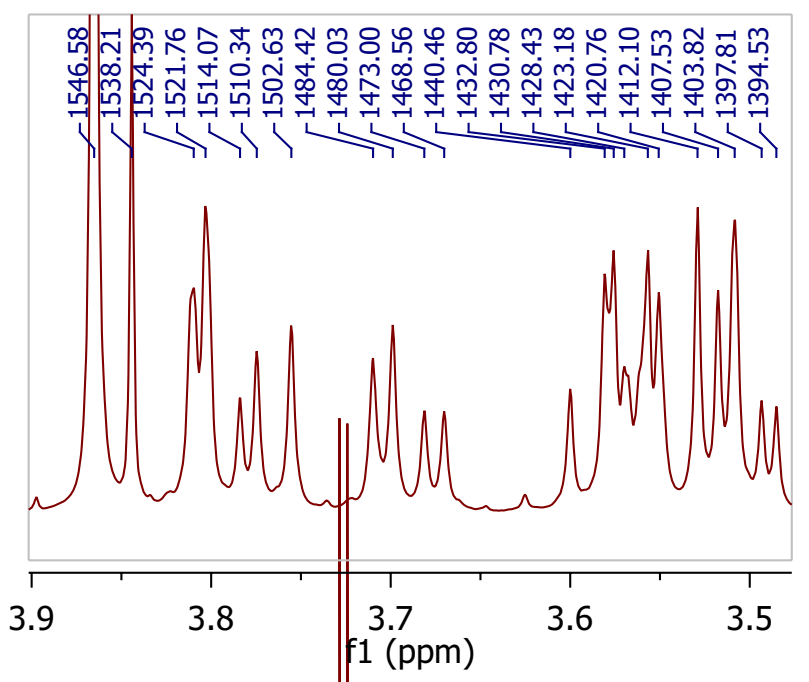

$\mathrm{HOOH}$

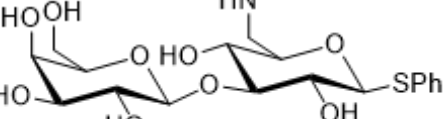

HO 32

${ }^{1} \mathrm{HNMR}, 400 \mathrm{MHz}, \mathrm{CD}_{3} \mathrm{OD}$

$7.5 \quad 7.0$

6.5

$\begin{array}{llc}6.0 & 5.5 & 5.0 \\ & \mathrm{f} 1(\mathrm{ppm})\end{array}$

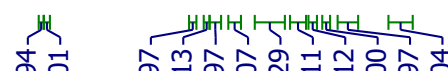

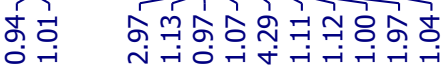

$10.5 \quad 10.0$

$9.5 \quad 9.0$

8.5

$8.0-7.5$

(2)

$\begin{array}{llll}4.5 & 4.0 & 3.5 & 3.0\end{array}$

2.5

$\begin{array}{llllll}2.0 & 1.5 & 1.0 & 0.5 & 0.0 & -0.5\end{array}$



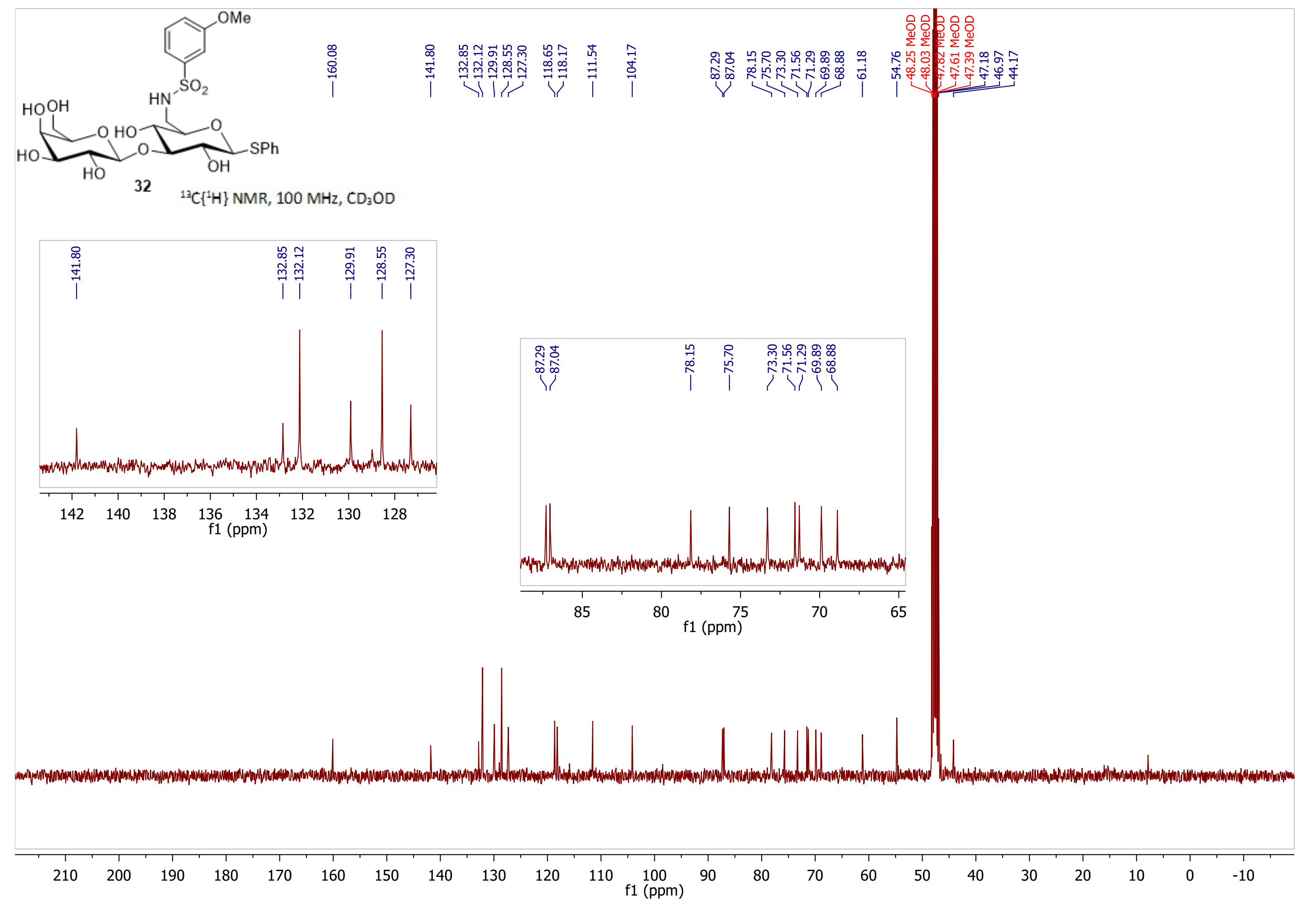


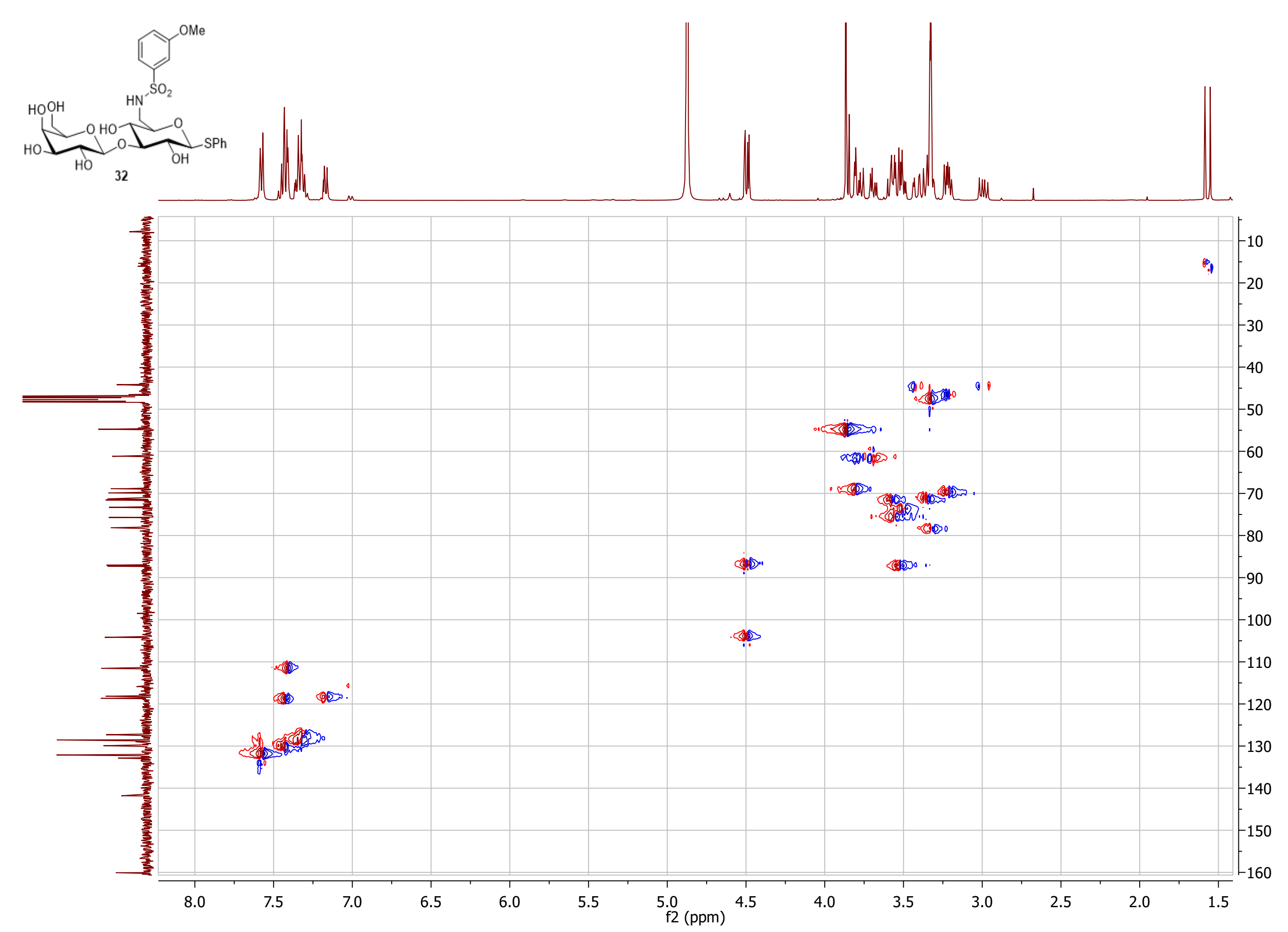




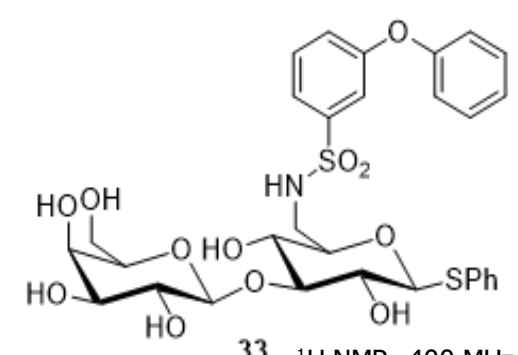

$33{ }^{1} \mathrm{H}$ NMR, $400 \mathrm{MHz}$, DMSO- $d_{6}$

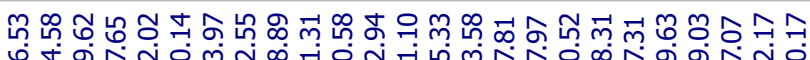

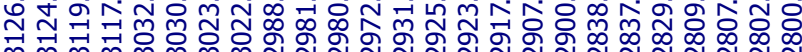
闻

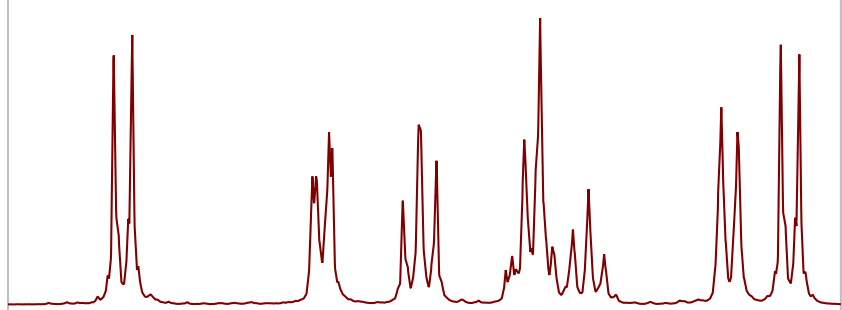

$\begin{array}{llllllllll}7.9 & 7.8 & 7.7 & 7.6 & 7.5 & 7.4 & 7.3 & 7.2 & 7.1 & 7.0\end{array}$

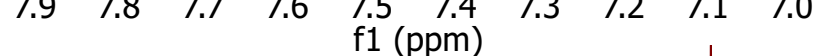
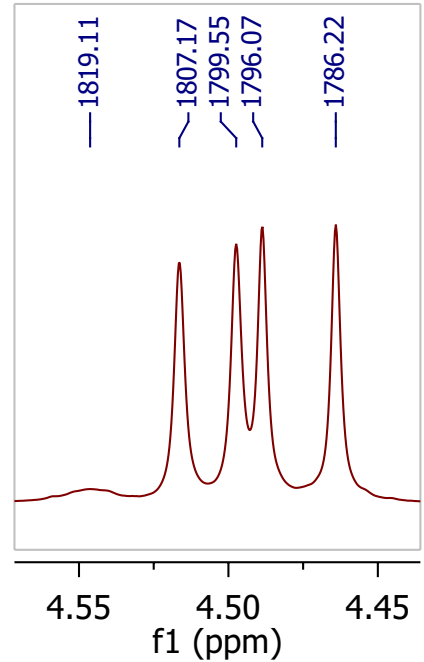
f1 (ppm)

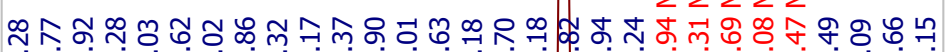

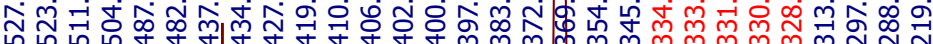
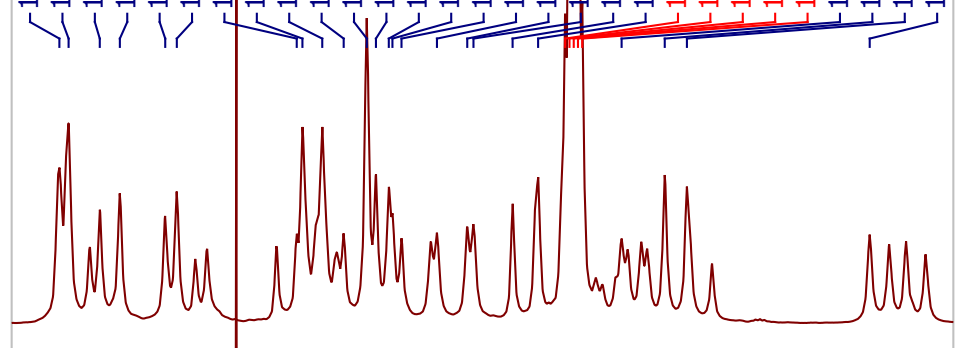
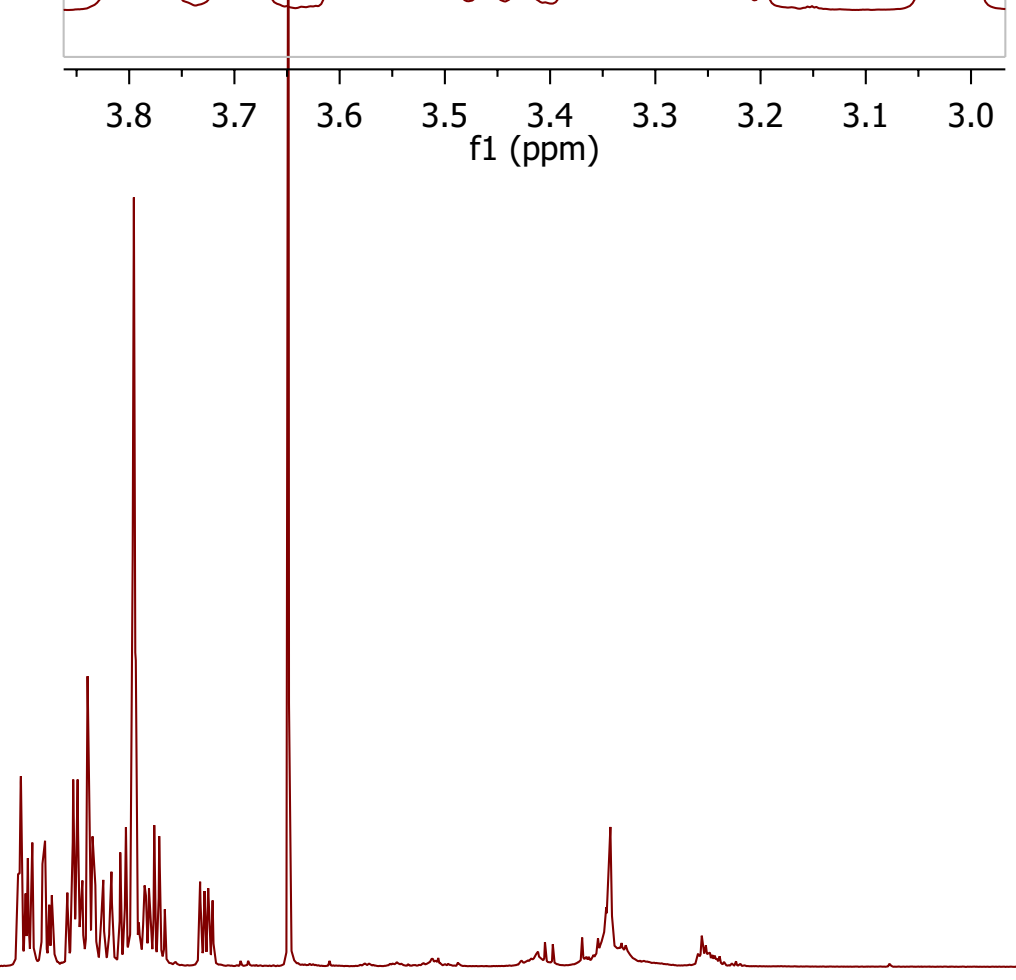

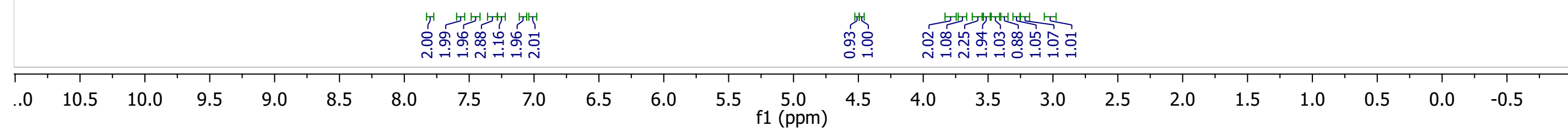




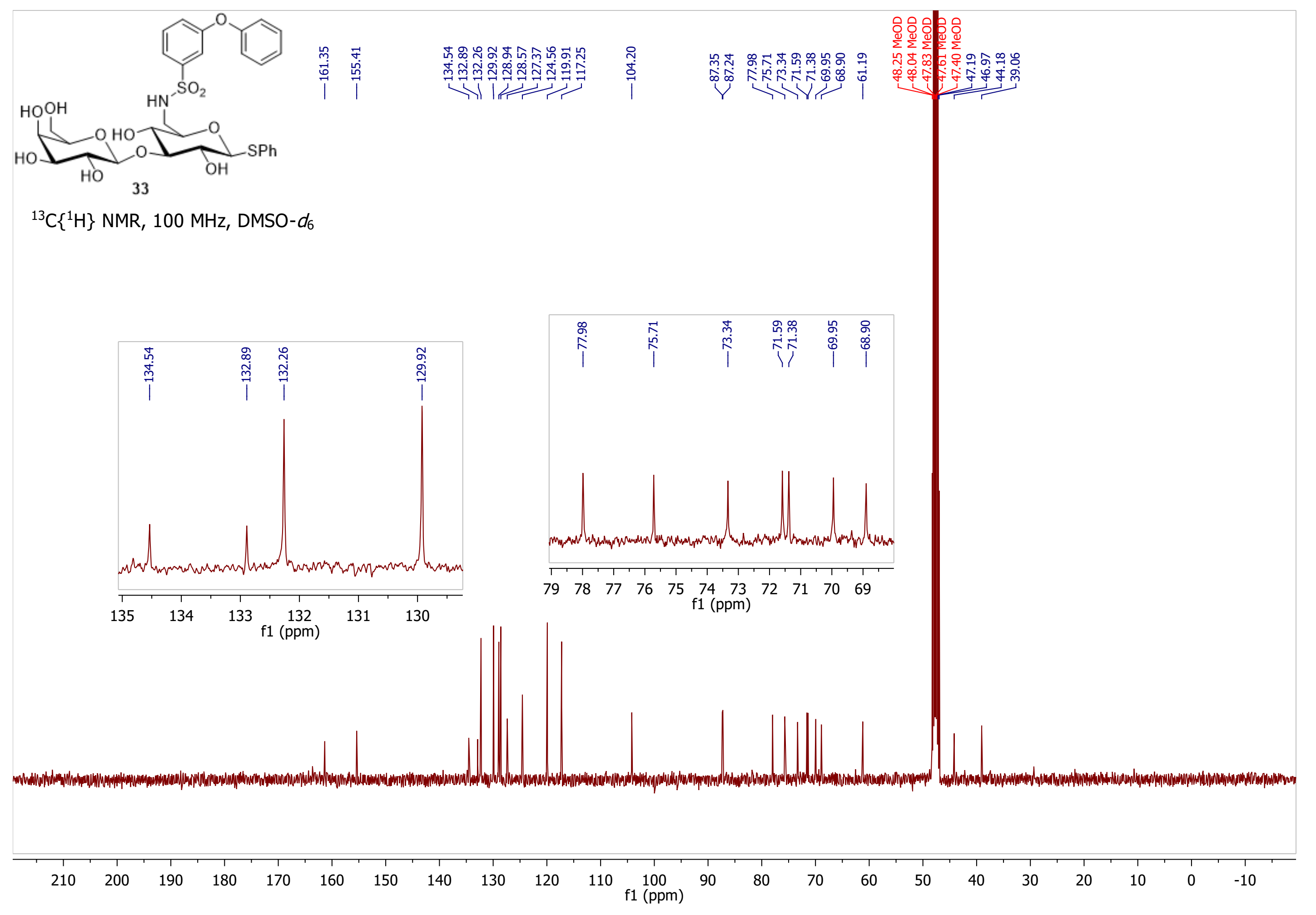




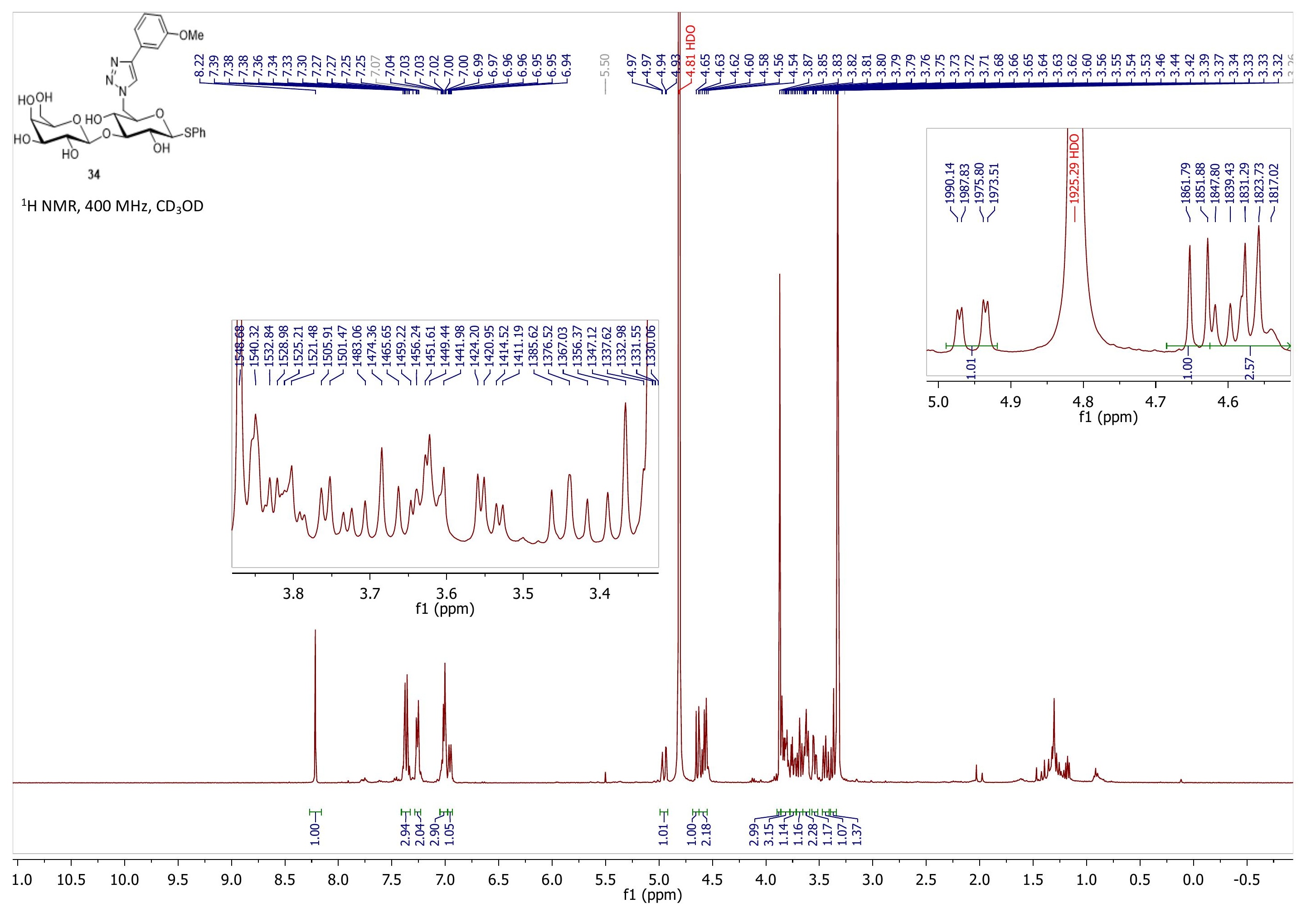




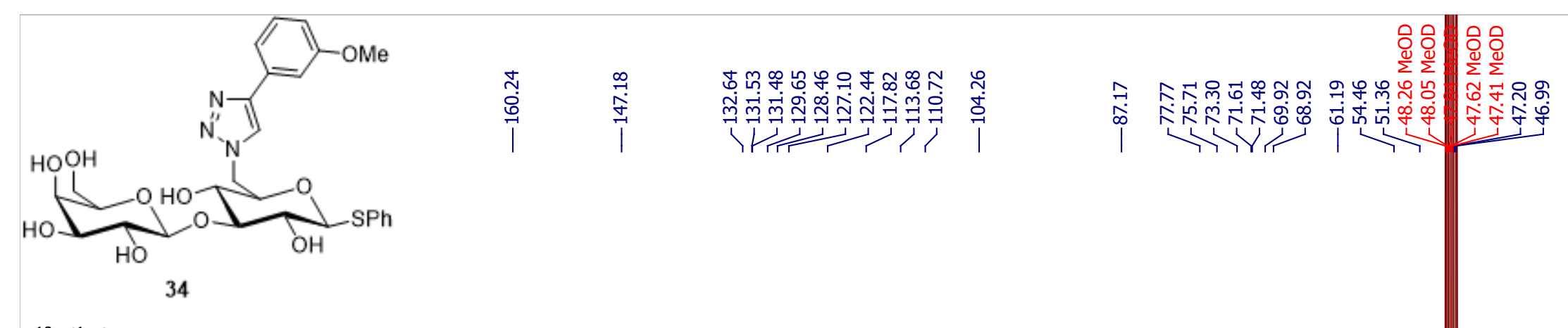

${ }^{13} \mathrm{C}\left\{{ }^{1} \mathrm{H}\right\} \mathrm{NMR}, 100 \mathrm{MHz}, \mathrm{CD}_{3} \mathrm{OD}$
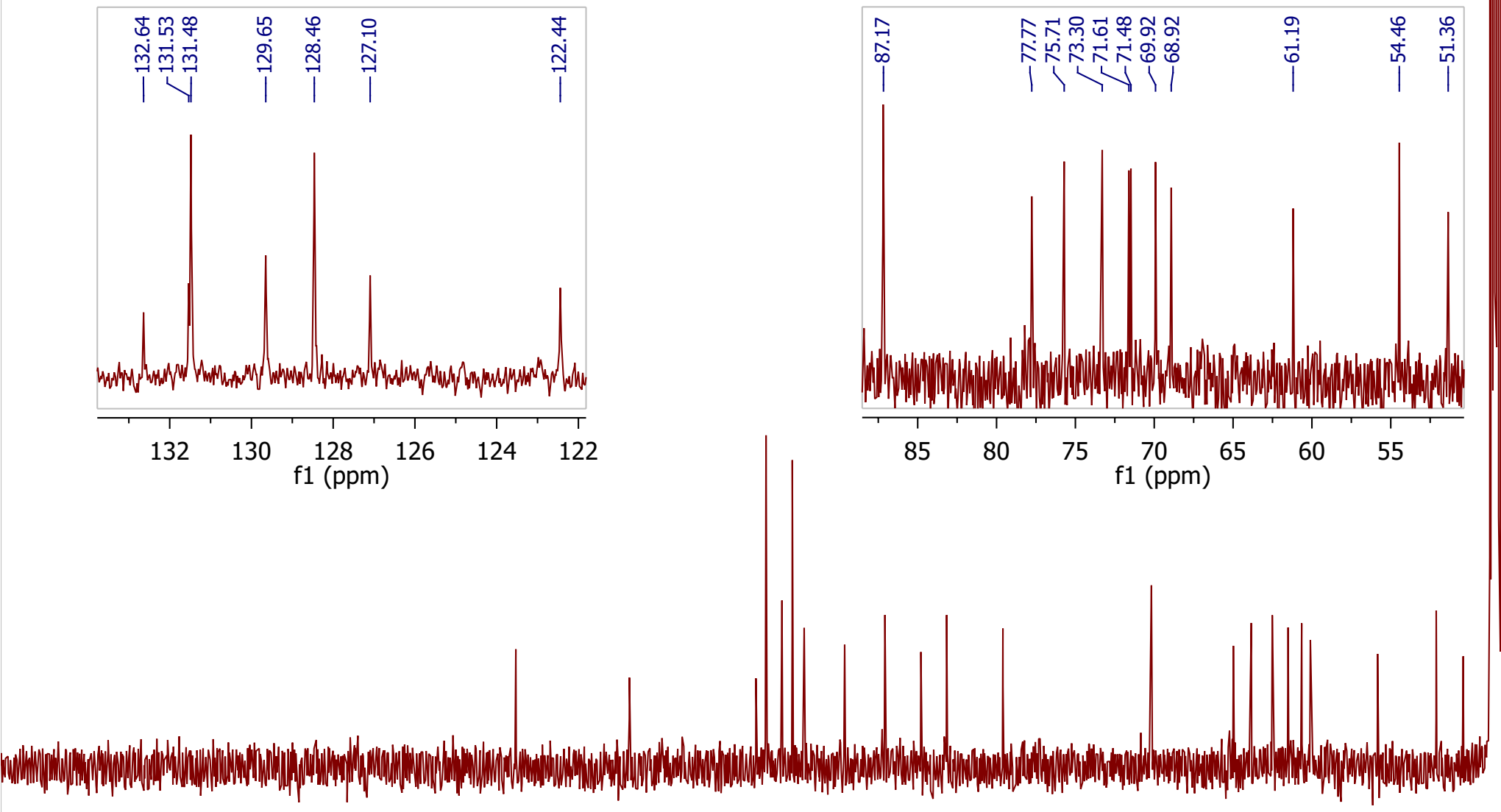

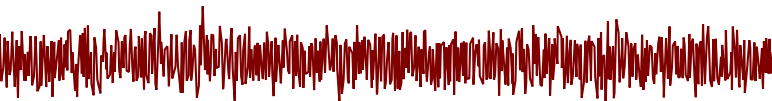

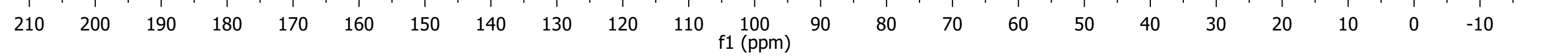




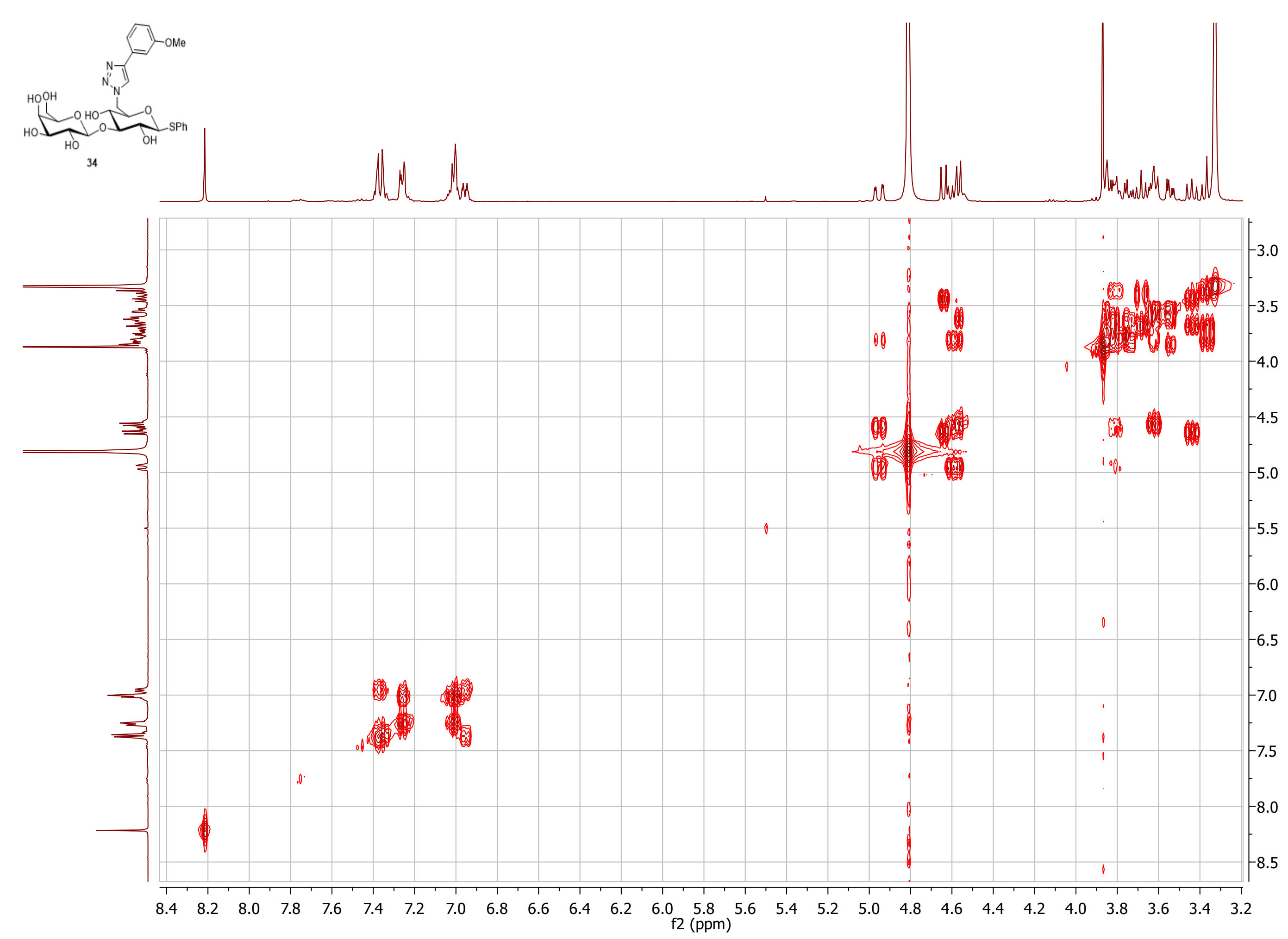




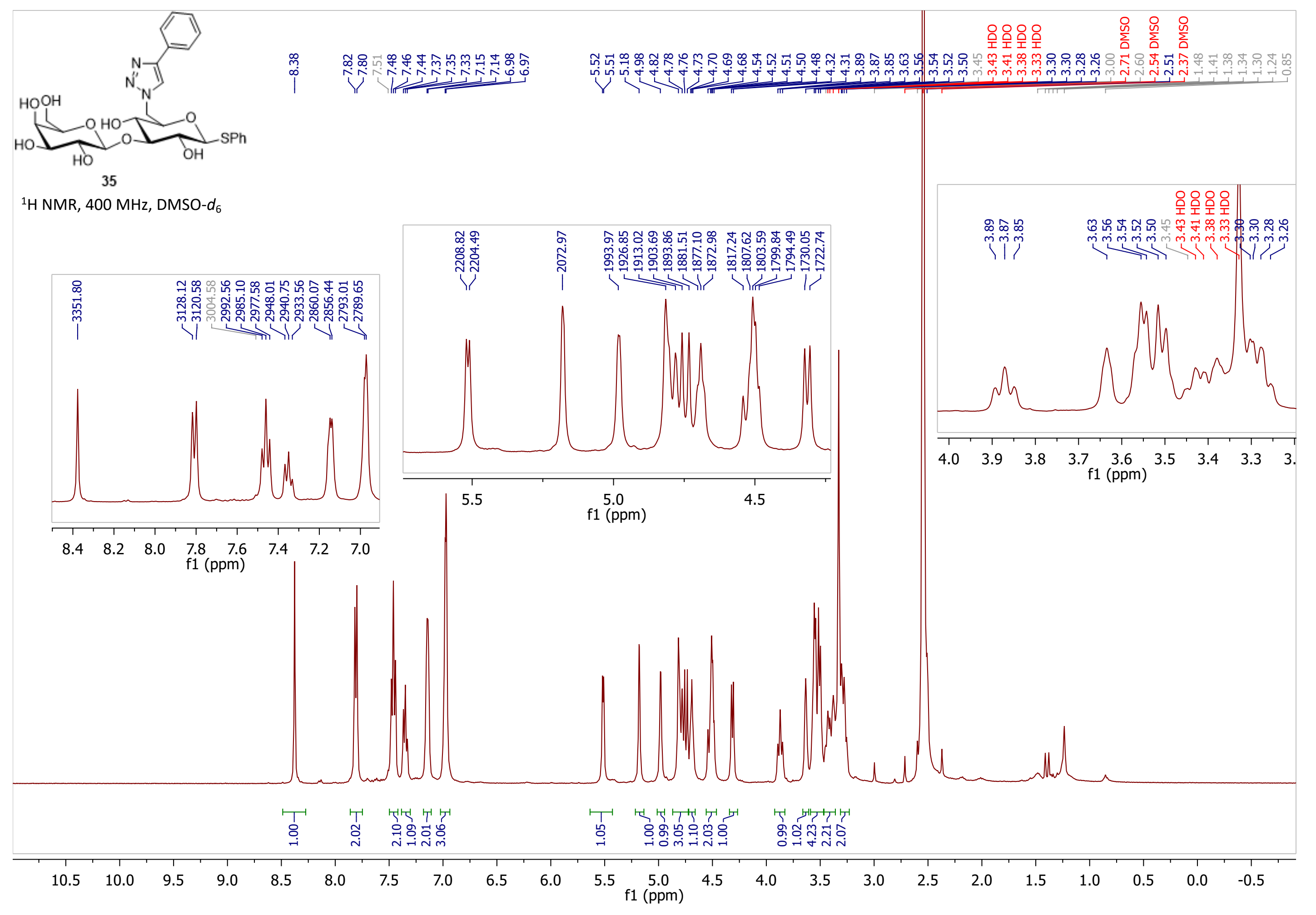




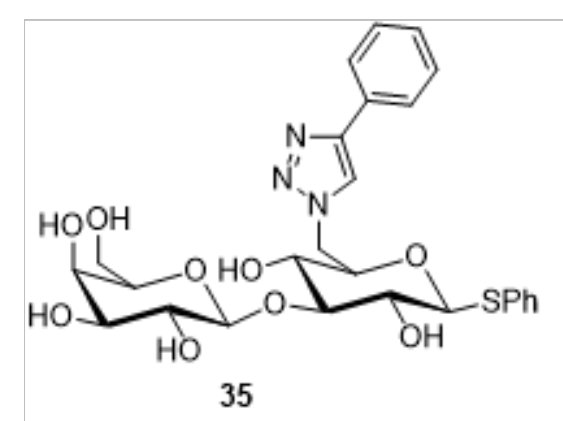

${ }^{13} \mathrm{C}\left\{{ }^{1} \mathrm{H}\right\}$ NMR, $100 \mathrm{MHz}$, DMSO- $d_{6}$
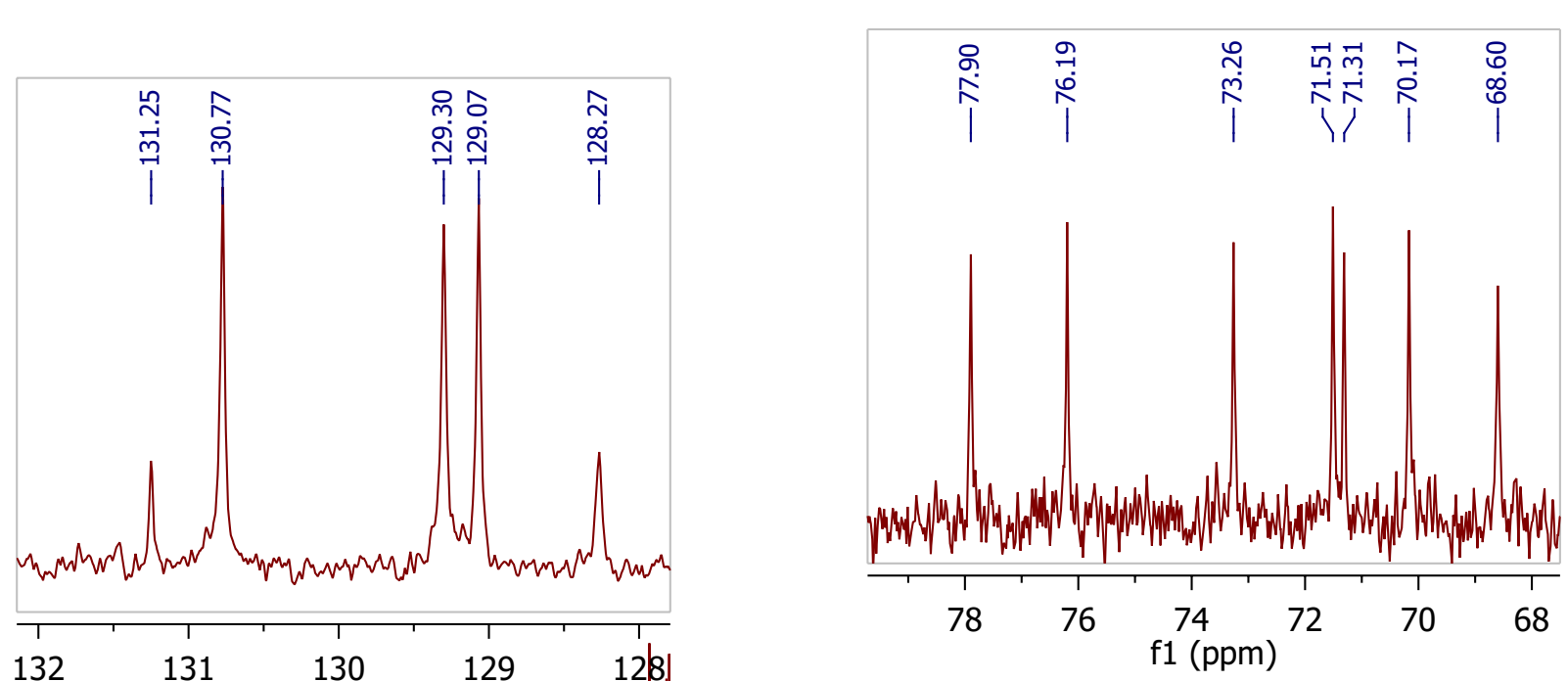

$\begin{array}{lllll}132 & 131 & \begin{array}{c}130 \\ \mathrm{f} 1(\mathrm{ppm})\end{array} & 129 & 128\end{array}$

128

$\begin{array}{llllll}40 & 30 & 20 & 10 & 0 & -10\end{array}$




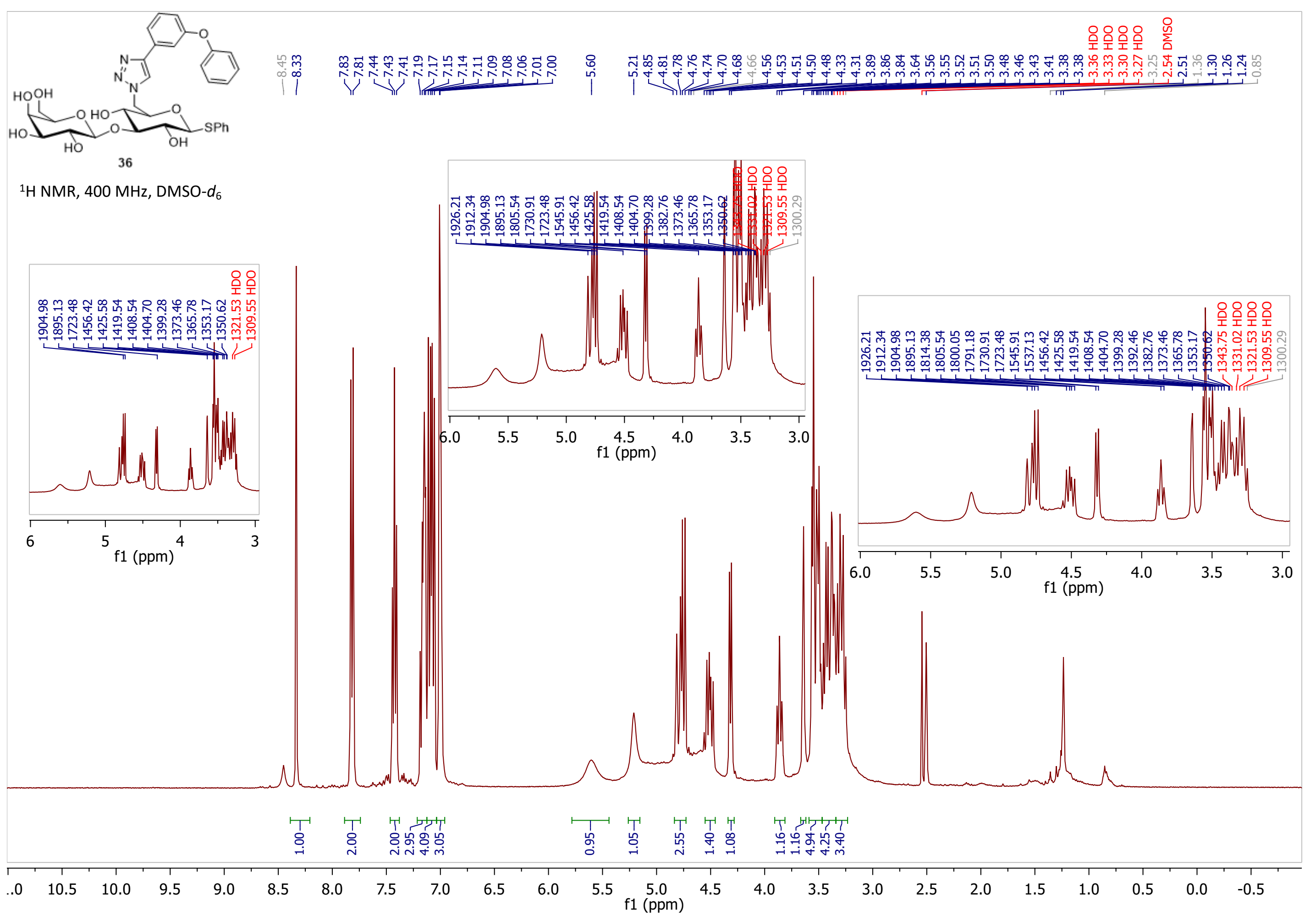




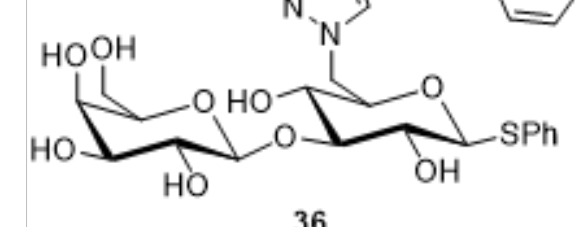

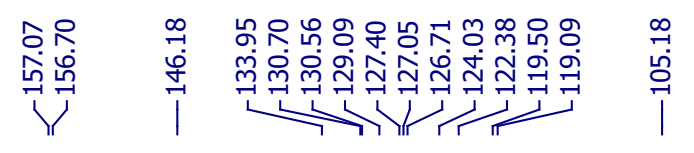

${ }^{13} \mathrm{C}\left\{{ }^{1} \mathrm{H}\right\}$ NMR, $100 \mathrm{MHz}$, DMSO- $d_{6}$
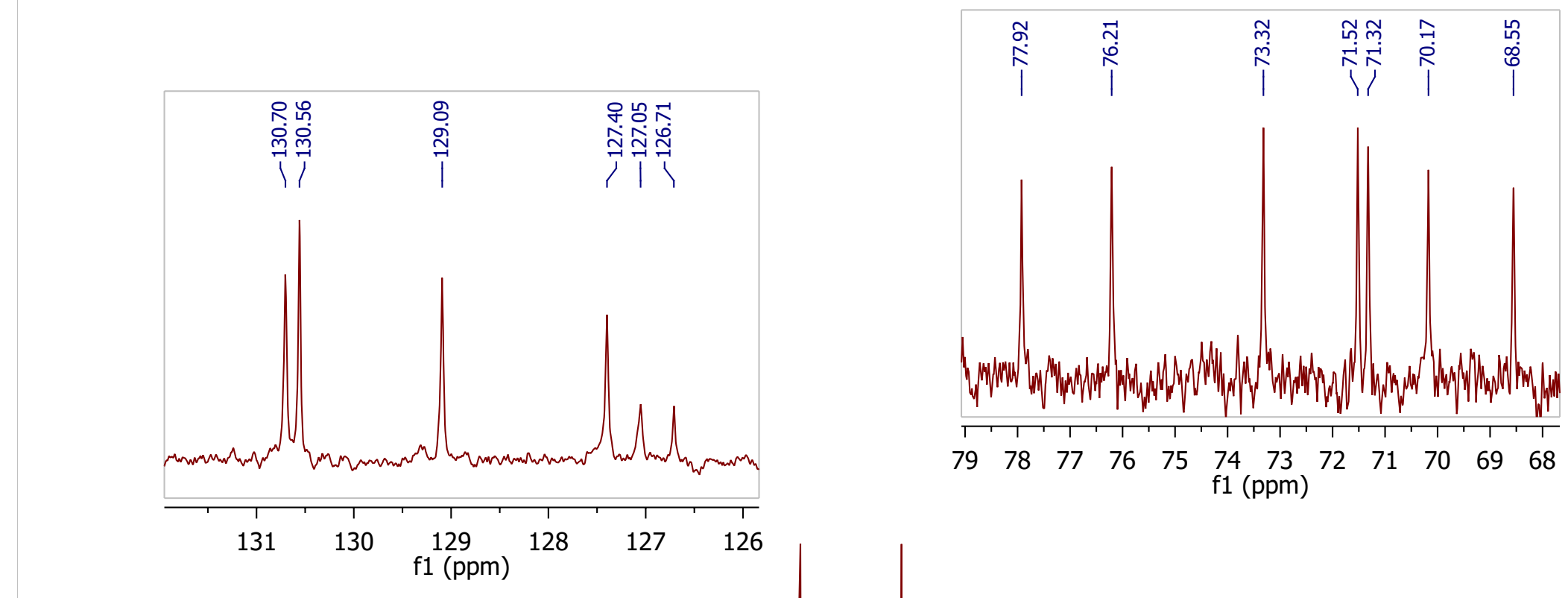


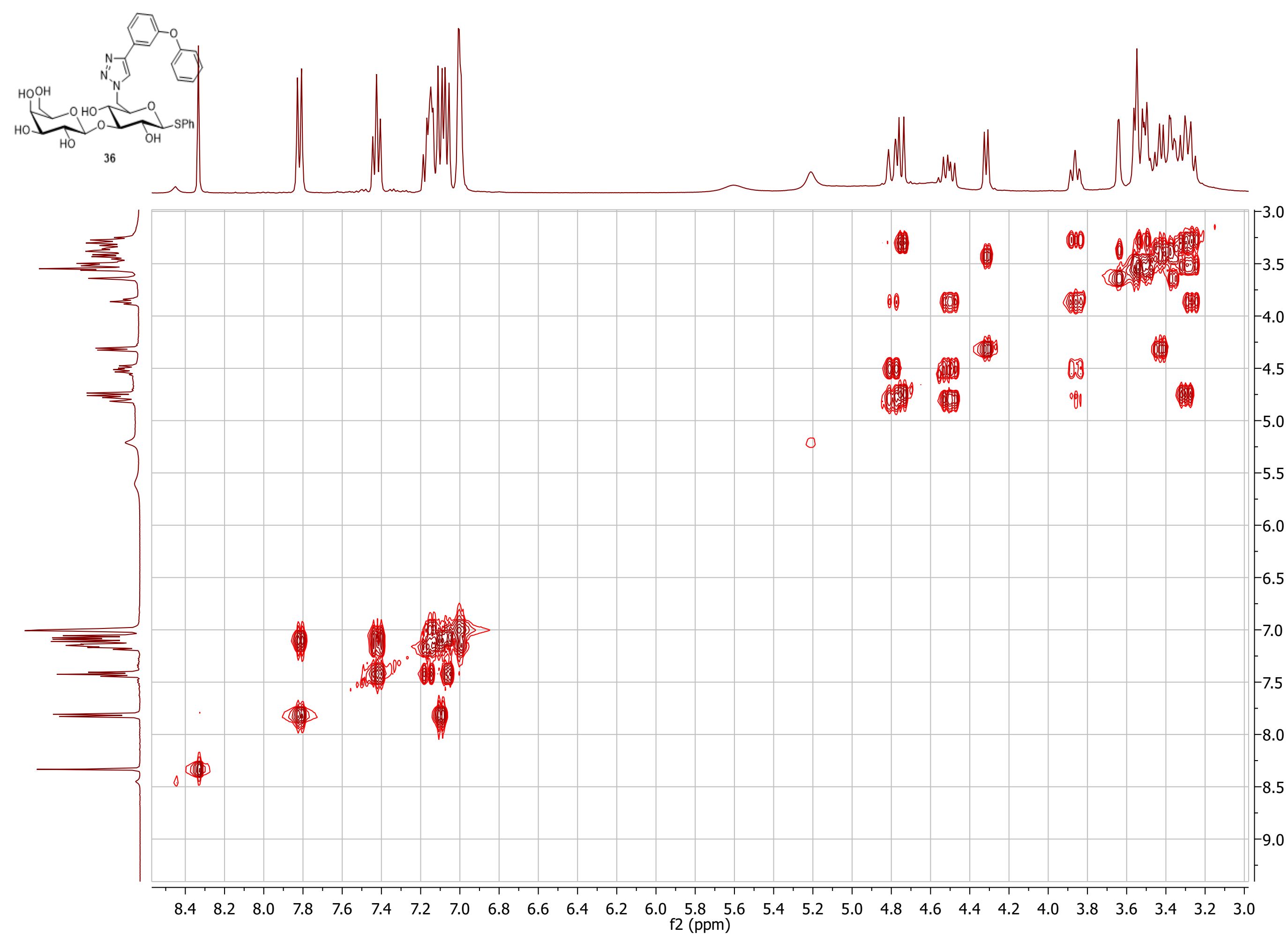

$\underbrace{\widehat{E}}_{\vec{E}}$ 0 
